\title{
CREDIT RISK ASSESSMENT AND MONITORING OF TIF BONDS
}

\author{
A Dissertation \\ by \\ DEOG SANG BAE
Submitted to the Office of Graduate and Professional Studies of Texas A\&M University in partial fulfillment of the requirements for the degree of
DOCTOR OF PHILOSOPHY

\begin{abstract}
Chair of Committee, Ivan Damnjanovic
Committee Members, Stuart Anderson

John Walewski

Sergiy Butenko

Head of Department, Robin Autenrieth
\end{abstract}

December 2017

Major Subject: Civil Engineering

Copyright 2017 Deog Sang Bae 


\begin{abstract}
Local governments have many different options to secure financing for infrastructure projects, including using Tax-increment financing (TIF) bonds. The key feature of this type of bond is the repayment source: defined as an increment in tax revenue attributed to higher property valuation within the TIF project-impact zone. While the TIF concept brings numerous benefits, such as transferring risks associated with local economic growth, it is also associated with several key challenges. One of the most significant challenges is its complexity. For example, it is often quite difficult to understand how TIF projects affect the surrounding properties, their market valuation, and, consequently, the credit risk of the underlying TIF bond. As a result, potential investors shy away from such assets, which, in turn, translates into increased premiums. This dissertation presents a framework that aims to help the investors, financial advisors, and other key market players better understand the credit risk associated with TIF bonds. The framework focuses on monitoring the performance of the underlying projects as well as other important endogenous and exogenous factors, with the goal of reconstituting the asset credit risk profile and detecting early warning signals of changing conditions. The key benefit of the proposed framework is its capacity to use publicly available, time series data. The case study, illustrating the framework, is based on the "Uptown Development Authority" Tax Increment Reinvestment Zone (TIRZ) bond, which is a type of TIF, structured to support redevelopment projects in Houston, Texas.
\end{abstract}




\section{CONTRIBUTORS AND FUNDING SOURCES}

This work was supervised by a dissertation committee consisting of Professor Ivan Damnjanovic as advisor and Professor Stuart Anderson, Professor John Walewski from Zachry Department of Civil Engineering, Professor Sergiy Butenko from the Department of Industrial Engineering, and Dr. Rafael Aldrete from the Texas A\&M Transportation Institute (TTI).

The research works for the dissertation were independently conducted by the student. No external funding was input to this study. 


\section{ACKNOWLEDGEMENTS}

First, I thank God. I cannot achieve anything without him. When I prayed, he always led me in a good way. Everything I have accomplished in this program and my life belongs to God. In addition, I cannot forget my wife Haeja. She has devoted herself for me. She encouraged me when I was in a critical moment, and prayed for our family. Without her dedication and efforts, I would not have been able to complete my doctoral program.

My doctoral program could not have been completed without help from Dr. Damnjanovic. As my advisor, he encouraged my work with his sincere and enduring support. He provided myriad insight and constant feedback during this project; I will never forget his support. He carefully listened to me when I faced difficult times and emotionally encouraged me to overcome many crises.

I cannot overlook Dr. Aldrete's support as well. He is head of the Texas A\&M Transportation Institute (TTI), El Paso and San Antonio Division. Despite his busy schedule and multiple responsibilities, he always found the time to contact me when I asked for his advice. His many insights are well integrated in both the academic and practical side of the work. As a result of his comments and suggestions, I broadened my ideas and found ways to address my research challenges.

I also would like to express my full appreciation to Dr. Walewski, who encouraged me extensively when I was having a difficult time, and provided me with many practical solutions. 
Additionally, I wish to acknowledge Dr. Anderson, who always gave me his full support. Finally, I want to thank Dr. Butenko, who was very supportive of my work and gracious enough to accept my request to become my committee member, despite the fact that was in another department.

There are so many people and organizations that greatly helped me and whom I did not mention. I remember, and appreciate, everyone who has helped and supported me throughout my work, and I thank them now, every one. 


\section{TABLE OF CONTENTS}

Page

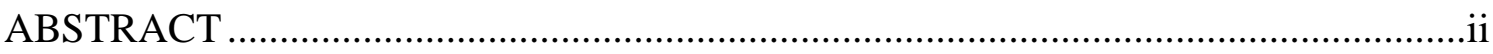

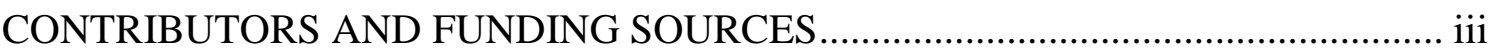

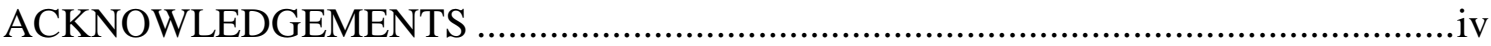

TABLE OF CONTENTS ..............................................................................

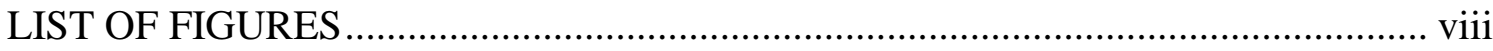

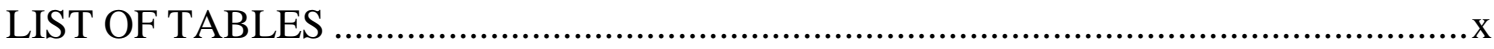

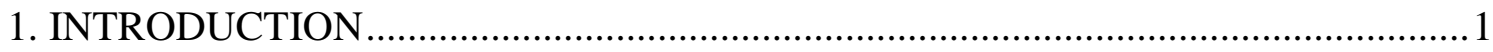

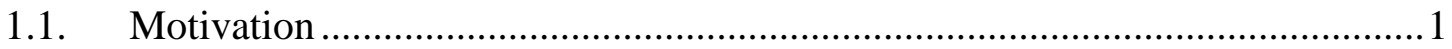

1.2. Research Framework .............................................................................. 3

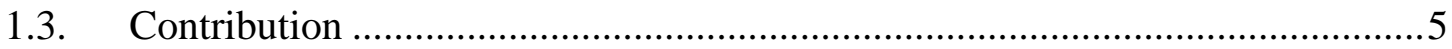

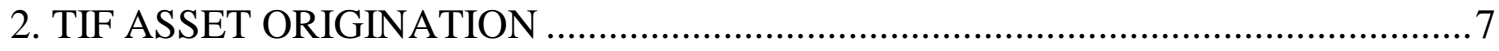

2.1. TIF General Characteristics ................................................................................ 7

2.1.1. Necessity of Value Capture Methods ............................................................ 7

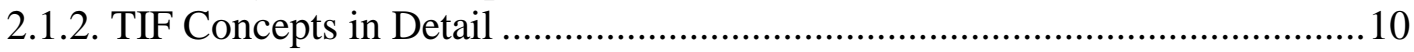

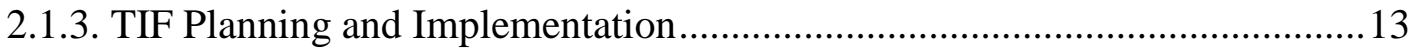

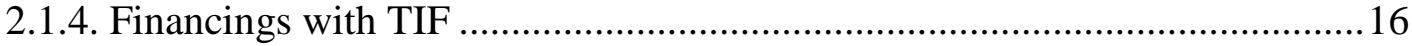

2.1.5. TIF Advantages over Other Value Capture Policies ...................................20

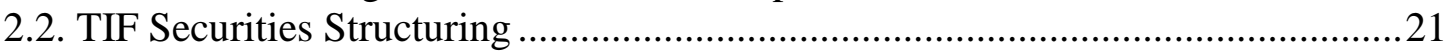

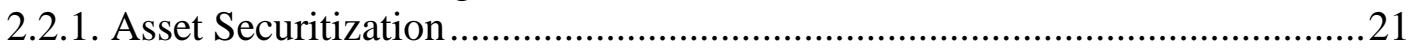

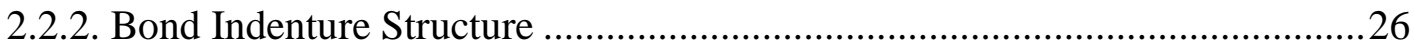

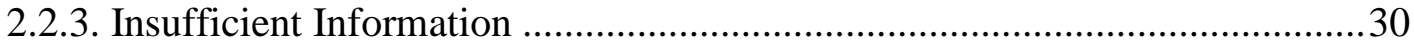

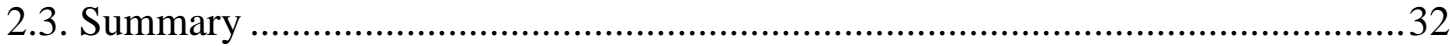

3. EARLY WARNING SIGNALS THEORY AND APPLICATION ...........................33

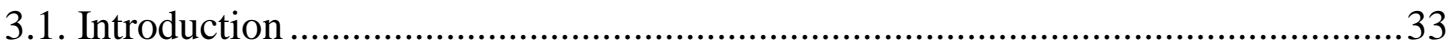

3.2. Early Warning Signals as an Abdicative Anomaly in Dynamic Systems..............36

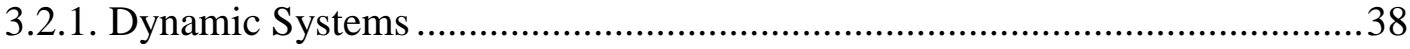

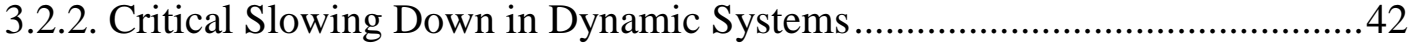

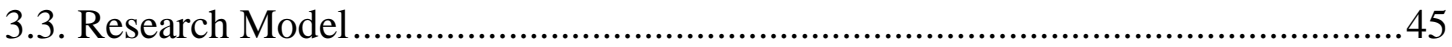




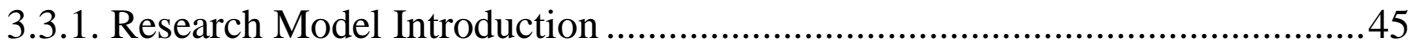

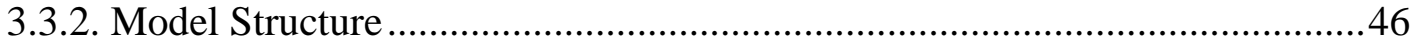

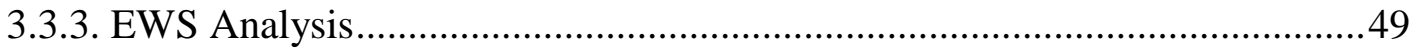

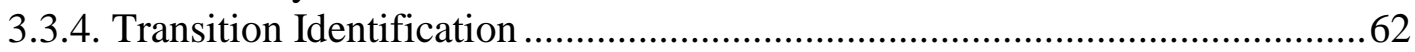

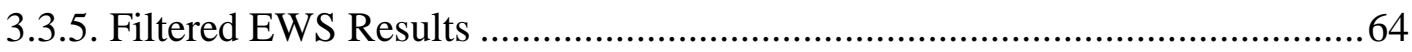

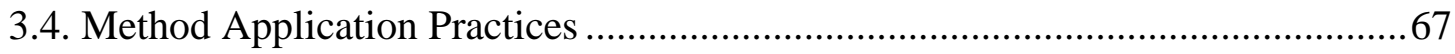

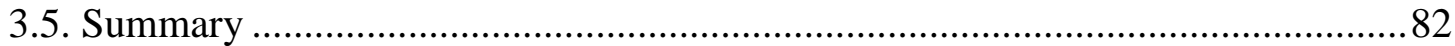

4. RISK ASSESSMENT AND MORNITORING METHODOLOGY ………………...... 84

4.1. Framework for Risk Assessment and Monitoring.................................................84

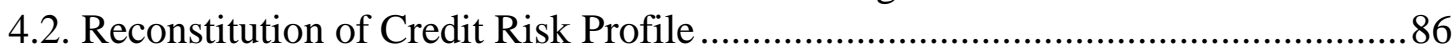

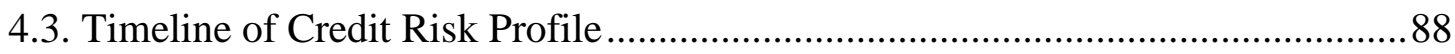

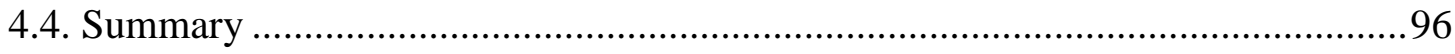

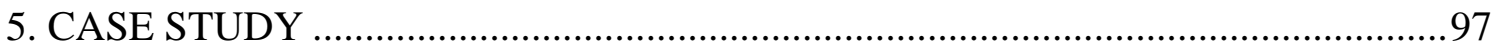

5.1. Houston's Tax Increment Reinvestment Zone (TIRZ) ........................................97

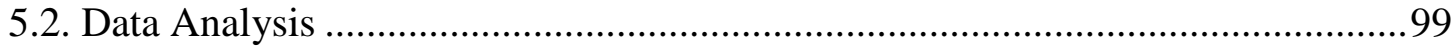

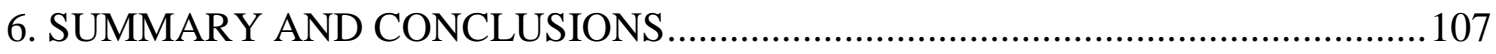

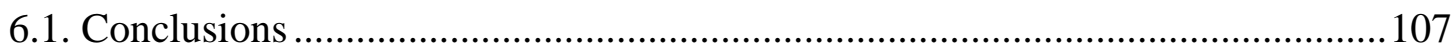

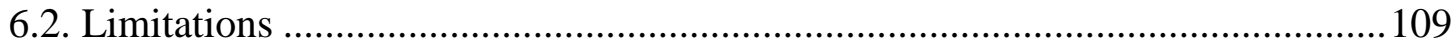

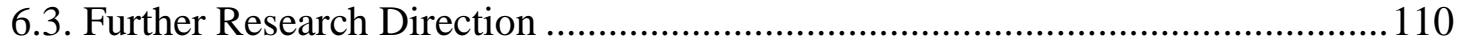

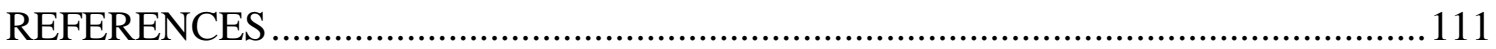




\section{LIST OF FIGURES}

Page

Figure 1 Tax Increment Financing Revenue Concept............................................... 11

Figure 2 Tax Increment Financing Implementation Process .....................................13

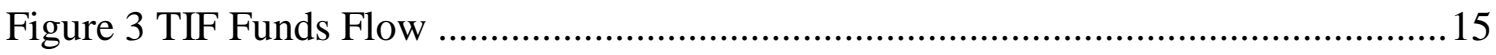

Figure 4 TIF Repayment Source and Bond Financing Type ....................................19

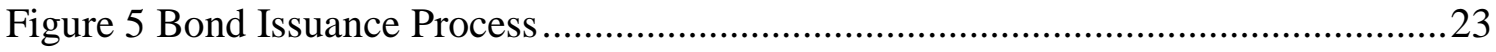

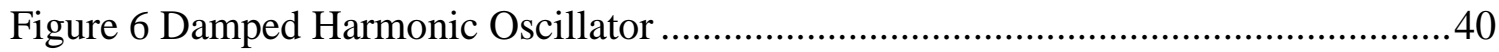

Figure 7 Statistical Patterns of Critical Transitions ................................................ 44

Figure 8 EWS Method Process Map ................................................................... 48

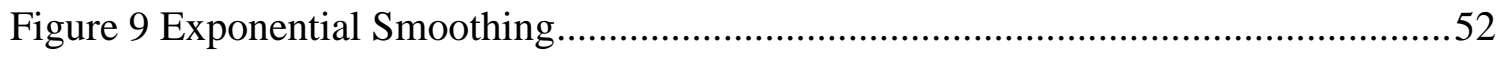

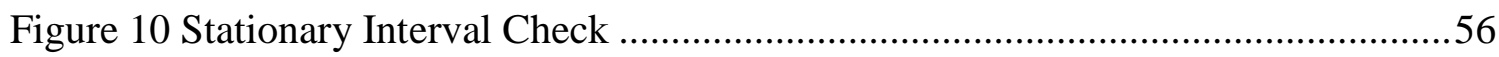

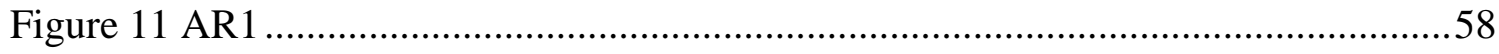

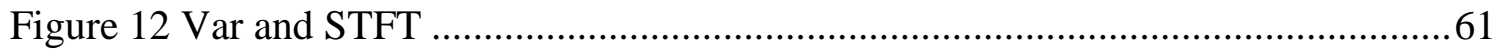

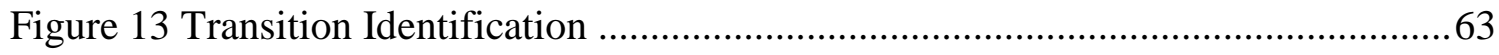

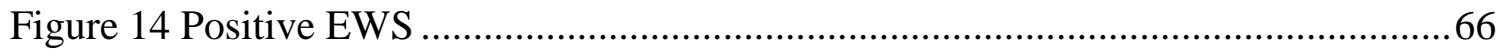

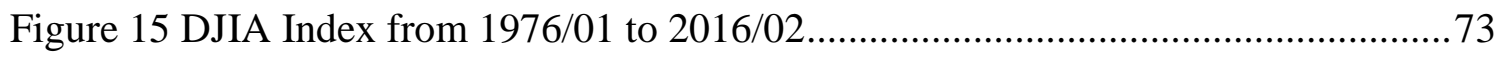

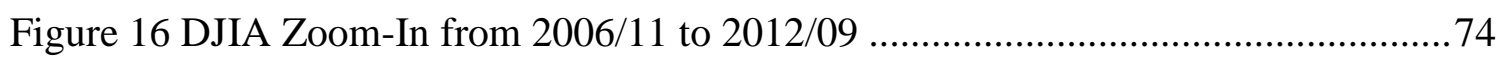

Figure 17 Unemployment Rate from 1990/12 to 2016/12 …......................................75

Figure 18 Unemployment Rate from 2005/11 to 2010/01 .......................................... 76

Figure 19 Influenza from 2004/01W to 2016/29W ................................................. 77

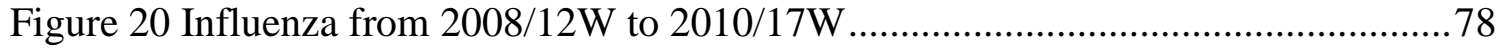

Figure 21 Drill from 118.6 meter to 164.9 meter ..................................................... 79

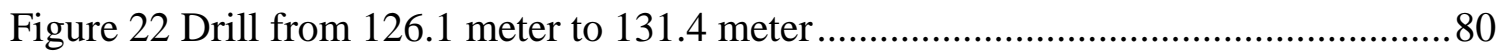

viii 
Figure 23 Trump Poll in GOP Campaign.............................................................. 81

Figure 24 Risk Assessment and Monitoring Framework ............................................ 86

Figure 25 Conceptual Reconstitution of Credit Risk Profile ...................................... 91

Figure 26 Future Risk Profile Process................................................................ 93

Figure 27 Future Credit Risk Profile Conceptual Diagrams ......................................95

Figure 28 Current Risk Profile ......................................................................... 100

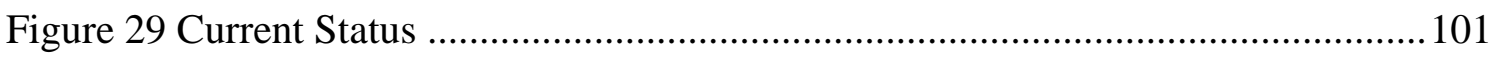

Figure 30 Future Risk Profile derived by EWS Method ......................................... 106 


\section{LIST OF TABLES}

Page

Table 1 Value Capture Method Comparison................................................................. 8

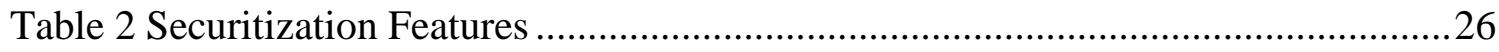

Table 3 Bond Indenture Structure ........................................................................29

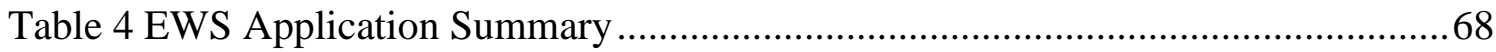




\section{INTRODUCTION}

\subsection{Motivation}

Value capturing methods such as Tax-increment Financing (TIF) provide an alternative way of securing financing for infrastructure development projects (Rybeck 2004). The basic idea behind TIF is to use only an increase in the revenue from property taxes as a repayment source. This increase is typically defined in relation to some base level of revenue. That is the revenue in property taxes before the project was executed. The typical TIF projects are the projects that promote real estate development: a) transportation access improvement projects, such as provision of new public transit services and stations; b) general infrastructure projects, such as improvements in water, wastewater, or electric distribution systems; and, c) brownfield development projects, such as environmental remediation of urban industrial facilities.

The key advantage of TIF when compared to other value capture methods is the fact that it is much less controversial. This is because TIF does not imply an increase in the overall tax rate (Council on Development Finance Agencies 2006). In other words, the actual tax rate in TIF zones for home and business owners remains the same; rather, it implies an increase in the overall taxes only if there is an increase in the market value of their properties. This risk allocation arrangement is preferable to home and business owners as the downside risk is limited.

The TIF structure is also less controversial from the perspective of local governments and municipalities. As the repayment source solely relies on the growth in 
property taxes, the baseline revenue remains reserved for already allocated budget items. Furthermore, unlike traditional government financing methods such as general obligation bonds, TIF bonds are typically structured with a limited recourse to other assets (Hamilton 2017).

Faced with a realistic prospect of a potential default the investors require more elaborate analysis to support their positions. However, the information and data needed for such analysis is not readily available or easy to come by. Some studies in past have developed models to capture the impact of TIF projects on tax increment, but their scope was limited. For example, Vadali, Aldrete, and Bujanda (2009) presented the valuation process based on developing a project-specific financial model that estimates property value growth, while Byrne examined the economic impact of TIF designation by analyzing local socio-economic factors (Byrne 2006). While these and similar studies provide procedures and methods to assess feasibility of TIF projects in specific local areas within a specific timeframe, they fail to consider that risks are not static but evolve over time.

Such circumstances leads to a summary that the TIF system benefits local government in adding a new financing source for infrastructure development but the debt associated with the TIF delivery can be regarded as a risker asset than its actual risk due to the uncertainty in property value growth and the lack of knowledge how to effectively assess the TIF asset.

In this sense, this dissertation presents the framework that builds upon publicly available information and credit ratings to update the bond's risk profile without the 
need for new formal rating. The bond profile formulated by this research model will help investors who need acute and timely information for decision-making. Through the expansion of information availability toward the TIF investment, ultimately, the author hopes that such information would improve the asset liquidity, therefore reducing the risk premiums and making delivery of new public infrastructure projects more affordable.

\subsection{Research Framework}

This research aims to quantify and measure the repayment uncertainty associated with TIF bonds. This approach consists of three parts:

- Characterize TIF financing process and its project impact.

- Develop the critical risk assessment method to capture early warning signals before critical events.

- Validate the method using case studies.

For the first component, this research will characterize the TIF financing process and its project impact. Many previous studies approached this topic by quantitatively measuring the local economic development associated with the TIF or by qualitatively comparing the TIF and other public financing systems. Even though they are meaningful for delivering the general characteristics of the TIF bond, they do not approach the core idea of TIF financing. Given that the money for TIF projects is financed by issuing bonds, the core process is the financing process of the TIF bond. Further, to reflect the repayment volatility of the bond, it is necessary to recognize the linkage between the economic development stimulated by the TIF project and the performance of the TIF 
bond. Bringing such core processes to light will provide a deep understanding of the TIF financing mechanism.

Second, this research will develop a critical risk assessment method to capture early warning signals before critical events. A variety of the social factors impact the performance of the underlying asset over time, giving rise to the variability of the default risk. Currently, no method exists to closely track this volatility. Such information deficiency mainly causes an increase in the risk premium, raising the financial cost of the issuer. This research will implement a warning method that indicates early warning signals before critical events. This method is based on the theory of "critical slowing down." The theory's main idea is that the recovery rate gets lower as a critical event is closer. By measuring the recovery rate of the input data, a system built using this theory can define proximity to critical events. Although this theory is quite new in the financial industry, it has been used in natural science for identifying the timing of early warnings. The data movements in both natural science and the financial industry have the same characteristics in which the data is dynamic. For example, the prediction of sea level is challenging because a variety of natural forces including climate and gravity affects the dynamicity of sea surface. In the sense of dynamicity, the financial data also shows unpredictable shifts over time. At the time of 2008 financial crisis, most experts did not expect that turmoil event considering a stable trend in the past. The common feature of unpredictability supports a claim that this EWS theory is applicable toward the financial sector. This implemented method could contribute to a decrease in the risk premium by indicating the asset status. 
Lastly, this research will validate the Early Warning Signals (EWS) method using case studies. For this validation, this research will collect local and macro type data from public sources; that is, it will gather regional and financial variables. Then, it will analyze the early warning signals of each data by using the developed EWS method and verify the results of these EWS outcomes. Finally, this work will analyze the potential of the proposal method towards assessing the risk of TIF bonds.

\subsection{Contribution}

This research is expected to contribute to the state of the art of TIF risk assessment in the following ways. The first contribution may be characterized from the policymaker perspective. Detailed illustration of the liquidation process of TIF bonds will help government officials understand the risks involved in the debt structure and the sale of bonds. Such financing process-centric description contribute to creating an optimal financing plan and ultimately reducing the unpredictability of project budgeting.

The second contribution could be characterized from the issuer and investor perspectives. From the investor perspective, this proposed method could quantify the quality of bonds in terms of warning signal existence. This information could lead the potential buyers to avoid risky assets. Such avoidance tendency would decrease the risk premium and eventually decrease the bonds issuance cost to the issuer. From the issuer perspective, this method could guide the issuer to the favorable timing of Initial Public Offerings (IPO) for bond sales. If this method indicates "warning" on an asset, the issuer may postpone the IPO timing until the signal is shut off. Such guidance could lower 
unpredictability of the selling price and increase the work efficiency in the capital budgeting.

Lastly, this EWS method is universally applicable to the social variables associated with TIF. A variety of the social variables can impact the performance of the underlying asset. Measuring the EWS amplitudes of each variable has the potential to provide more chances to accurately identify the asset status. Eventually, such increase in the available information could lead to a better investment decision. 


\section{TIF ASSET ORIGINATION}

\subsection{TIF General Characteristics}

\subsubsection{Necessity of Value Capture Methods}

Many public entities experience urban planning challenges caused by an increase in the demand for sustainable transportation infrastructure and the lack of funds to meet the demand within the budget (Rybeck 2004). As an alternative to providing public facilities under the budget limit, the concept of value capture is created. The value capture policy aims to capture a portion of the betterment, which is a newly created value from the new project, and uses this captured value toward the construction cost payment. Although this policy is different from the common taxation system, it is not a contemporary fiscal method. In the 1800 s, a local government in Washington D.C. proposed a road pavement project, which was expected to positively impact the property values adjacent to the pavement project. By agreeing with the economic expectation, the local council enacted to collect fifty percent of the total cost from the beneficiaries (Rybeck 2004).

This value capture policy has been specified in multiple ways. Specifically, Iacono, Levinson, and Zhao (2010) categorize these innovative financing policies into seven mechanisms: Tax Increment Financing (TIF); Special Assessments District (SAD); Transportation Utility Fee (TUF); Impact Fee (IF); Negotiated Exactions (NE);

Joint Development (JD); and Air Rights (AR). Vadali (2014) compared each value 
capture mechanism and defined the degree of political and administrative risk of each

policy. Table 1 summarizes the Vadali's report.

Table 1 Value Capture Method Comparison

\begin{tabular}{|c|c|c|c|c|}
\hline $\begin{array}{l}\text { Contribution } \\
\text { Category }\end{array}$ & Mechanism & Concepts & $\begin{array}{l}\text { Political } \\
\text { Risk }\end{array}$ & $\begin{array}{l}\text { Admin } \\
\text { Risk }\end{array}$ \\
\hline $\begin{array}{l}\text { One-time } \\
\text { Special Fee } \\
\text { charged to } \\
\text { Developers }\end{array}$ & $\begin{array}{l}\text { - Impact Fees (IF) } \\
\text { - Negotiated } \\
\text { Exactions (NE) } \\
\text { - Air Rights (AR) }\end{array}$ & $\begin{array}{l}\text { - Selling a permit to the } \\
\text { development project } \\
\text { associated with a new } \\
\text { public project. } \\
\text { - The government } \\
\text { levies such fee to the } \\
\text { developer when the } \\
\text { project is in operation. }\end{array}$ & $\begin{array}{l}\text { Low/ } \\
\text { Medium }\end{array}$ & $\begin{array}{l}\text { Low/ } \\
\text { Medium }\end{array}$ \\
\hline $\begin{array}{l}\text { Compulsory } \\
\text { Additional Fee } \\
\text { charged to } \\
\text { property } \\
\text { owners }\end{array}$ & $\begin{array}{l}\text { - Special } \\
\text { Assessment } \\
\text { District (SAD) } \\
\text { - Transportation } \\
\text { Utility Fees } \\
\text { (TUF) }\end{array}$ & $\begin{array}{l}\text { - Levying an additional } \\
\text { tax to the property } \\
\text { owners who are } \\
\text { beneficiaries of a new } \\
\text { public project. } \\
\text { - The levying process is } \\
\text { proceeded before the } \\
\text { construction start. }\end{array}$ & $\begin{array}{l}\text { Medium/ } \\
\text { High }\end{array}$ & $\begin{array}{l}\text { Medium/ } \\
\text { High }\end{array}$ \\
\hline $\begin{array}{l}\text { No Change in } \\
\text { Taxation }\end{array}$ & $\begin{array}{l}\text { - Tax Increment } \\
\text { Financing (TIF) }\end{array}$ & $\begin{array}{l}\text { - In the government } \\
\text { accounting system, } \\
\text { the government } \\
\text { internally allocates an } \\
\text { increase in tax } \\
\text { revenue generated } \\
\text { from a new public } \\
\text { project to a special } \\
\text { account for } \\
\text { construction cost } \\
\text { repayment. } \\
\text { - The property owners } \\
\text { do not bear any } \\
\text { additional burden. }\end{array}$ & Medium & Medium \\
\hline $\begin{array}{l}\text { Developer } \\
\text { Voluntary } \\
\text { Contribution } \\
\text { to Public } \\
\text { Projects } \\
\end{array}$ & $\begin{array}{l}\text { - Joint } \\
\text { Development } \\
\text { (JD) }\end{array}$ & $\begin{array}{l}\text { - Private developer } \\
\text { construct a public } \\
\text { project under the } \\
\text { concessionaire given } \\
\text { from a public entity. }\end{array}$ & Medium & High \\
\hline
\end{tabular}


A fee is paid by private developers who seek new development near a new or preexisting public infrastructure. For example, if a developer pursues a housing project near a new transit station, a IF will be charged to the developer (Nicholas and Nelson 1988). NE is similar to IF, in the sense that the private developers pay a fee if their projects are located within an NE district. However, these two policies are different regarding tax rate negotiation. The NE fee is determined by the negotiation between the government and the private developers. Therefore, the tax rate of NE is different, case by case (Cervero 1988). A fee of AR is charged when the private developers need a new development right to build a taller building than the legal elevation limit (Salon 2014, Marcus 1983). This tax policy is applicable in the central business district, where buildings are densely located. AR is charged when new construction needs a special elevation permission.

SAD charges an additional tax, beyond the regular property tax basis, to the property owners who have their properties near the new project and are expected to experience economic benefits. This tax rate increase can cause taxpayer resistance (Rolon 2008). TUF is a transportation utility fee, ensuring the maintenance and improvement of the local roads and streets. It is charged in addition to the regular tax basis. This fiscal policy has been expanded across the nation (Voulgaris 2016).

TIF is a mechanism with which to allocate increased tax revenue, caused by the new infrastructure, to be deposited into a special account for repaying the new construction cost. In this way, there is no additional burden to the taxpayers (Davis 1989). The concept of TIF will be discussed in more detail in the following section. 
JD is a partnership development between the government and the private developer. For example, for a rail station implementation project under the JD policy, the government provides the land and the private developer is responsible for the construction, operation, and maintenance of the new rail station (Zhao, Das, and Larson 2012).

\subsubsection{TIF Concepts in Detail}

TIF is a fiscal program to support a specific local area where economic development cannot occur without public budget input (Greenbaum and Landers 2014). For such purpose, a local government designates geographical boundaries, establishes economic development plans for that area, and finances the development plans with future tax revenue increment generated by the new development plan. By internalizing the future growth in tax revenue, the TIF program captures an increment in property or tax revenue beyond the base value, without any change in the current taxation configuration. In short, the TIF does not impose an additional tax burden on taxpayers but transfers part of the current revenue into a special account. That current revenue part, mentioned here, is an increment in tax revenue beyond the base value. In short, the success of a TIF program depends on economic growth in the local area of the TIF. Vadali, Aldrete, and Bujanda (2009) conceptually described the financial model of a value capturing mechanism associated with the Transportation Reinvestment Zone, which is similar to TIF, in terms of internalizing the future economic potential of a new project, but it is exclusively applicable to transportation projects (see Figure 1). 

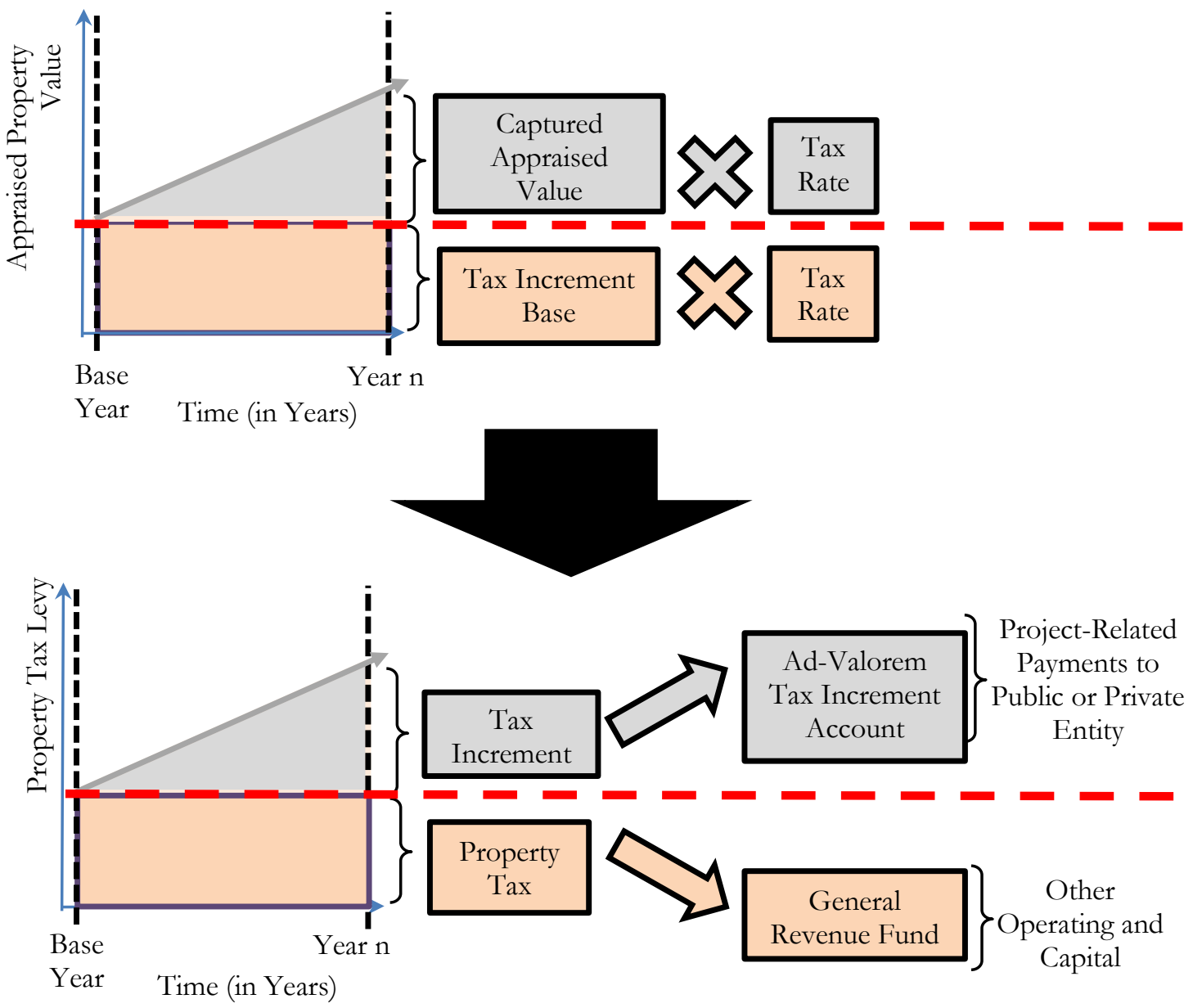

Figure 1 Tax Increment Financing Revenue Concept

The terms introduced in Figure 1 are defined as follows:

- Tax Increment Base: Total appraised taxable value inside the geographical boundaries of a TIF zone.

- Captured Appraised Value: Total of an increase beyond the Tax Increment Base of properties within the zone. 
- Property Tax: Tax revenue generated from the Tax Increment Base. The generated revenue is allocated to the general revenue fund of the local government for other public expenses.

- Tax Increment: Tax revenue generated from the Captured Appraised Value. The revenue is allocated to the Ad-Valorem Tax Increment Account to cover the TIF project expenses.

An example is presented to describe the figure and terms in detail. In 2014, a local government established a TIF zone to redevelop a barren area inside its jurisdiction and set the TIF period for 20 years. A parcel (Parcel ID \#100) is located inside the TIF zone. The tax appraised property value of that parcel was $\$ 1000$ in 2014 and was increased to $\$ 1200$ in 2015 . The property tax rate is 3 percent. In this example, the base year was 2014 when the TIF was established, and the year " $n$ " is 2034, when the TIF 20year period ends. The tax increment base is $\$ 100$, which is the tax appraised value in the base year. The captured appraised value in 2015 is $\$ 200$ ( $\$ 1200-\$ 1000)$. The property tax over the entire TIF period is $\$ 30$, which is the tax revenue from the tax increment base ( $\$ 1000 \times 3$ percent). The tax increment in 2015 is $\$ 6$, which is the tax revenue from the captured appraised value $(\$ 200 \times 3$ percent $)$.

TIF revenues are small at the beginning of the TIF program but will grow over time if the targeted projects contribute to the local economy as expected. However, if the targeted project fails to achieve their goals, the TIF authority will have to re-allocate other resources to the TIF account in order to bridge the fund gap. Despite the fact that the TIF mechanism works with uncertainty, introducing TIF is less politically 
controversial than other methods, since the introduction of TIF does not impose any additional taxes. This political advantage provides local administrators with the opportunity to consider the TIF mechanism as a financial solution for solving urban development issues.

\subsubsection{TIF Planning and Implementation}

Greifer (2005) described five steps involved in the TIF mechanism (see Figure 2).

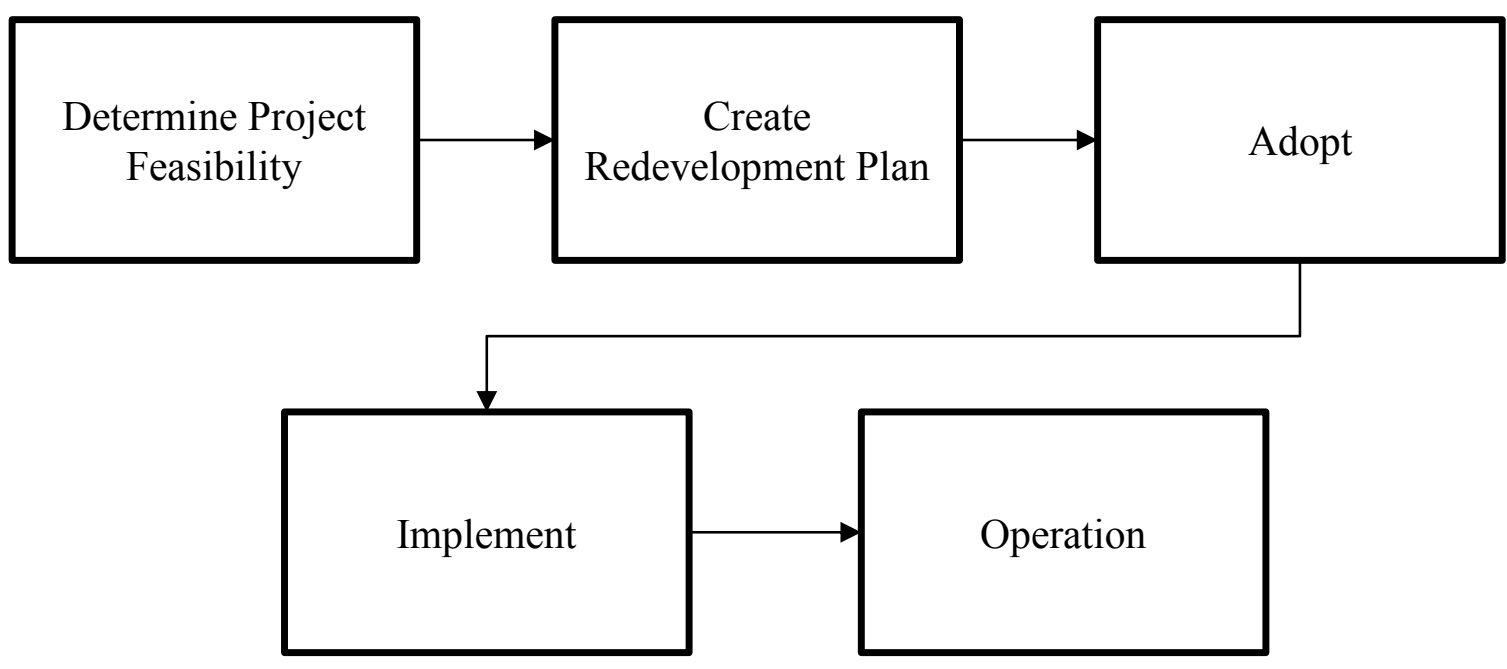

Figure 2 Tax Increment Financing Implementation Process

The first step is to define the project's feasibility. It is a preliminary plan that defines why a project is needed and how it gets funding. The necessity is defined following the TIF act in each state. For example, in Texas, the Tax Increment Financing 
Act defines the requirement to be designated as a TIF zone as "an area must substantially arrest or impair the sound growth of the municipality or county designating the zone, retard the provision of housing accommodations, or constitute an economic or social liability, and be a menace to the public health, safety, morals, or welfare in its present condition (Texas Legislature 1987)." The fund can come from either solely incremental financing or a combination of other sources.

Second, according to the findings from the first step, the government needs to create a redevelopment plan. The redevelopment plan includes the geographical boundaries of a TIF zone, the timeline of the TIF, project capital and maintenance costs, base year's total taxable value in the zone, the projection of the tax increment revenue during the TIF period, and the financing plan to pay the project costs. Also, government officials need to proceed with the legal processes as well (creating ordinances or orders).

Third, initiation of the TIF requires adoption from stakeholders. In this step, the government hosts public hearings and manages legal works with other jurisdictions. Also, the redevelopment plan information is disclosed to the public.

Fourth, the government implements the TIF redevelopment plan. In this step, the government contracts with general contractors to start the targeted projects and also raises money to pay the project expenses by issuing debt or borrowing money from other public entities. The government also establishes a special account that allocates the amount of the tax increment, which covers debt repayment and other project expenses. 
Lastly, the public body operates the TIF project. The most critical part of this operation is to manage the flow of funds. Figure 3 illustrates the funds flow associated with TIF by referring to the Port Authority's Transportation Reinvestment Zone Guidebook (Aldrete et al. 2017). In this figure, the first stage is that the city issues bonds for paying project capital expenses and other administrative costs. During the redevelopment period, the government transfers tax increment revenues to a special account, which is exclusively established to deposit the increment revenue. Then, the money from the special account flows to the contractual stakeholders, such as bondholders. When the TIF terminates, if there is any remainder in the special account, that money will be transferred to the government's general account.

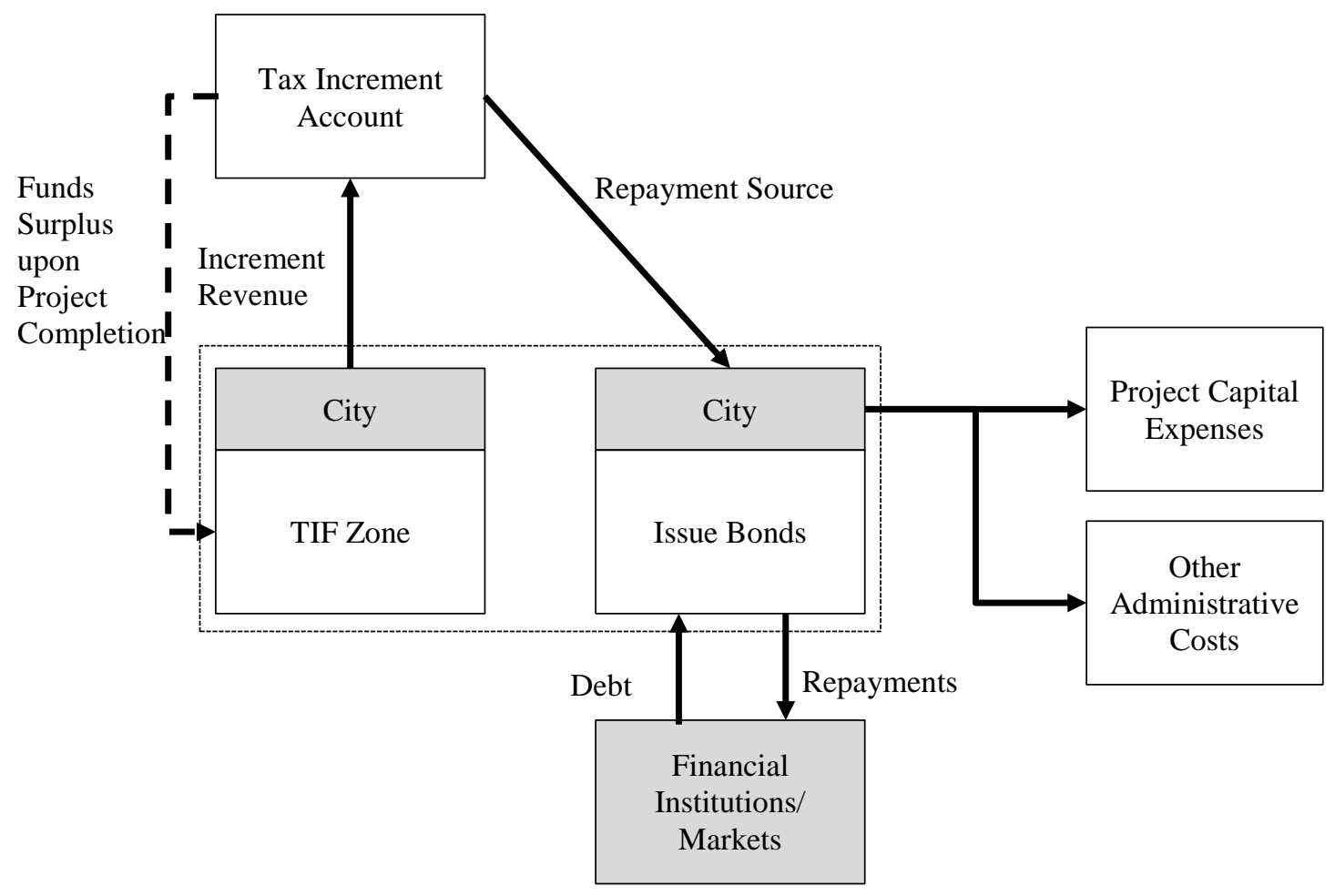

Figure 3 TIF Funds Flow 


\subsubsection{Financings with TIF}

TIF is a financing policy widely used by municipalities to improve their local economies. The principle of TIF financing is to borrow money from outside entities and then use this raised money for a new public project. For the repayment, the increase in tax revenue caused by the new project is used. In detail, there are three financing options for a TIF project (Greifer 2005) (see Repayment Source in Figure 4):

- Pay-as-you-go financing: This policy aims to manage the TIF project on an annual basis. The government collects the tax increment and pays the project cost only from the collected tax. The government does not borrow money from the outside, so it can save on financing costs. However, this annual basis financing structure cannot support a large-scale infrastructure project.

- Developer financing: This is a partnership with financing between the government and a private developer. For public development, the government provides credit assurance to a private developer, and the private developer issues its corporate bonds with the provided assurance and spends this raised money on the public project. Because of the warranty provision, the government is responsible for any default of the corporate bonds.

- Municipal bonds financing: In this option, the government issues bonds and uses the raised money for up-front financing of a large-scale project. Depending on the repayment pledge of the bonds, the issuer is either responsible for, or exempt, from default. 
This research focuses on municipal bonds financing. The primary goal of TIF is to positively affect the local economy by delivering new infrastructure. Infrastructure development needs an extensive budget in the beginning phase. In that sense, the first option is not matched. In the second option, the private developer delivers a new public infrastructure by issuing its corporate bonds. However, this policy is selectively applicable in a few cases where this developer can have an economic benefit. Besides, the government is exposed to the project risk because of the government credit pledge. Unlike the first and second options, the third option enables the government to achieve the TIF primary goal without financial interference. The government can finance nonprofit projects by issuing municipal bonds. In addition, the government can determine the risk exposure degree of default by designing the repayment pledges. Therefore, it is concluded that the third option can be regarded as the primary TIF financing option. For municipal bonds financing, the government has two choices (Greifer 2005) (see Bond Financing Type in Figure 4):

- General Obligation (GO) bonds: The issuer pledges full faith for retiring the bonds. The guarantee of the full repayment by the issuer allows for a lowinterest rate for borrowing, but the issuer is fully exposed to the financial risks of TIF.

- Revenue (Rev) bonds: The issuer is not responsible for the repayment, but bondholders are fully exposed to the financial risks of TIF. This potential risk causes an increase in the risk premium of the revenue bonds. 
In many cases, the government has issued TIF bonds in the form of Revenue bonds to avoid default risks. This phenomenon may lead to an opportunity for the TIF bondholders. If the TIF bonds do not fail during the lifetime, or if the bondholders leave before default, these assets will provide a more economic return to the investors than the GO bonds. For decreasing the risk premium of the TIF bond, and in creating the economic benefit of the buyers, the stakeholders of the TIF bond need a reliable risk assessment method. 
Repayment Source

\begin{tabular}{|l|l|l|l|}
\hline Type & Form & Advantage & Disadvantage \\
\hline Pay-as-you-go & $\begin{array}{l}\text { Expenditure within } \\
\text { the budget limit }\end{array}$ & No Financial Cost & $\begin{array}{l}\text { Impractical for up- } \\
\text { front large capital } \\
\text { expenditure }\end{array}$ \\
\hline $\begin{array}{l}\text { Developer } \\
\text { financing }\end{array}$ & $\begin{array}{l}\text { Private Financing } \\
\text { with government } \\
\text { credit }\end{array}$ & $\begin{array}{l}\text { Able to finance } \\
\text { large projects }\end{array}$ & $\begin{array}{l}\text { Selectively } \\
\text { applicable }\end{array}$ \\
\hline $\begin{array}{l}\text { Municipal } \\
\text { bond } \\
\text { financing }\end{array}$ & Public Financing & $\begin{array}{l}\text { Able to finance } \\
\text { large projects }\end{array}$ & Financial Cost \\
\hline
\end{tabular}

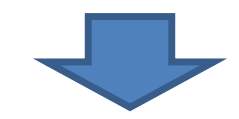

\section{Bond Financing Type}

\begin{tabular}{|l|l|l|l|}
\hline Type & Collateral & Advantage & Disadvantage \\
\hline $\begin{array}{l}\text { General } \\
\text { Obligation } \\
\text { Bond }\end{array}$ & $\begin{array}{l}\text { Issuer's Entire } \\
\text { Tax Bases }\end{array}$ & Low Interest Rate & $\begin{array}{l}\text { Impact on the issuer's } \\
\text { credit and } \\
\text { Political Risks }\end{array}$ \\
\hline Revenue Bond & $\begin{array}{l}\text { A specified } \\
\text { revenue stream }\end{array}$ & $\begin{array}{l}\text { Not responsible } \\
\text { for the Project } \\
\text { Financial Risk }\end{array}$ & High Interest Rate \\
\hline
\end{tabular}

Figure 4 TIF Repayment Source and Bond Financing Type 


\subsubsection{TIF Advantages over Other Value Capture Policies}

Among these value capture policies, TIF is widely applied across the nation. All value capture policies, except TIF, charge an additional tax, beyond the regular tax basis. This new taxes can cause taxpayer resistance. For example, in the case of the Metro Rail project in Los Angeles; the government charged an extra tax to the property owners who had properties near the rail project. The government had a plan to use the collected tax from that particular charge for supplementing the construction fund of the project. However, the taxpayers did not agree with this extra tax charge and sued the local government (Stopher 1993). Along with the social problem aroused by the tax increase, configuring the particular zone, where an additional tax levy occurs, is a challenging issue (Zhao and Larson 2011).

On the other hand, TIF has not experienced that kind of difficulty. It does not change the current tax policy but does create a special account that is used for the TIF project. If the property values inside a TIF zone increase, due to the project delivered by TIF, these increased property values will generate more tax revenue than before. Then, the government allocates this increased revenue to the special account, and reimburses the cost of the TIF project by using the allocated money. This 'no change' feature in the taxing policy is a positive aspect of TIF. California has used the TIF policy since the 1950s, and all states adopted this policy in 1999 (Greenbaum and Landers 2014).

In addition, TIF is useful for a variety of public development purposes; from small-scale projects, such as street environment improvement, to large-scale projects, such as transit station construction (Briffault 2010). All value capture policies, except 
TIF, are selectively pursued, because the government ensures that the taxpayers' contributions will be compensated from new development. On the contrary, TIF does not need to generate tangible economic outcomes for the property owners in a short time. For example, a streetlight project, pursued by TIF, can improve the environment of the community, but may not instantly provide a real economic outcome. In that case, the property owners near the new project will not complain to the government, because of 'no change' in the tax policy. This example leads to a consensus that TIF is more applicable than the other value capture policies because it generates little resistance from the taxpayers.

\subsection{TIF Securities Structuring}

\subsubsection{Asset Securitization}

Securitization of TIF bonds is similar to the securitization of other Asset Backed Securities (ABS) (Pacewicz 2012). This process includes three sequential steps: separation; structuring; and Initial Public Offerings (IPO) (see Figure 5) (Public-Private Infrastructure Advisory Facility (PPIAF) 2013). In the first step, the originator identifies

the assets that need to be securitized and transfers them to a financial intermediary (Jobst 2008). For example, a municipal government transfers the underlying asset of TIF (the property tax increment revenue account in which deposit is collected within specific geographical boundaries) to a new redevelopment entity. By doing so, this increment revenue asset is taken away from the municipal balance sheet and becomes the key asset of the new development agency. Due to such separation, economic consequences of the originator do not impact the financial status of the newly created entity and vice versa. 
The legal form of such entity is referred to as a Special Purpose Vehicle (SPV). It issues debt, controls TIF construction projects, and commits to the repayment of the debt by using the incremental tax revenue received from the municipal government.

Once separated, the asset is then financially structured and transformed into a marketable security. This step includes three sub-components: developing marketing strategies, defining financial characteristics, and assessing credit rating.

First, the issuer defines the asset marketing strategy; in other words, the issuer needs to identify target customers and the type of market placement. Typically, it is necessary to distinguish three types of asset sale strategies; a competitive sale, negotiated sale, and a private placement. In fact, it is the type of market that determines the marketing strategy for the bonds sale. Among these three types, the competitive and negotiated sale types are most widely used (Joehnk and Kidwell 1979). In a competitive sale, the local government defines the bond structure and the timing of the bonds sale, manages the credit rating, and specifies legal conditions of the bond contract (Simonsen and Robbins 1996). Because of the complexity of the debt structuring and the unfamiliarity with the bond market, the issuer may hire a financial advisor who helps with the issuance process. Once the bond is structured, the issuer sells the structured securities to the underwriters on a competitive sale basis. 


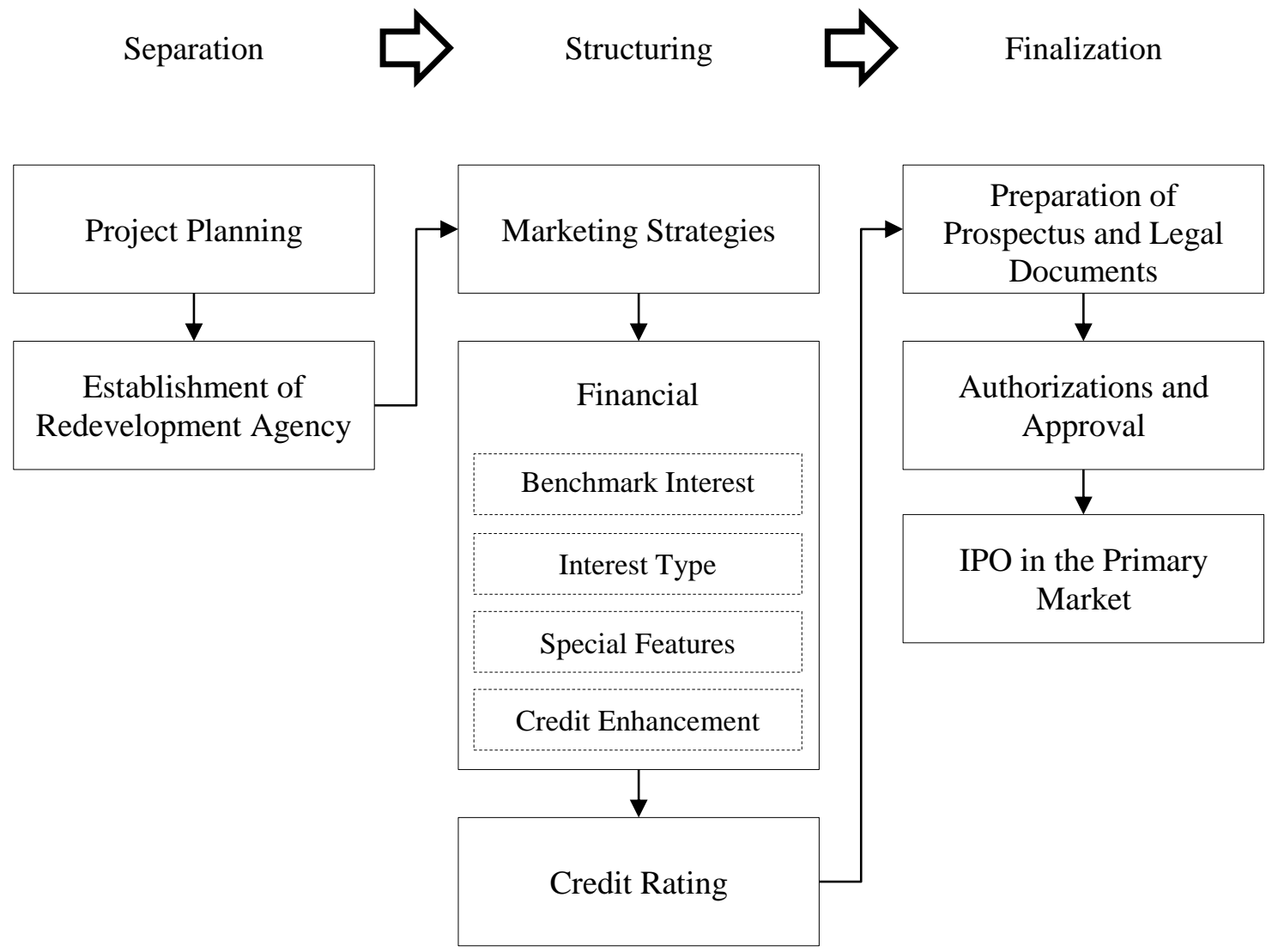

Figure 5 Bond Issuance Process

On the other hand, in a negotiated sale, the underwriter manages the whole bond issuance process (Simonsen and Robbins 1996). After designing the financial structure of the securities, the underwriter itself can buy these assets or sell them to other underwriters. For selecting the underwriter, the local government may host a competitive bidding process. Many studies have compared the competitive and negotiated sales in terms of their impact on the total financial cost to the issuer. The majority of these 
studies favored competitive sales (Simonsen and Robbins 1996, Joehnk and Kidwell 1979, Braswell, Nosari, and Sumners 1983).

Defining the financial characteristics of the security is closely related to the choice of the bond marketing strategy, and, as such, the specified characteristics are the key criteria for potential buyers who expect to gain interest in a relatively safe environment. There are four attributes that define bond characteristics; the benchmark interest rate, interest type, special features, and credit quality enhancement (see Table 2).

The major benchmark for structuring municipal bonds is the interest on the US Treasury bonds, as these securities are assumed to be default-free assets. The Treasury bonds have several maturity types, such as repayment period, and each is associated with different interest rates (Fleming 2000). By matching the maturities of the Treasury bonds and TIF bonds, the benchmark interest rate of the TIF bonds can be predetermined. This is considered a Lower Bound Interest Rate to which a risk premium will be added.

The bond's interest type can be either fixed or floating. Under the fixed interest rate type, the bondholders gain a constant amount of interest coupon until the bond is fully repaid (Investopedia). On the other hand, the floating bond pays interest based on the market conditions (James). For example, if a bondholder holds a bond with a fixed interest rate and if the market interest rate falls down, the investors get overcompensated for the risk they are taking. Therefore, determining the interest rate type is very important, as it determines the bond value (Longstaff and Schwartz 1995).

Similar to corporate bonds, TIF bonds may include special features, such as call, put, sinking fund, and refunding provisions (Harris and Piwowar 2004); each affecting, 
in different ways, the issuers and investors. For example, the call option is favorable to issuers but unfavorable to investors, as the issuer has an opportunity to retire the issued bonds prior to their expiration date. As a result, investors require an increase in the risk premium on the callable bond (Longstaff 1992, Dunetz and Mahoney 1988).

The last attribute in defining bond characteristics is credit enhancement. In short, credit enhancement is an insurance that protects investors from a default event. This feature can be procured either internally or externally. The internal method relies on the issuer to deposit a certain amount of funds to a special account, managed by a trustee. Then, if the bond defaults, the trustee distributes the deposited fund to the investors. The external method, on the other hand, is based on purchasing an insurance policy or a letter of credit from a third party. If the bonds default, the third party is liable for assuring the full repayment to the bondholders. This feature is attractive to the potential buyers and, eventually, can result in a decrease in the risk premium (Kidwell, Sorensen, and Wachowicz 1987). 
Table 2 Securitization Features

\begin{tabular}{|c|c|c|c|}
\hline Determinants & Purpose & Component & Impact on Investors \\
\hline \multirow{2}{*}{ Interest Rate } & \multirow{3}{*}{$\begin{array}{l}\text { Determining the } \\
\text { interest payment } \\
\text { amount }\end{array}$} & - Basis Rate & - Neutral \\
\hline & & - Risk premium & - Negative \\
\hline Interest Type & & $\begin{array}{l}\text { - Fixed } \\
\text { - Floating } \\
\text { - Zero }\end{array}$ & $\begin{array}{l}\text { - Depends on the } \\
\text { Investor preferences }\end{array}$ \\
\hline \multirow{2}{*}{ Special Features } & \multirow{2}{*}{$\begin{array}{l}\text { Additional conditions } \\
\text { affecting cash flows of } \\
\text { the investor's income }\end{array}$} & - Call option & - Negative \\
\hline & & - Put option & - Positive \\
\hline Credit Enhancement & Insurance at default & $\begin{array}{l}\text { - Letter of Credit } \\
\text { - Insurance from } 3^{\text {rd }} \\
\text { party }\end{array}$ & - Positive \\
\hline
\end{tabular}

After the financial characteristics of the bond are defined, the issuer requests a credit rating of the newly created debt product from a credit rating agency. The rating agency comprehensively reviews the debt repayment potential of the TIF project, as well as the regional economic outlook in which the issuer is located (Moody's 2015).

The issuance process is finalized with the approval of the municipal council and the sale, through an Initial Price Offering (IPO), in the primary market. This is when the bond becomes a legal contract between the issuer and the holders. The municipal council authorizes the contract and approves the issuance. It is only then that the debt security can be sold to investors through an IPO.

\subsubsection{Bond Indenture Structure}

TIF bonds are municipal bonds that must be fully repaid by public institutions. However, unlike other municipal bonds, their redemption depends entirely on the 
performance of underlying assets. This complexity requires investors to fully understand TIF project characteristics as well as the general nature of local debt. The investor can review the bond indenture and access the information. TIF indenture documents consist of two parts: common and TIF project-oriented (Table 3). An example is presented to describe clearly understand the structure (CUSIP-6: 26118R).

A typical feature consists of three components: general information, reimbursement security, and supplemental information. The general information explains the debt outlook. In this example, the issuer's name is the Downtown Redevelopment Authority (TIRZ \# 3, Houston, Texas). The amount of debt is $\$ 41$ million. The type of bond is a tax increment, meaning that only incremental revenues are the sole source of repayment. Insurance is provided by the Build America Mutual (BAM) Insurance Company. The credit rating of the underlying assets, before the insurance is applied, is BBB +, which is slightly higher than the investment grade and the credit rating after the insurance is AA. It is a serial bond with the same conditions except for maturity dates and interest rates. It does not have a callable feature, so the issuer cannot change the repayment schedule until maturity.

Repayment security consists of three components; the source of payment, legal liability of issuer in default, and risk factors. In this example, the payment source is a tax increment within the TIF boundaries. Second, if the bond defaults, the issuer has no legal liability but the insurance will be engaged in the failure. Third, financial and legal attributes are defined, which may impact the bond security. Legal risks are attributed to 
changes in the authority configuration, such as tax rate changes, termination of the TIF zone, and so on. Financial risks are primarily related to changes in property values. Supplementary information includes other relevant facts not covered in the previous part. One element is the source and use of the bond proceeds. In this example, the source comes from bond sales revenue. The uses contain the distribution of the raised money toward construction costs, the debt service reserve fund, and the reimbursement cost of issuance. In addition, the disclosure plan for the delivery of the annual report and special events, and the summary of the recent financial statements, are included as well.

The nature of the TIF repayment sources that come from tax increments, raises the need to deeply understand the characteristics of the TIF's underlying assets. The bond contract describes the underlying asset characteristics in three ways; the TIF zone location, project list, and asset value history data. First, the contract contains a visualization of the terrain of the TIF zone and surrounding environment. Second, if the raised funds are to finance a particular project, the contract describes the nature of each project. In this example, the contract does not contain a specific list, which implies that money will be used to account for the need. Finally, asset value history data provides a view of the underlying asset performance. 
Table 3 Bond Indenture Structure

\begin{tabular}{|c|c|l|}
\hline \multicolumn{1}{|c|}{ Categories } & \multicolumn{1}{c|}{ Contents } \\
\hline \multirow{4}{*}{ Common } & $\begin{array}{c}\text { General } \\
\text { information }\end{array}$ & $\begin{array}{l}\text { issuer name, debt amount, issuing date, bond type, } \\
\text { insurance, credit ratings, maturity date, call, and } \\
\text { interest rate }\end{array}$ \\
\cline { 2 - 4 } & $\begin{array}{c}\text { Repayment } \\
\text { security }\end{array}$ & $\begin{array}{l}\text { source of payment, legal liability of issuer when } \\
\text { default, and risk factors }\end{array}$ \\
\cline { 2 - 3 } & $\begin{array}{c}\text { Supplementary } \\
\text { information }\end{array}$ & $\begin{array}{l}\text { sources and uses of bond proceeds, information } \\
\text { disclosure plan, and financial statement summary } \\
\text { of the issuer }\end{array}$ \\
\hline \multirow{2}{*}{ TIF underlying asset feature } & $\begin{array}{l}\text { TIF area location, project lists, historical data of } \\
\text { property value }\end{array}$ \\
\hline
\end{tabular}

Each component of a bond contract has a distinctive impact on its creditworthiness. For example, a road extension project, funded by a TIF bond, could impair its creditworthiness if the projected tax increase is not realized due to a lack of real demand. This highlights the importance of careful interpretation of the bond indenture. In addition to these endogenous factors defined within the contract, the creditworthiness also gets impacted by exogenous factors, such as stock market indices, macroeconomic parameters, and so on. Of course, the sensitivity of the asset creditworthiness on these endogenous and exogenous factors will depend on mitigation strategies that are again part of the bond indenture. The credit rating agencies review this sensitivity, using both quantitative and qualitative methods, and provide the best estimate of the TIF asset's performance and the underlying bond credit risk. 


\subsubsection{Insufficient Information}

Bond investors, in general, struggle to find relevant information about the asset's financial soundness (Peng and Brucato 2004). This is an endemic problem to all ABS securities but is particularly visible for TIF bonds. As a result, the investors generally increase the minimally acceptable criteria for investment, which transfers into higher risk premiums. Therefore, it is important for both the issuer and the investors to have enough information to evaluate the risks associated with the underlying asset.

This 'lack of information' problem and the resulting increase in premiums can be explained from three different, yet interrelated viewpoints. It is helpful to first look at the problem from the information asymmetry viewpoint. Here, the information asymmetry implies the difference in the quantity and quality of the information available to the seller and the buyers. Due to its specialized nature, the buyers have only limited knowledge about the specific assets that are underwritten in the security and they rely on the general information about the asset-type as a class. Hence, there is a fear that the security might be structured in such way as to expose the investors to unacceptable levels of risk. In fact, the information asymmetry problem is one of the key characteristics of the bond market (Peng and Brucato 2004).

Credit rating is an alternative for resolving the information asymmetry. In that sense, Liu and Seyyed (1991) and Daniels, Diro Ejara, and Vijayakumar (2010) used credit rating information for measuring bond quality. Although the credit rating provides insights into the risk associated with the specific assets, it is infrequently published, so it may not reflect the current credit rating status. For example, Moody's evaluates the 
underlying asset of a TIF bond using four categories; local economy, tax revenue potential, financial strength of the issuer, and debt structure (Moody's 2015). At the time of IPO, the rating could deliver relatively accurate information about the default probabilities; however, its accuracy diminishes as the time gap between the rating and the transaction date increases. Therefore, solely relying on the credit rating to proactively assess the evolving risks is not a good strategy.

In the presence of unique and asset-specific risks associated with securities, one may be tempted to look at the market-implied yield spreads as an information source. The difference in yield-to-maturity (YTM) between the US Treasury bonds and municipal bonds will increase if the market believes that the municipal bonds are exposed to more financial risk than before. Leonard (1983) stated that the performance of the local economy is a major attribute in determining the level of YTM of the municipal bonds. Contrary to the general obligation (GO) bonds, in which the issuer guarantees the repayment, TIF bonds do not include any guarantee of repayment, increasing the YTM level of these securities. In terms of socioeconomic variables, Capeci (1991) argued that the fiscal policy and tax bases of the issuer are directly connected to the yield spread. However, the yield spreads are, in general, inaccurate as they are driven more by market liquidity than underlying risk. In other words, the YTM method should be used as a supplemental, not the main method, of assessing the risks.

Finally, the third way of looking at the information problem is the general difficulty in reviewing details of the bond's official statement. As the bond represents the borrowing contract between the issuer and the buyer, all the requirements for 
repayment must be explicitly specified in the statement. However, understanding these statements requires patience and full knowledge of both legal and financial jargon. In fact, this "designed" complexity of the statement significantly reduces the pool of potential risk evaluators.

\subsection{Summary}

To summarize, TIF bonds, similar to other ABS securities, have an inherent problem with accessibility to the information required to assess the risk. Crediting ratings and the yield spreads provide some insights into the underlying risk; however, as discussed above, they are considered incomplete and, in some instances, highly misleading. As a result, the investors remain pricing-in this lack of information in the premium, and illiquidity continues to affect the whole asset class. TIF bonds are particularly affected due to due to the dynamic nature of uncertainty associated with the real estate market and property tax revenue collection. This dissertation aims to address this challenge by proposing a risk assessment and monitoring method that leverages publicly available data sets to detect early warning signals that the underlying asset, such as the property tax increment revenue, is being affected by the changes in internal and/or external drivers. 


\section{EARLY WARNING SIGNALS THEORY AND APPLICATION}

\subsection{Introduction}

Risk analysis is an essential part of the planning process. Regardless of whether planning a summer vacation, a replacement of a valve on an offshore platform, or highly complex operations in projects such as the Mars Exploration Rover Mission, it is necessary to go through the same process of imagining the situations that can lead to damage, loss, and other forms of distress. To this aim, it is necessary to use data, information, and other available scientific evidence to develop a model representation of the system and its environment. In fact, it is this model, conceptual or mathematical, upon the development of a description of risk (Covello and Mumpower 1985).

However, the model is only an approximation of the reality. It is based on various assumptions and simplifications of the processes that govern the system's behavior. Hence, a description of risk is inherently conditional on the model assumptions which reflect the current state of knowledge (K); more formally, and in general terms, the risk description can be written as $(\mathrm{A}, \mathrm{C}, \mathrm{Q}, \mathrm{K})$, where A represents the considered event, $\mathrm{C}$ the considered consequence(s), and Q, the measure of uncertainty in a broad sense (Beard 2004).

Consider a probability triple (outcome space, event set, and probability measure) that defines a risk description in a narrower sense. Given that the model is just an approximation of reality, based on background knowledge, the sample space and the event set can never be defined with the absolute certainty. In other words, if the behavior 
is unpredictable, there is nothing to assure that the list of outcomes/events is exhaustive, and that unforeseen events are not possible. Clearly, the background knowledge is a source of risk, and consequently, must be explicitly accounted for in a description of risk (A,C,Q,K) (Aven 2014).

However, explicitly defining the state of background knowledge in risk description is a challenging task. A recent study aims to address this problem by providing a general Data-Information-Knowledge-Wisdom (DIKW) framework that requires an explicit account of the assumptions upon which the analysis is conducted. (Aven 2013a). Flage and Aven (2009) propose a direct method of grading the strength of knowledge, on a scale from weak to strong, while Aven (2013b) introduces a scorebased measure that captures deviations from the conditions or states used in the assumptions.

An assessment of the strength of knowledge plays a critical role in the robust and adaptive analysis of systems that are characterized by deep uncertainty (Linkov et al. 2006). Even though these analyses emphasize the dynamic nature of making optimal decisions, they provide little or no contribution to the dynamic assessment of the strength of knowledge and validity of the assumptions. A continuous validation process offers a basis to incorporate new information for the assessment of model assumptions (Sornette et al. 2007). However, its focus is limited to the previously identified models and assumptions, not on the state of knowledge about the system behavior and early warning signs. 
Alternatively, there have been a number of methods developed to investigate early warning signs of failure (Weick, Sutcliffe, and Obstfeld 2008); yet these do not provide a link between the observed signals and warnings on one side and the knowledge about the system behavior on the other side. What is missing is the framework that will link observations and knowledge to the early warning signals.

The proposed framework is based on the notion that the changes in the system's operating regime are often associated with unknown and unpredictable behavior associated with the lack of knowledge. Hence, it is not necessary to define a quantitative measure of the strength of the knowledge directly, but rather it is necessary to focus on capturing early warning signals (abdicative anomaly) that the system is exhibiting a critical transition; or, in other words, it is desirable to develop a measure that can warn us against potentially unknown and unanticipated behavior. The concept of critical transitioning closely relates to the method of statistical process control, as both aim to capture early signs of the anomaly in data that may be indicative of changes in the system behavior and the emergence of a new equilibrium.

At the critical transitioning moment, it is easy to detect the critical slowing down phenomenon. Critical slowing down means a low recovery rate and a long recovery period to reach the original status, at a moment when the moment is proximate to the timing of a critical transition. For example, when a ship is perpendicular to the sea surface, a small perturbation will not affect the survivability of the ship because the recovery rate at that moment is high, requiring minimal time. However, when the ship rolls to the left side and its rolling angle is proximate to the limit of the return allowance, 
a small perturbation may cause the ship to capsize. As the ship is approaching the balance limit, which is a critical transition point, the recovery rate of the ship is going to be smaller than the previous status. Eventually, at the end of the transition limit, this recovery rate difference - between the previous and current state - is going to be minimal but the recovery time difference, between two states, is going to be infinite. This example explains the phenomenon of the critical slowing down. Wissel (1984) described that, at the tipping point, which is located at the end of a stationary interval, the recovery rate near the tipping point usually decreases, verifying the theory of critical slowing down.

The autoregressive order one (AR1) analysis and variance (Var) have been broadly used as primary Early Warning Signs (EWS) methods. This detection method can be applied to both climate change and financial markets (Scheffer et al. 2009). Ives (1995) suggested that the recovery rate can be measured by observing the coefficients of AR1 and that supports the argument that the phenomenon of critical slowing down leads to an increase in the autoregressive coefficient. Carpenter and Brock (2006) argued that an increase in Var is a predictive indicator of a decrease in the recovery rate.

\subsection{Early Warning Signals as an Abdicative Anomaly in Dynamic Systems}

To understand early warning signs for surprise and unforeseen events, one first needs to consider the nature of the risk description process itself. This process can be viewed in two modes; the prediction mode, where the initial description is developed, and the observation mode, where observations to revise the initial judgments are used. In the prediction mode, assumptions are adopted based on the current state of knowledge 
and then proceed to develop a model of the system behavior. The predicted system behavior represents the foundation upon which the probability is developed and the risk description is defined. Note that the term "system model" can be interpreted in a broad sense, encompassing both experts' mental constructs and mathematical formulations.

In the observation mode, on the other hand, it is necessary to collect data and, consequently, gain or lose confidence that "system model" is the accurate representation of reality. Note that this is fundamentally in line with a Bayesian paradigm, where new information is used to update the prior beliefs. However, rather than applying it in a narrow context of the event set probabilities or model selection, which will ignore previously unaccounted for events/models (Chipman et al. 2001), the analysis should be set in the context of the knowledge about the system behavior. To do so, one first needs to understand what system observations contradict the knowledge about how the system should behave (e.g. assumption models). The scientific method provides a general framework for acquiring new and correcting previous knowledge from observations (Crowell 1937).

Peirce, Hartshorne, and Weiss (1935) define the scientific method as spiral interplay among the following methods of reasoning; deduction, induction, and abduction. The process begins with abduction - a hypothesis where a conjecture about the observed phenomenon or anomaly is postulated. This is followed by a set of deductive inferences and is concluded with experimental observations to test the candidate hypotheses. The answer to this test is hidden in the very first step of the scientific method - detecting an anomaly in observations (abductive anomaly). The 
presence of an anomaly in the system observations can be interpreted as a measure of knowledge, or rather, an inverse measure of the capacity to predict the future dynamics of the system, hence warranting further investigation. This need for investigation is the warning sign that the obtained knowledge is inconsistent with the observation and the early warning sign of potential surprise and unforeseen events.

In the next section, an overview of the key properties of dynamic systems is presented. A simple oscillator is used as an example to describe a system's phase space and potential function. This brief introduction to dynamic systems allows us, then, to present the concept that is fundamental to the proposed framework - the concept of critical slowing down.

\subsubsection{Dynamic Systems}

All active systems generate data in the form of a time series; a sequence of data representing the time evolution of system observables. While, in the eyes of a layman, this data appears to be random and insignificant. In reality, it provides important information about the current and the future state of the system (Katok and Hasselblatt 1997).

Consider a simple harmonic oscillator, such as a ball suspended on an elastic string, as an example of a dynamic system that generates time series data (see Figure 6). Subjected to external force $F$ (Figure 6 (a)), the system will move away from the initial point $x_{0}$, generate a signal $x(t)$, and gradually settle back to the point $x_{0}$ at time $T$ (Figure 6 (b)). It is referred to $x_{0}$ as an equilibrium point. Now, based on the data in Figure 6 (b), a phase space of the system (Figure 6 (c)) can be reconstituted. A phase space is the 
space that uniquely represents all possible states of a system. For example, the state of the oscillator is uniquely defined by its speed $(\dot{x})$ and position $(x)^{1}$. If the system is in state $(\dot{x}, x)$, then the phase space defines a unique trajectory of the system evolution from that point.

One can also notice, from Figure 6 (b) and Figure 6 (c), that the system's trajectory can be bounded by a parabolic function $V(x)$. The system appears to behave as a ball rolling down the surface of this function $V(x)$. It is referred to the function $V(x)$ as the system's potential function. In fact, the behavior of dynamic systems can be characterized by this function. Along with this function, all the states in phase space move in a downward trajectory (Packard et al. 1980). It is possible to visualize the potential function as a complex "spatial geography" of valleys, hills, and mountains, where the system moves on the path of the maximum decrease in potential energy, such as the steepest descent, until it settles at the local minimum. It refers to these valleys as orbits, and to the lowest point in the orbit as an attractor point. Guckenheimer, Holmes, and Slemrod (1984) provide a more formal description of dynamic systems and their potential functions.

\footnotetext{
${ }^{1}$ Using momentum and position is typical phase space representation for mechanical systems. Note that the definition of the space varies for different applications, yet always defines a unique system state.
} 


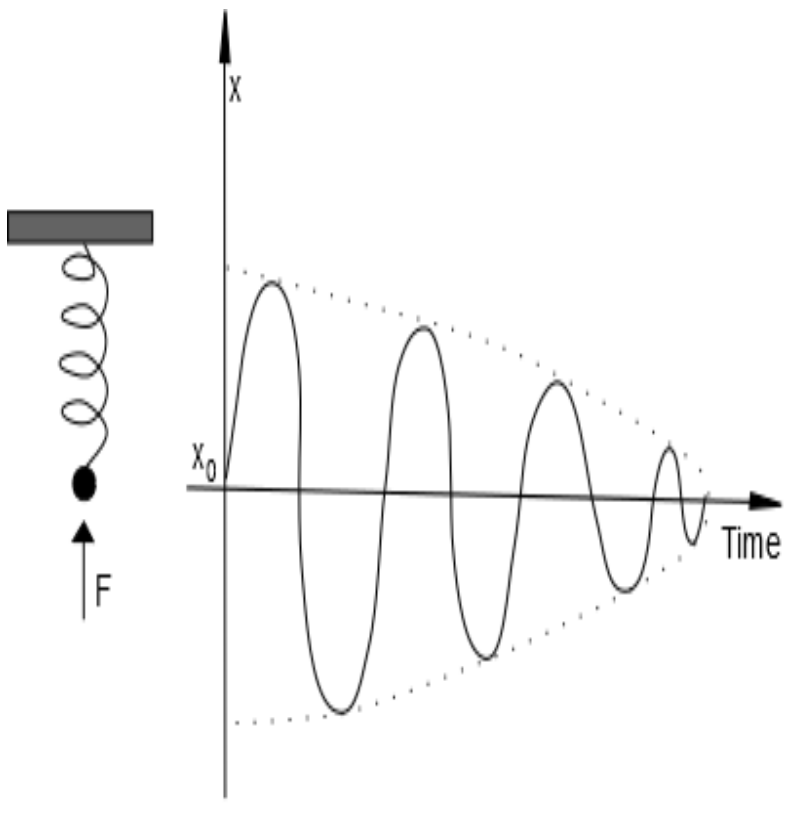

$1 A$ OSCILATOR
$1-B$

ORGINAL SIGNAL

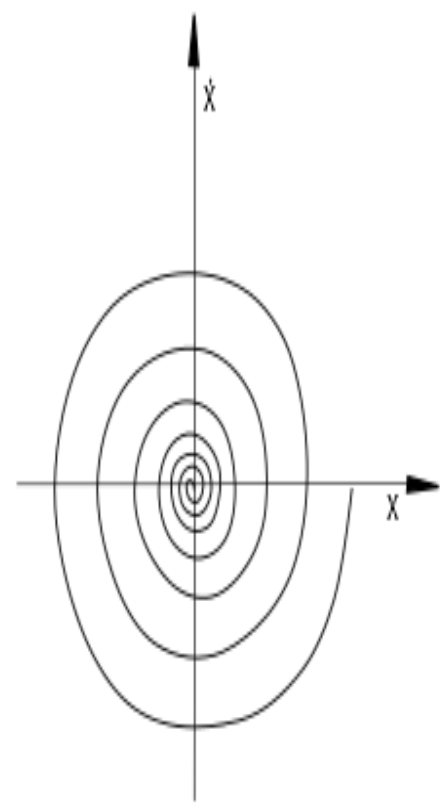

$1-\mathrm{C}$ PHASE SPACE

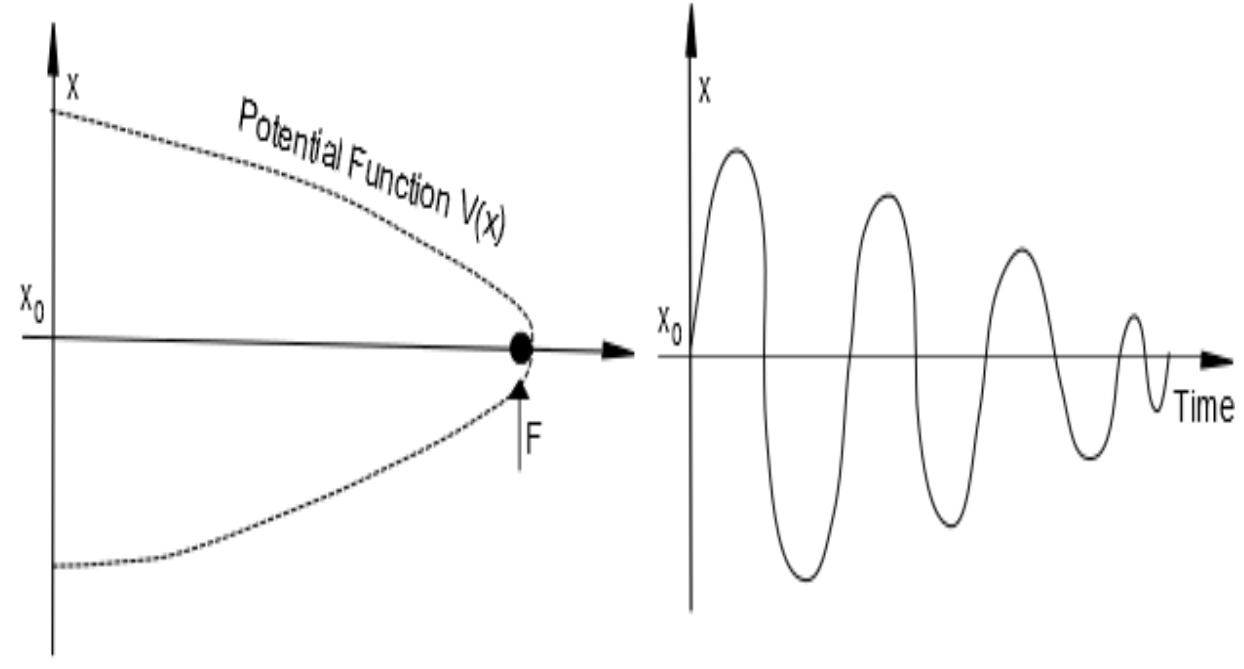

1-D POTENTIAL FUNCTION $1-\mathrm{E}$ SIGNAL FROMPOTENTIAL FUNCTION

Figure 6 Damped Harmonic Oscillator 
Figure 6 (d) shows formulation of the dynamic behavior of the damped harmonic oscillator based on potential function $V(x)$. Subjected to an external force $F$, the system will leave the equilibrium and move along the orbit of the potential function $V(x)$ until it settles back at the attractor $x_{0}$ when the effect of the forcing $F$ on the system has dissipated. Note that, in general, these forces can be strong enough to perturb the system away from the current orbit and into new convex regions characterized with new attractor points.

The state-time profile of the oscillator movements, represented by the potential function, $V(x)$ is captured in Figure 6 (e). Note the equivalency of Figure 6 (a) and Figure 6 (e). In other words, to describe the dynamics of the system, it is not necessary to know its modus operandi (what generated the signal); it is sufficient to know its phase space and potential function (Scheffer et al. 2009). This has a profound implication in studying complex systems, allowing us to focus on a whole, rather than on the sometimes difficult to understand inner workings of the system components. However, non-trivial dynamic systems have complex potential topologies that are, at best, difficult to express analytically. For the most part, the potential function of a system is unknown a priori and must be reconstituted from data (Packard et al. 1980).

Dynamic systems are constantly subjected to random external forces, such as perturbations, which make the reconstitution process difficult. In such situations, the statistical analysis of time series becomes relevant and can provide insights about the underlying phase space structure and the shape of the potential function. More specifically, as the systems approach the saddle points in the potential function, they 
exhibit the universal statistical signature of critical slowing down (Scheffer et al. 2012). In other words, statistical analysis of the time series allows us to detect proximity to new orbits and attractors.

In summary, the phase space and the potential functions can provide a detailed structure of the long-term trend of the dynamics of the system. Even though this structure may be difficult to reconstitute from data, the dynamic systems theory framework allows us to think about the system as a whole without the need to model interactions among the system's components. Further, this framework implies the existence of a universal pattern, such as critical slowing down, as the system moves away from the previous one and approaches new orbits. This is precisely at the point where a link between system-wide observations, "abduction anomaly" in the form of critical slowing down, and the knowledge about the system behavior, can be established. In other words, if the time-series metrics from the system observations indicate a pending transition to a new attractor that has not been previously accounted for or anticipated from the background knowledge, then such an event constitutes an abdicative anomaly and provides an early warning sign that surprises are possible.

\subsubsection{Critical Slowing Down in Dynamic Systems}

This section explains the phenomena of critical slowing down by focusing on the potential functions of two distinctively different systems; the system that is far from the transition and the system that is close to the transition. Figure 7 illustrates the potential function of the two systems and the associated time-series metrics. The system on the left-hand side is characterized by a "deep basin" of attraction with steep slopes around 
the equilibrium point. Such systems, subjected to stochastic perturbations, will promptly return to the equilibrium point. In other words, the system is resilient to perturbations. The time series metrics, such as variance and autocorrelation of lag 1 , show the behavior that is consistent with the system being in a stable orbit; the variance and correlation are constant and relatively low.

The system on the right-hand side, however, is in an equilibrium point with a relatively flat basin of attraction. Subjected to stochastic perturbations, this system will slowly return back to the equilibrium. Hence, even minor disturbances can take the system to the saddle point and into a new basin of attraction that may be associated with fundamentally different system behavior. Figure 7 also shows the statistical signatures of these two systems' topologies. Far away from the transition point, where the topology is characterized with a "deep basin," the system exhibits lower autocorrelations and variances; close to transitions, where the topology is characterized with a "shallow basin," the system shows increases in variances and autocorrelation. 

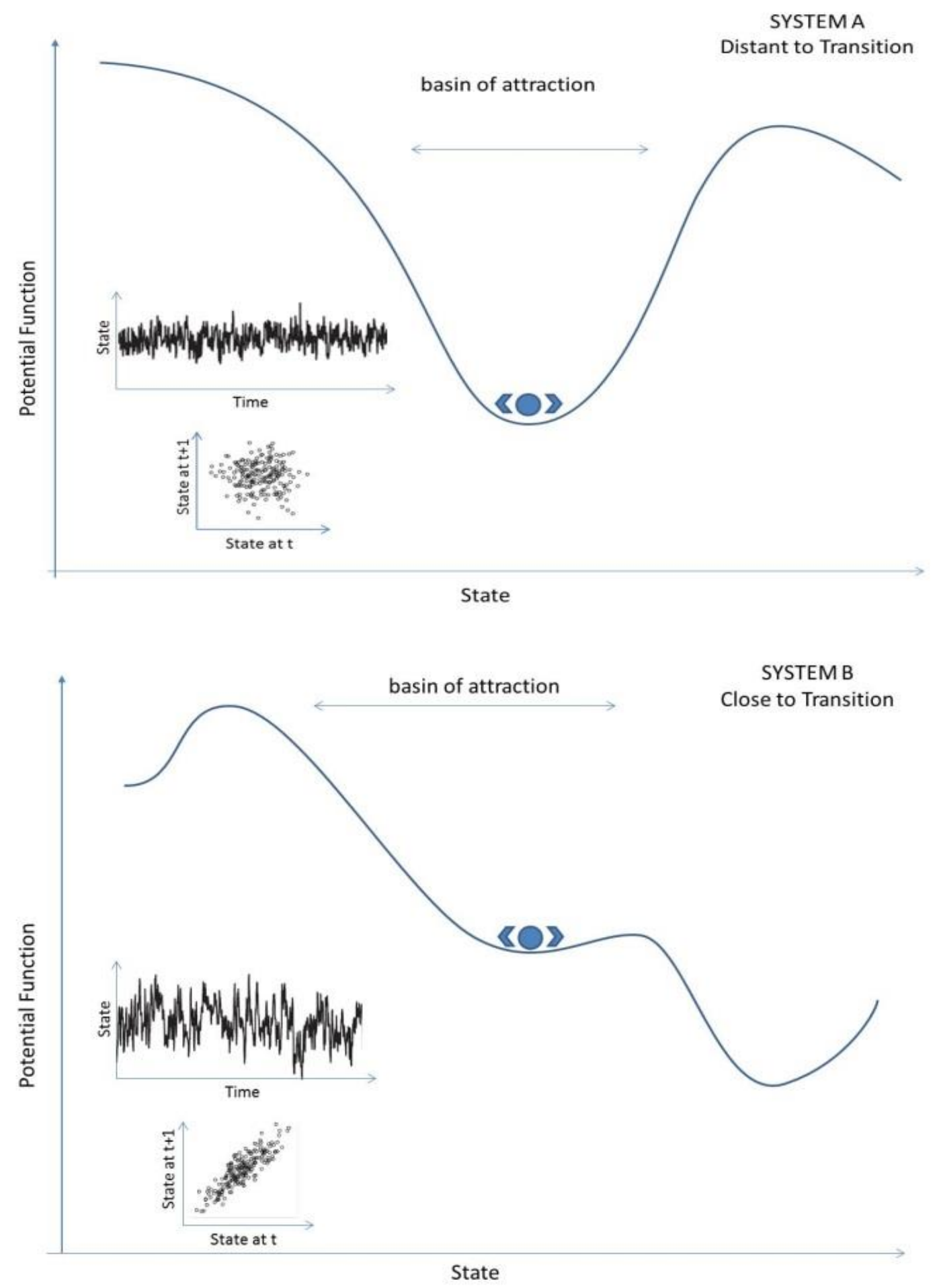

Figure 7 Statistical Patterns of Critical Transitions 
In fact, some of the general principles of critical transitioning have already found applications in reliability analysis and safety engineering. For example, recovery time models are often used in vibration analysis of rotary equipment to identify changed operating conditions (Eisenmann 1998). Similarly, accosting monitoring devices are placed to analyze pressure relief valves and warn against potential failures (Fletcher 1993). Although these and similar approaches are largely empirically-driven, their development can be traced back to the fundamental principles of dynamic systems and the critical slowing down concept (Ellestad 1986, Blaschke et al. 2001).

\subsection{Research Model}

\subsubsection{Research Model Introduction}

Dakos et al. (2008), used the early warning methodology to predict a critical moment between thawing and glaciating periods. This study argued that the AR1 has the potential to predict a critical shift. Lenton (2011) used Var and AR1 for detecting warning signals before a critical transition time of sea level and concludes that these methods are useful for alerting us to upcoming shifts.

However, these previous studies are only applicable to test the punctuality of the generated EWS against previously occurring events but are not useful for prediction (Lenton 2011, Dakos et al. 2008). For measuring AR1 and Var, it is critical to accurately calculate the mean structure of the input, because the residuals are plugged into these models. These studies used past and future data to calculate a mean at the current moment for the sake of maximizing accuracy. In addition, they subjectively determined the length of a moving window. The length critically affects the outcome because it 
specifies the length of input to calculate the EWS amplitude at the current moment. For example, Dakos et al. (2008) used a half of the total input length as a moving window. In the case of a system where critical transitions occur in a relatively short period, his approach cannot be applicable.

This research method is created to overcome such limitations. It calculates the mean structure by using the past data and uses an optimized moving window to calculate the EWS amplitude at each moment. Note also that the proposed method does not aim to replace the traditional methods for accounting for new information to update probability judgment and select models, such as Bayesian methods; rather, it aims to complement the existing methods by providing a tool to detect early signs of surprise and unforeseen events.

\subsubsection{Model Structure}

This section specifies the model in detail. This model has four parts: (1) EWS Analysis, (2) Transition Identification, (3) Filtered EWS Results, and (4) EWS Current Status (Figure 8). The first part is designed to compute the EWS amplitude of each input. It is processed by the autoregressive order one (AR1), variance (Var), and spectral density, derived by Short Time Fourier Transformation (STFT) methods, frequently used for the EWS calculation. Second, the transition identification identifies the timing of actual critical events on the input stream and provides a standard for EWS filtering. Third, the 'Filtered EWS Results' module identifies positive warning timings, which capture a near-critical moment. The filtered results are derived by screening the EWS results using four filters, such as EWS amplitude, positivity in EWS difference between 
the current and past moments, the Kendall coefficient with a moving window of three, and the Kendall coefficient with a moving window from the last critical moment to the current time. Lastly, this model measures the current level of EWS by applying the filtering technique for estimating the possibility of proximate warning. In this task, a EWS analysis model, based on Matlab®, is implemented. It consists of three modules: (1) Residuals Calculation, (2) Stationary Intervals Definition, and (3) EWS Amplitude Calculation. The conceptual procedure is described in Figure 8. 


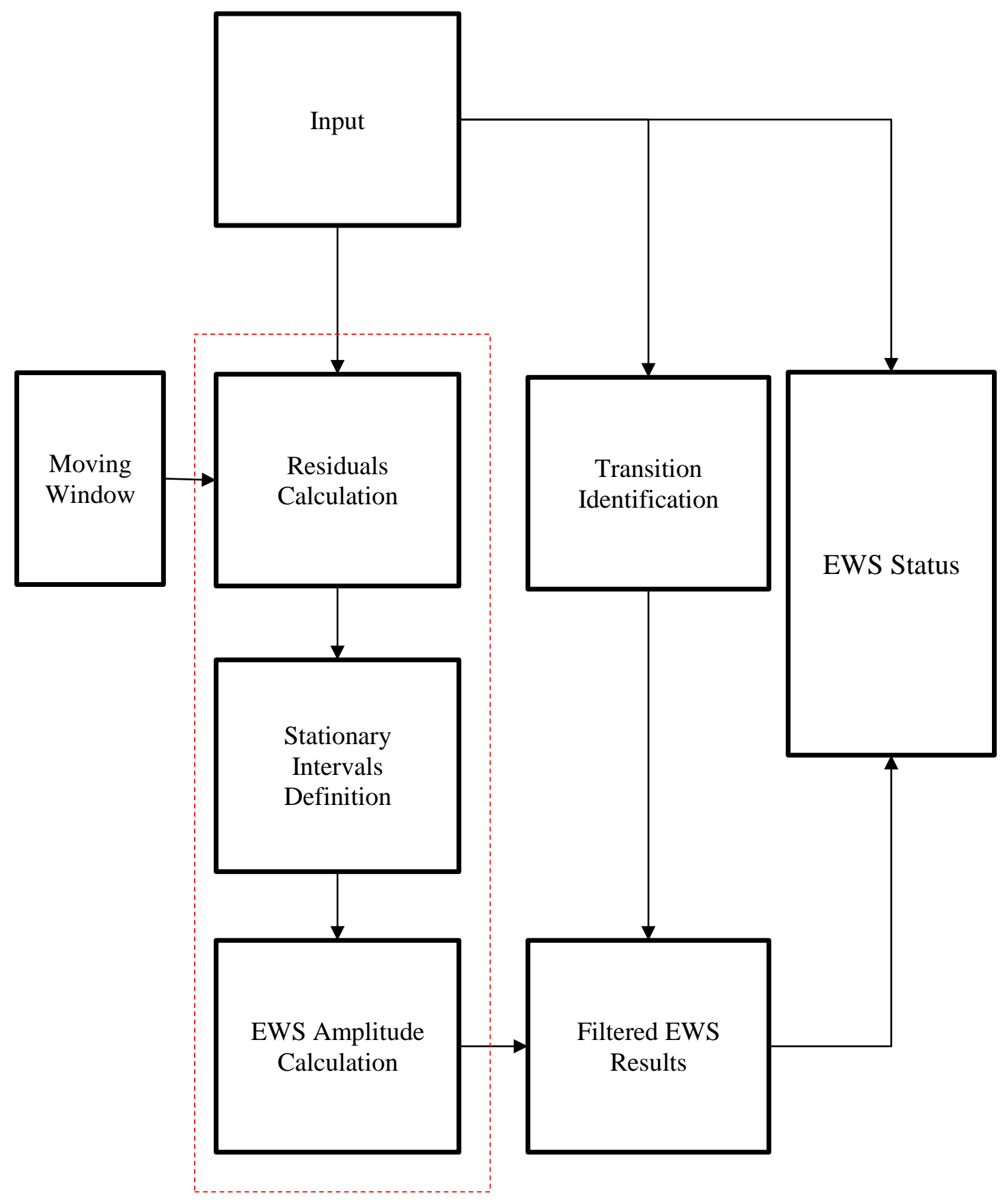

EWS Analysis

Figure 8 EWS Method Process Map 


\subsubsection{EWS Analysis}

\section{Residual Calculation}

The first step of EWS processing is to calculate the residual of the input data. For the residual calculation, this study uses the exponential smoothing method. This method is similar to the simple moving average method that requires only using the past data at the current moment. In addition, this method has a shared feature with the Gaussian kernel method in the sense that it assigns varying weights to the neighbors of the current moment, regarding the distance between the neighbors and the present moment. There are two data processing options under the exponential smoothing method; either simple or double smoothing. Among them, this study uses the double exponential smoothing method to counteract the data dynamicity.

The most critical part is to define level, trend, and mean (Bozarth 2011). The model calculates a level $\left(S_{t}\right)$ using a weighted average between the most recent input $\left(y_{t}\right)$ and the past mean value $\left(S_{i-1}+b_{i-1}\right)$ (Eq. 1), with the parameter of $\alpha$. The trend is also a weighted growth value between the current $\left(S_{t}-S_{i-1}\right)$ and past growth $\left(b_{i-1}\right)$ (Eq. 2) applied with the parameter of $\beta$. This calculation continues until the end of a moving window length. The mean at the end of the moving window $\left(\mu_{t=e n d}\right)$ is derived by summating the level $\left(S_{t=e n d}\right)$ and trend values $\left(b_{t=e n d}\right)$ (Eq. 3). Finally, the residual $\left(\varepsilon_{t=e n d}\right)$ is calculated (Eq. 4). 
If $t$ is a moment inside a moving window length for the smoothing :

$$
\begin{aligned}
& \begin{array}{ccc}
y_{t}, & t=1,2 & \text { Eq. } 1
\end{array} \\
& b_{t}=S_{2}-S_{1}, \quad t=1,2 \quad \text { Eq. } 2 \\
& \mu_{t=\text { end }}=S_{t=\text { end }}+b_{t=\text { end }} \quad \text { Eq. } 3 \\
& \varepsilon_{t=\text { end }}=y_{t=\text { end }}-\mu_{t=\text { end }}
\end{aligned}
$$

Figure 9 shows the smoothing process. The example here uses the moving window length of twelve. In the first trial, the model calculates the difference at time 12 using moving window length of 12 , alpha of 0.05 , and beta of 0.05 . The level of time 3 is calculated by assuming level 1 and 2 as the input of 1 and 2 . The level and trend calculation continues until time 12. At time 12, the model calculated the level and trend using the current raw input and two previously calculated levels; it measures a difference between the input value at the current moment and the calculated mean. Then, the time, alpha, beta, moving window, and difference are logged onto the database. This smoothing process continues until time 100, which is the end of the input data stream. Then, the model iterates this calculation process, varying the alpha and beta parameters.

The residual at each time is squared and summated regarding the set of alpha and beta parameters. The model selects a residual stream having the least difference and finally defines the alpha and beta parameters.

In the case of a moving window length, this study empirically determines the moving window length regarding the input stream. A short length causes the mean structure to be almost the same as the input value, making it impossible to have long- 
term aspect's residuals. On the other hand, a long length causes large residuals, making it impossible to detect a short-term aspect's residuals. Therefore, the study empirically determined a moving window length for balancing these two consequences. 


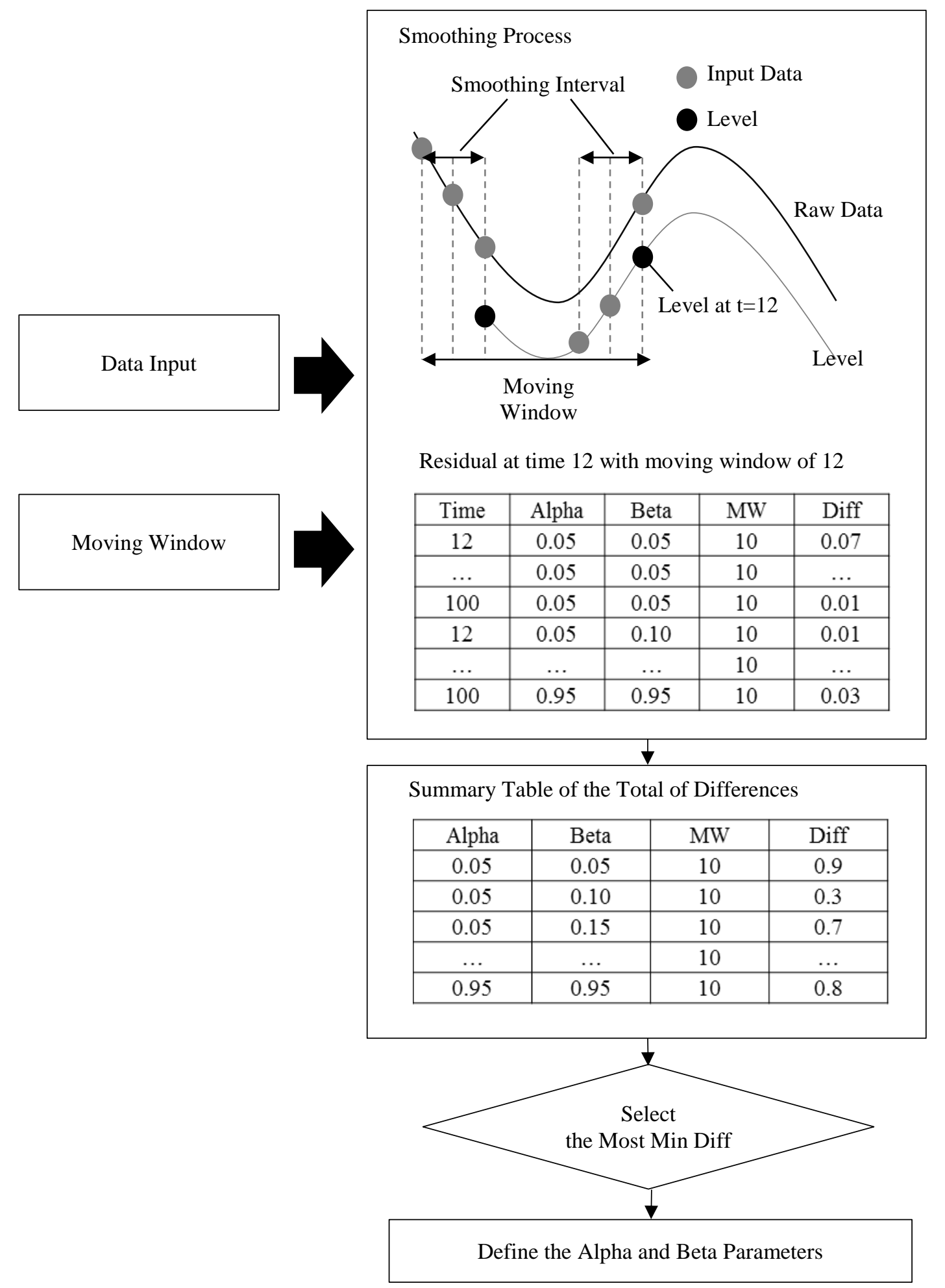

Figure 9 Exponential Smoothing 


\section{Stationary Intervals}

The EWS analysis should be processed on stationary intervals (Lenton et al.

2012). The stationary interval concept is defined in two ways. The first is that the mean and standard deviation of the input data are constant within the stationary interval. The second is that the autocorrelation function should depend on a lag, not on a time. If these two conditions are met, the time series can be defined as weakly stationary (Challis and Kitney 1990). For example, the equation Eq. 5 is weakly stationary. This can be proved by considering the theoretical mean (Eq. 6), standard deviation (Eq. 7), and autocorrelation function (Eq. 8) of the time series of $y_{t}$. The mean and standard deviation values are constant if $\alpha, \beta$, and $\sigma_{w}^{2}$ values are fixed. The autocorrelation function value is degraded by the lag if the value of $\beta$ is constant and its absolute value is less than one.

$$
\begin{aligned}
& y_{t}=\beta \times y_{t-1}+w_{t}+a, \quad\left(|\beta|<1, \omega_{t} \sim \operatorname{Random}\left(0, \sigma_{w}^{2}\right)\right) \quad \text { Eq. } 5 \\
& \mu=\frac{a}{1-\beta} \\
& \sigma=\frac{\sigma_{w}^{2}}{1-\beta^{2}} \\
& \begin{array}{lll}
\rho_{i}=\beta^{i}(i \text { is lag from } t) & \text { Eq. } 8
\end{array}
\end{aligned}
$$

This study uses the Augmented Dickey-Fuller (ADF) test for testing stationarity (Harris 1992). If the time series of $y_{t}$ is residuals computed from exponential smoothing, it is assumed that $\varepsilon_{t}$ follows a random distribution, with the mean of zero and the standard deviation of $\sigma_{w}^{2}$ and $a$ is zero because the input is residual. The equation (Eq. 9) 
shows the transformed equation from the equation (Eq. 5), by plugging the residuals into the equation and subtracting $\varepsilon_{t-1}$ from both sides ( $\delta_{t}$ is error term).

$$
\Delta \varepsilon_{t}=(\beta-1) \times \varepsilon_{t-1}+\delta_{t}, \quad \Delta \varepsilon_{t}=\varepsilon_{t}-\varepsilon_{t-1}
$$

One of the critical stationary features is that the absolute value of $\beta$ should be less than one. For this check, the t-test of the regression analysis is useful. The hypothesis of the regression is that the coefficient of the independent variable is zero. If the $\mathrm{p}$-value of $(\beta-1)$ is below a certain level, $(\beta-1)$ can be statistically regarded as zero, leading to the indication that this time series is not stationary. If the result rejects this hypothesis, this time series can be regarded as stationary.

Figure 10 describes an example showing the process of the stationary test. For applying this method to this study, it is necessary to define an input data size. The model initially tests the stationarity of the 11 residuals from the current moment. The size of 11 is predefined by Matlab®. This test starts from time 22, which is the end point of each stationary interval. The residual structure starts from 12 due to the moving window length of 11 . The model inserts the residual from time 12 to 22 to the ADB test, and the result confirms that they are stationary. Then, the model records the start, which is 12 , and end time, which is 22 , in the database.

Likewise, the model tests the stationarity of the initial interval at the time 23 and records the start and end times. However, at time 24, the model determines the initial interval is not stationary. In this case, the model continues to expand the interval up to the start of the residual structure until achieving the stationarity. If impossible to find stationary up to the start, the model then assigns the start point as the beginning of the 
interval. The model expands up to time 12 but it is impossible to secure stationarity so it assigns the start of the interval as time 12. At time 100, the model finds the stationarity with the interval between time 50 and 100 . 


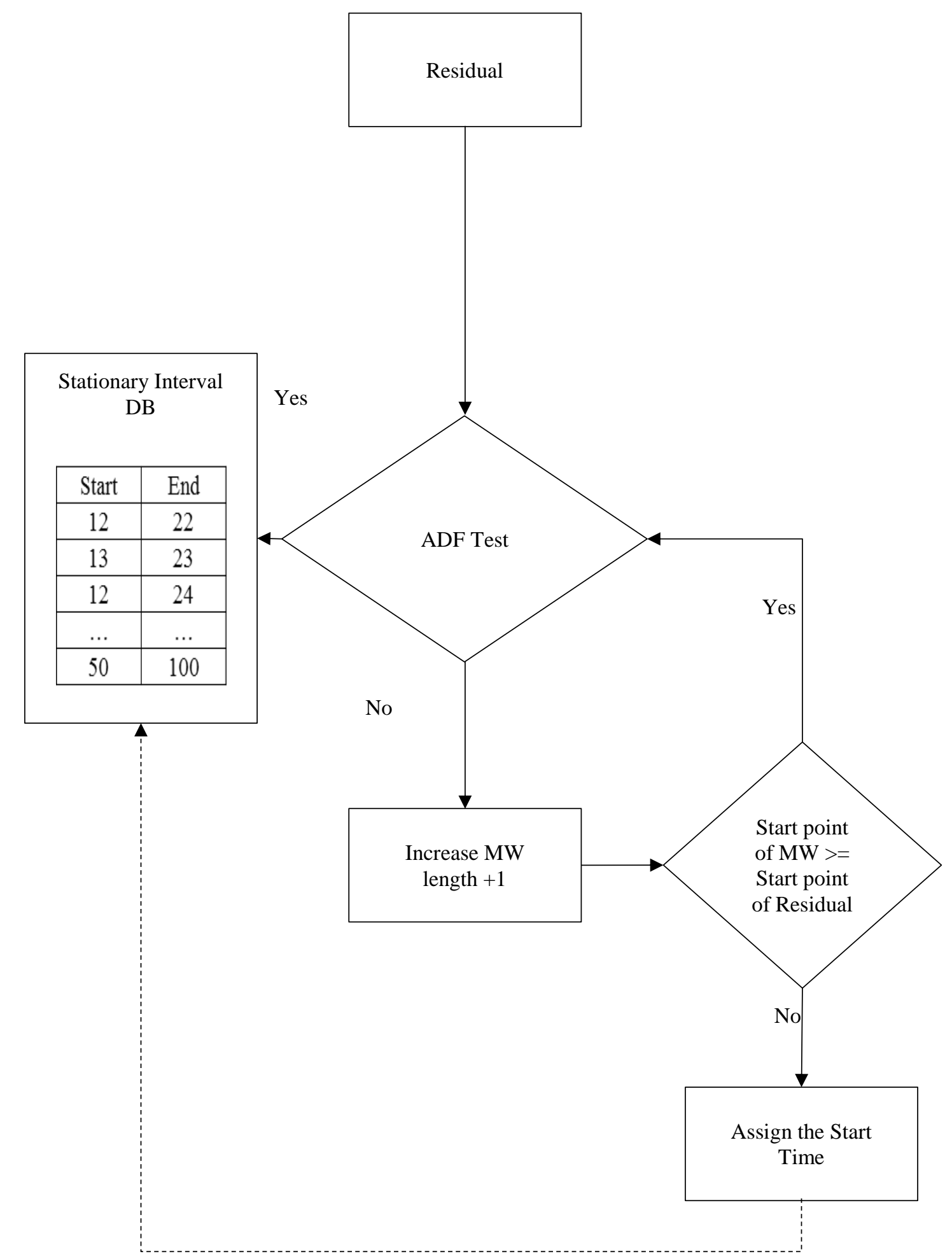

Figure 10 Stationary Interval Check 


\section{Autoregressive order 1 (AR1)}

The computed residuals and stationary intervals are used for Autoregressive order 1 (AR1), Variance (Var), and Short Time Fourier Transformation (STFT). AR1 and Var methods have been extensively used in early warning analysis. Scheffer et al. (2009) theoretically explained the practicability of autocorrelation and variance methods for the EWS processing. They argued that an abrupt increase in AR1 and Var indicates that a tipping point will be coming shortly.

Figure 11 describes the AR1 procedure. The model aims to provide the maximum AR1 value at each point by comparing four alternatives. This calculation includes four steps; residual input, initial AR1 calculation, iterative AR1 calculation by expanding the moving window, and selection of the AR1 value at the point. First, the model calculates an initial value of AR1, using the residual within the predefined stationary interval ( $\delta_{t}$ is error term) (Eq. 10). The model records the calculation result with the mark of 1 , which indicates the first attempt.

$$
\varepsilon_{t-i}=\alpha \times \varepsilon_{t-i-1}+\delta_{t-i} \quad(i: 0 \sim \text { Interval }) \quad \text { Eq. } 10
$$

Second, the model repeats the AR1 calculation until securing four alternatives. The process enlarges the interval, tests the stationarity, and calculates and records the AR1 value if the expanded residual input is stationary. After securing four alternatives, the model selects the highest AR1 value as the value at this moment. 


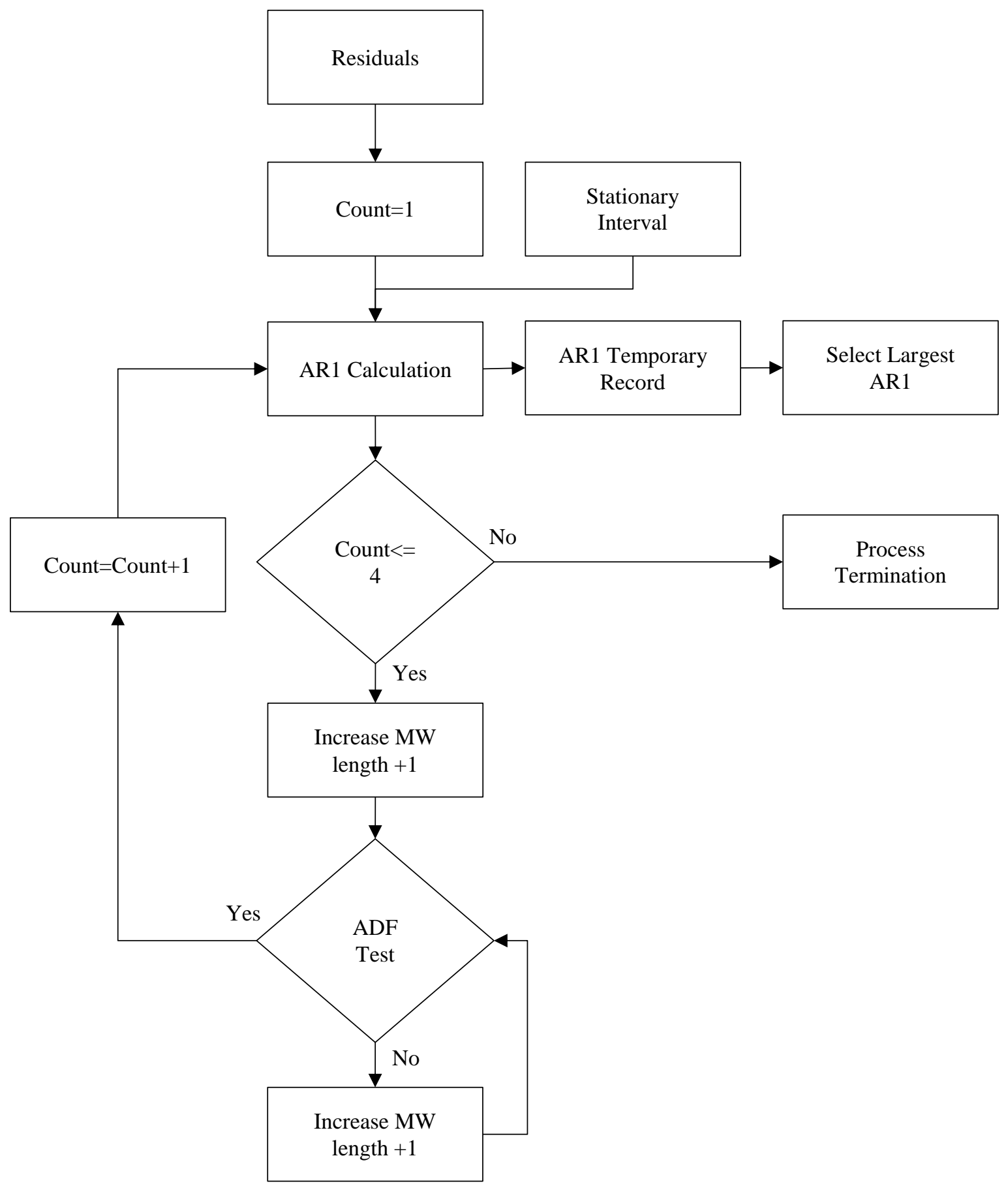

Figure 11 AR1 


\section{Variance (Var), and Short Time Fourier Transformation (STFT)}

Unlike AR1, theory of Var does not dictate the window length. Within a stationary interval, there may be short-term transitions the AR1 cannot capture. To detect such transitions, this study sets the window length of Var to be smaller than the window length defined by the stationarity process. Then, it determines the value of Var through the optimization process identical to that in the AR1. This selection process is useful to provide reliable EWSs, because these different windows can closely react to the dynamicity of the data.

Figure 12 describes the Var process in detail. This model calculates, in real time, the Var value using the stationary interval at the moment, the residual $\left(\varepsilon_{t-i}\right)$ within the interval, and the moving window option. The moving window option includes four alternatives; the last three data points; the last one-fourth, last one-third, and last one-half of the stationary length. At the first trial $($ Count=1), the model uses the last three data points in the interval, calculates the Var (Eq. 11), and records the result in the calculation database. This calculation iterates until applying the last moving window option. Then, the model selects the largest Var as the EWS value at that moment.

$$
\sigma^{2}{ }_{t}=\frac{1}{\text { Moving Window Length }-1} \times \sum_{i=0}^{\text {Moving Window Length }} \varepsilon_{t-i} \quad \text { Eq. } 11
$$

In addition to the autocorrelation and variance, this study uses the Short Time Fourier Transformation (STFT) (Eq. 12). Here, $x(t)$ is an input stream, and $w(t-\tau)$ is a function to determine a window size, which captures an input structure with the range of $\tau$. The notion of $X(\tau, \omega)$ indicates the power of amplitude at the frequency of $\omega$ and at the center of $\tau$. 


$$
X(\tau, \omega)=\int_{t=-\infty}^{t=\infty} x(t) w(t-\tau) e^{-j w t} d t
$$

At a time close to a tipping point, the amplitude of a low frequency tends to be high (Kleinen, Held, and Petschel-Held 2003, Dakos et al. 2012). For applying this theory, this study converts the data input to the domains of time and frequency by applying the Fourier transformation within a moving window of each stationary interval. The calculation flow is the same as the process of Var. 


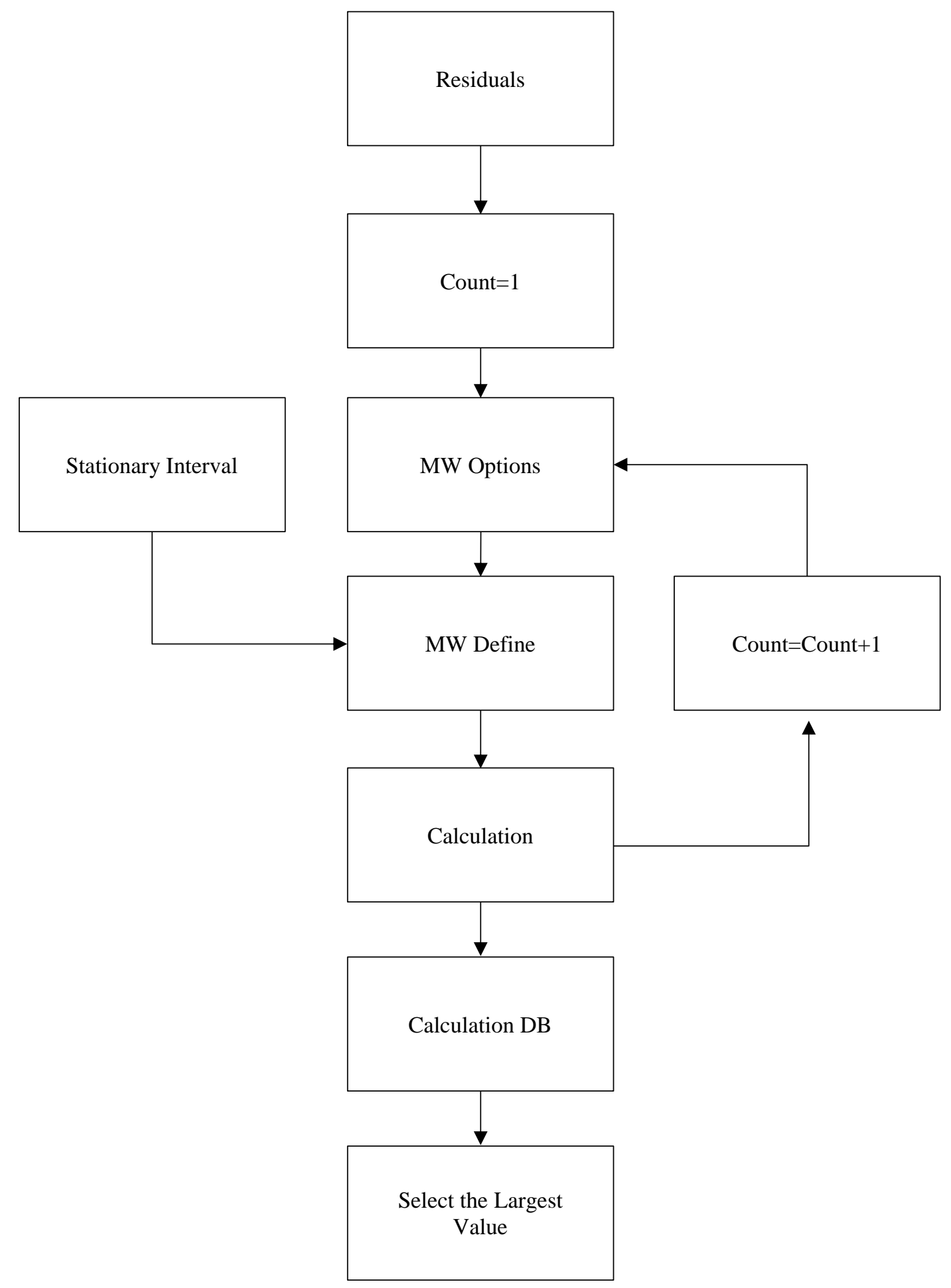

Figure 12 Var and STFT 


\subsubsection{Transition Identification}

It is imperative to identify the really critical tipping points to examine the accuracy and practicability of a newly developed model. This implementation has three processes; defining upper and lower thresholds, identifying potential tipping points; and comparing locations (see Figure 13). First, the model calculates the mean $(\mu)$ and standard-deviation $(\sigma)$, using the input data's growth rate, and defines the upper $(\mu+1.65 \times \sigma)$ and lower $(\mu-1.65 \times \sigma)$ thresholds. Second, the model identifies the potential tipping points that are out of the bounds. Lastly, the model defines the real tipping point by comparing potential tipping points. If two points are located within twice the moving window length, which is used for the residual calculation, the model adopts only the first point (black arrow) and drops the second one (light gray arrow). Through the filtering, real tipping points are determined. 


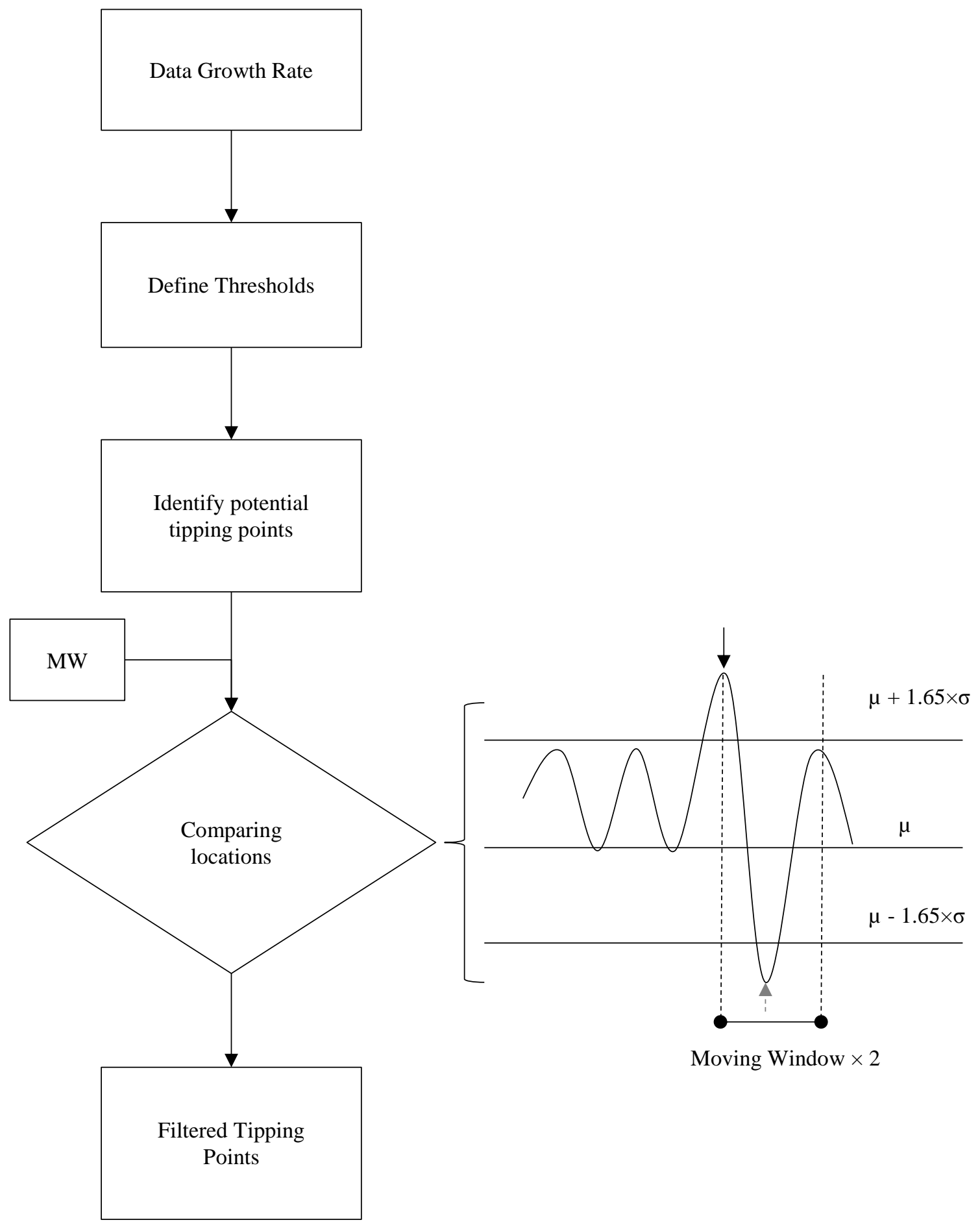

Figure 13 Transition Identification 


\subsubsection{Filtered EWS Results}

Lastly, the model identifies positive EWS, which presumably alarms at a time proximate to a real critical moment (see Figure 14). This identification uses several filtering criteria: (1) an increase in the EWS amplitude between the previous and present moment, (2) the Kendall coefficient within three data intervals, and (3) the Kendall coefficient within six data intervals (see figure 7). First, the model chooses EWS points if the current amplitude of EWS is higher than that of the previous. This selection rationale is that an amplitude of EWS increases as much as the proximity to the critical event (Lenton 2011, Dakos et al. 2008). Then, using initially filtered results, the model iterates two loops to define the thresholds for the second and third filters. These loops are created between the least and most value of each component. At each trial, the model identifies positive EWSs whose all two filter values are higher the thresholds. It then calculates the positive likelihood ratio by comparing the tipping locations and the calculated positive EWS locations (Eq. 13).

$$
L R+=\frac{\operatorname{Pr}(T+\mid E+)}{\operatorname{Pr}(T+\mid E-)}
$$

Here, $\mathrm{LR}+$ is the positive likelihood ratio, $\mathrm{T}+$ is the positive signals generated by the model, and $\mathrm{E}+$ is the critical event. The notation of $\operatorname{Pr}(T+\mid E+)$ is the probability of accurate prediction by the model such that positive signals $(\mathrm{T}+)$ are accurately generated prior to critical events $(\mathrm{E}+)$. This study assumes that a positive signal predicts a critical moment if the positive signal is generated within three data points to the critical moment. Otherwise, the notation of $\operatorname{Pr}(T+\mid E+)$ implies the probability of inaccuracy such that positive signals $(\mathrm{P}+)$ are generated away from the critical moments $(\mathrm{E}-)$. The ratio above 
1 confirms the model's reliability. This iteration process proceeds for all AR1, Var, and STFT results. After the iterations, the model selects a filter combination, which has the highest positive likelihood ratio and then uses the combination to filter the positive signals for the future prediction. 


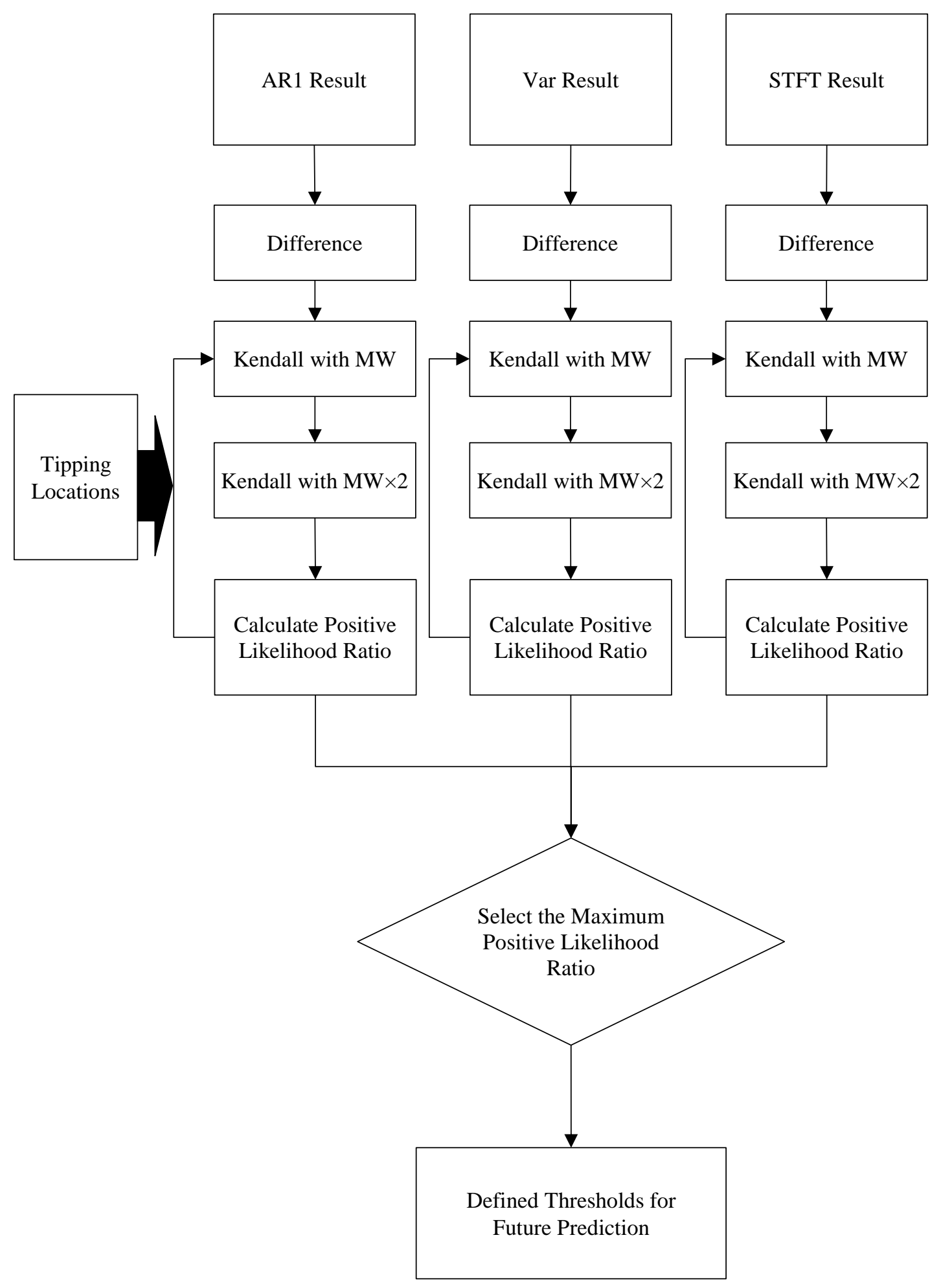

Figure 14 Positive EWS 


\subsection{Method Application Practices}

The universal applicability of this method is examined by analyzing six sets of data: Financial (Dow Jones Industrial Average (DJIA)), Social (Houston's unemployment rate (UnEmp), Biological (Influenza pandemic), Geological (Drilling), and Political (Trump Poll in the 2016 presidential election). The residual moving window length is set to three data points. A short length moving window can predict both short- and long-term transitions, while a long length window only captures longterm transitions. In addition, it is subjective to define a standard to identify short- and long-term critical moments. Such background provides more favorability to adopt a short-term moving window length, and therefore this study uses the shortest moving window length of 3 , which is the minimum size for residual calculation. To check the validity of warnings, this study assumes that if the model generates at least one warning anytime within three moments prior to a critical event, the generated warnings are accurate. The summary of the EWS accuracy test is presented in Table 4. 
Table 4 EWS Application Summary

\begin{tabular}{|c|c|c|c|c|c|c|c|c|c|c|}
\hline Category & $\begin{array}{c}\text { Tot } \\
\text { Data } \\
\end{array}$ & $\begin{array}{l}\text { Tot } \\
\text { Sta } \\
\end{array}$ & $\begin{array}{c}\text { Tot } \\
\text { Trans } \\
\end{array}$ & $\begin{array}{c}\text { Suc } \\
\mathrm{Rt}\end{array}$ & $\begin{array}{c}\text { Tot } \\
\text { Neg } \\
\end{array}$ & $\begin{array}{c}\text { Fal } \\
\text { NegRt }\end{array}$ & $\begin{array}{l}\text { Tot } \\
\text { Pos } \\
\end{array}$ & $\begin{array}{c}\text { Fal } \\
\text { PosRt }\end{array}$ & LR+ & LR- \\
\hline \multicolumn{11}{|l|}{ DJIA } \\
\hline AR1 & 482 & 470 & 24 & 0.67 & 340 & 0.02 & 130 & 0.80 & 3.21 & 0.31 \\
\hline Var & 482 & 470 & 24 & 0.63 & 382 & 0.02 & 88 & 0.69 & 5.34 & 0.29 \\
\hline STFT & 482 & 470 & 24 & 0.75 & 329 & 0.02 & 141 & 0.81 & 3.14 & 0.25 \\
\hline \multicolumn{11}{|c|}{ Unemployment Rate in Houston } \\
\hline AR1 & 303 & 291 & 5 & 0.80 & 199 & 0.01 & 92 & 0.90 & 3.05 & 0.14 \\
\hline Var & 303 & 291 & 5 & 0.80 & 240 & 0.00 & 51 & 0.75 & 6.77 & 0.08 \\
\hline STFT & 303 & 291 & 5 & 0.80 & 215 & 0.00 & 76 & 0.93 & 3.35 & 0.22 \\
\hline \multicolumn{11}{|l|}{ Influenza } \\
\hline AR1 & 655 & 643 & 15 & 0.53 & 429 & 0.02 & 214 & 0.89 & 2.46 & 0.34 \\
\hline Var & 655 & 643 & 15 & 0.87 & 499 & 0.00 & 144 & 0.83 & 4.79 & 0.09 \\
\hline STFT & 655 & 643 & 15 & 0.73 & 414 & 0.01 & 229 & 0.88 & 2.64 & 0.19 \\
\hline \multicolumn{11}{|l|}{ Drill \#324 } \\
\hline AR1 & 305 & 293 & 9 & 0.56 & 260 & 0.02 & 33 & 0.58 & 11.26 & 0.24 \\
\hline Var & 305 & 293 & 9 & 0.56 & 264 & 0.02 & 29 & 0.79 & 7.38 & 0.44 \\
\hline STFT & 305 & 293 & 9 & 0.56 & 254 & 0.02 & 39 & 0.79 & 6.04 & 0.37 \\
\hline \multicolumn{11}{|c|}{ Trump Poll } \\
\hline AR 1 & 171 & 159 & 9 & 0.56 & 110 & 0.04 & 49 & 0.78 & 2.78 & 0.36 \\
\hline Var & 171 & 159 & 9 & 0.44 & 131 & 0.04 & 28 & 0.82 & 3.24 & 0.59 \\
\hline STFT & 171 & 159 & 9 & 0.67 & 107 & 0.03 & 52 & 0.83 & 2.56 & 0.35 \\
\hline
\end{tabular}

* TotData: number of total data; TotSta: number of moments securing stationarity; TotTrans: number of total transitions; SucRt: success rate; TotNeg: number of moments without warning; FalNegRt: false negative rate; TotPos: number of moments with warning; FalPosRt: false positive rate; LR+: positive likelihood rate; LR-: negative likelihood rate 
First, this study tests the financial applicability by using the Dow Jones Index Average (DJIA), as an example. Predicting critical moments of financial variables is challenging because the trend dynamically flows without any signals for incoming changes. In the case of the financial crisis in 2008 , all economic indices prior to the crisis, including the stock market, real estate market, and GDP growth rate, positively moved. Due to the favorable environment, financial professionals had not predicted incoming catastrophic risks. Conventional methods also did not capture any signals that would potentially shake fundamental economics. Such failures resulted in multi-billiondollar losses in the global economy. This study challenges the prediction malfunction. It collects monthly DJIA data from Yahoo Finance. 'Monthly data' is defined as of the closing price of each month's first day. The period of time is 40 years, from 1976 to 2016, and the data interval is monthly. As discussed above, the dynamics, both index and growth rate, are clearly observable. Prior to the 2008 financial crisis, the growth rate was recorded at around 0 percent. Then, the growth rate once reached -10 percent at the catastrophic moment and afterward, dramatically recovered in the following month to 0 percent. 7 months later, the growth rate peaked at approximately +10 percent, and the positivity was kept for a while. To predict an incoming critical moment in advance, this study applies three EWS methods and concludes the Var method is the most accurate. It presents the success rate of 0.63 , the positive likelihood ratio (LR+) of 5.34, and the negative likelihood ratio (LR-) of 0.29. It also captures the 2008 financial crisis moment by generating warnings prior to that crisis (see Figure 15 and Figure 16). 
Second, this study confirms that the model is applicable to social variables. This study uses Houston's unemployment rate as an example of social variables. Like the stock index, the unemployment rate trend sometimes faces a dynamic change due to a sudden change in the economy but also faces seasonality variations. The seasonal variation can be easily identified from experience, such that unemployment rate rises in winter. The model is designed to identify unpredictably critical moments in advance. For such purpose, the seasonality is removed by smoothing the data with taking 12 months moving average. Houston's unemployment data is collected from the Bureau of Labor Statistics, and the data is smoothened as shown in Figure 17. The data period is 26 years, from 1990 to 2016, and the data interval is monthly. At the time of the financial crisis, an incomparably sharp increase occurred in the unemployment rate. If the government acknowledges the crisis in advance, it can more effectively address the issue. This model confirms the Var as the most accurate method. The Var presents a success rate of 0.80 , LR+ of 6.77 and LR- of 0.08. More specifically, this model predicted an exponential hike in the unemployment rate during the financial crisis (see Figure 17 and Figure 18).

Third, the applicability of biological data was tested and influenza pandemic data was used as an example. Like other variables, it is difficult to predict impending pandemic moments. If the trend is accurately predicted, the society can save tremendous capital by preparing in advance. The data was collected from the National Institute of Health (NIH). The data period is 12 years, from 2004 to 2016, and the data interval is weekly. Among the three methods, the Var is identified as the most reliable method with a success rate of 0.87, LR+ of 4.79 and LR- of 0.09 (see Figure 19 and Figure 20). 
Fourth, in the case of the geological data, gamma-ray amplitude was used. It is generally used to identify the composition of ground in the ocean. The drill tip has a gamma-ray sensor. When a drill tip crushes the ground, the sensor gauges the gammaray's amplitude. The pattern of the gamma-ray dynamically changes when the tip faces a different soil layer. Predicting the start of a new layer is crucial in drilling. Equipping with an inappropriate tip will cause a malfunction of the entire drilling machine. The International Ocean Discovery Program (IODP) executes multiple drill experiments in a variety of spots in the ocean. This study uses the drill data of \#324-1346A point. The hole is located around the Shatsky Rise in the northwest Pacific Ocean. The data is composed of gamma-ray amplitudes, which are detected by the sensor on a drill tip. The data range is from 118 to 164 meters in depth under the sea ground and the data interval is 0.15 meter. This study identified AR1 as the most accurate method. The AR1 presents the success rate of $0.56, \mathrm{LR}+$ of 11.26 , and LR- of 0.24 . Figure 21 illustrates the pattern of gamma-rays regarding the soil composition. Also, Figure 22, which is a zoom-in diagram of Figure 21, presents the AR1 capturing a critical event at 131.0 meters, which is the interval in which the soil property changes from silty limestone to typical limestone.

Last, this study examined the political data. Predicting election results is not easy if a candidate's popularity is uncertain. It is also common to watch the unexpected emergence of a new politician. This study uses the poll records of Trump from the 2016 national republican primary published by Huffington Post as an example. He surprisingly emerged and extensively competed with Clinton for the 2016 US 
Presidential Election. Such characteristics made Trump's trend prediction challenging. The input data range is from 2015 to 2016 and each poll result is recorded with the poll's start date (see Figure 23). If there are more than two poll results at the same start date, these results are averaged. This EWS model determines the STFT method as the most accurate one. The STFT presents the success rate of 67 percent, LR+ of 2.56, and LR- of 0.35 . 


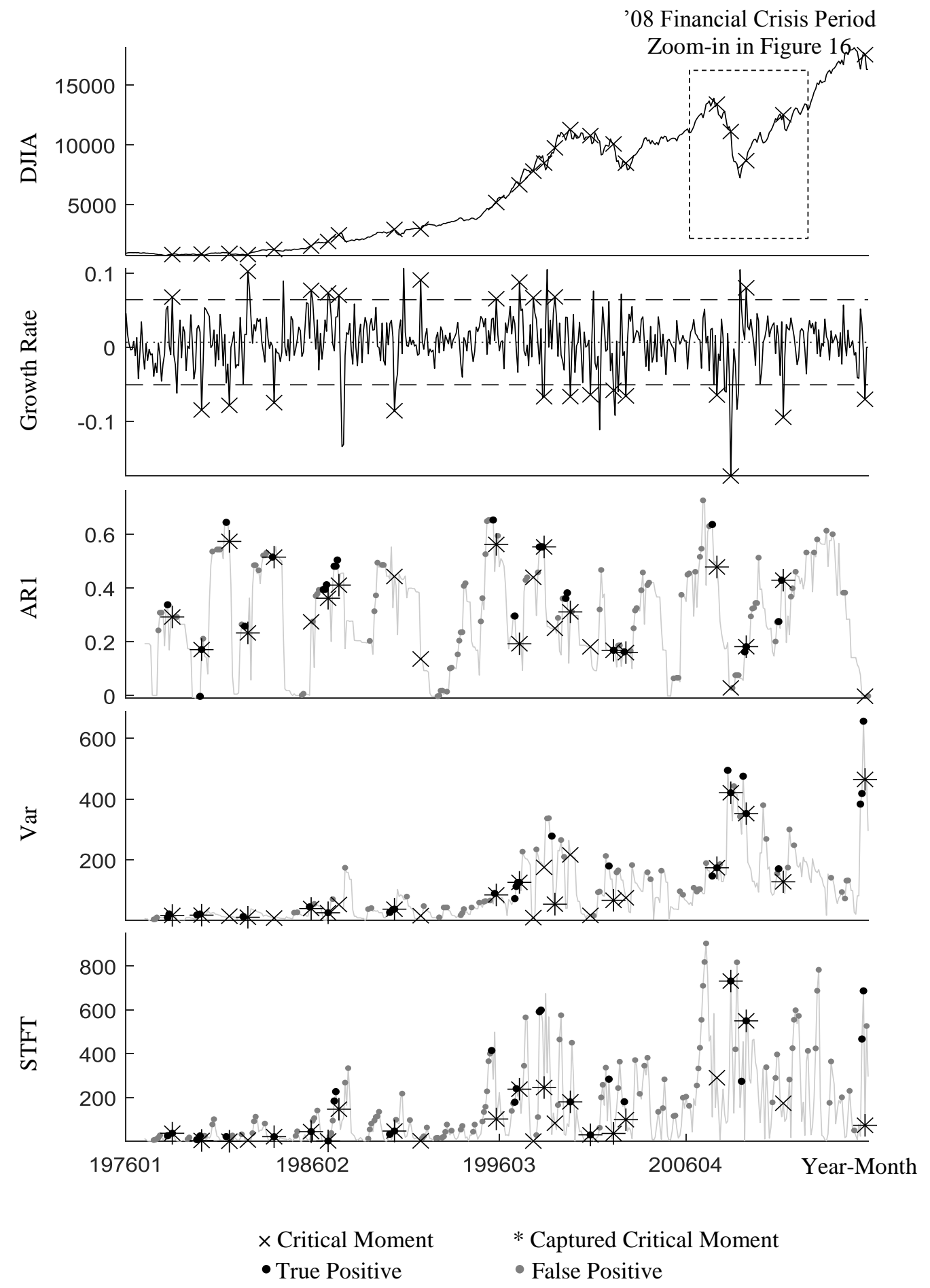

Figure 15 DJIA Index from 1976/01 to 2016/02 

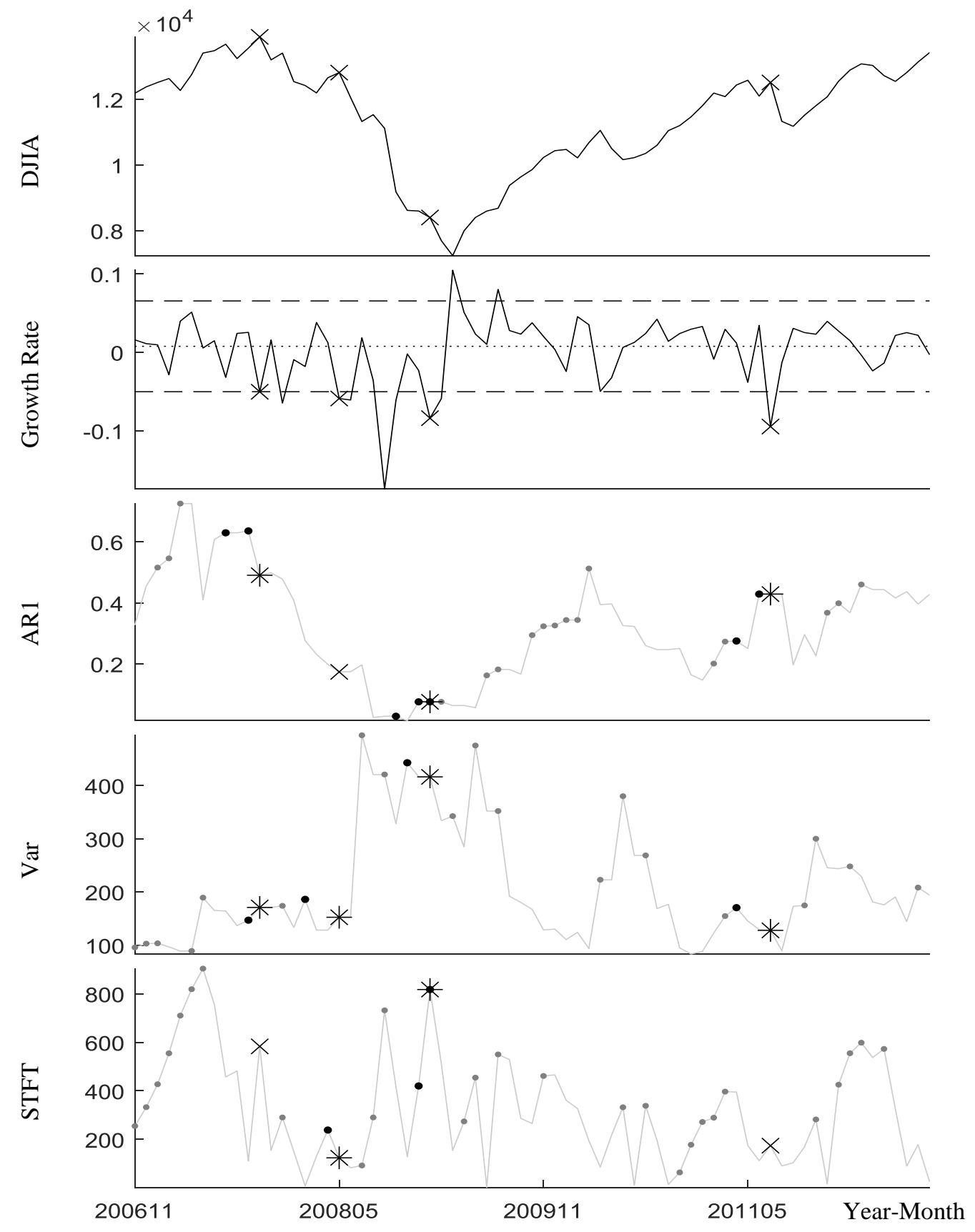

* Captured Critical Moment $\quad \times$ Critical Moment

- True Positive $\quad$ False Positive

Figure 16 DJIA Zoom-In from 2006/11 to 2012/09 

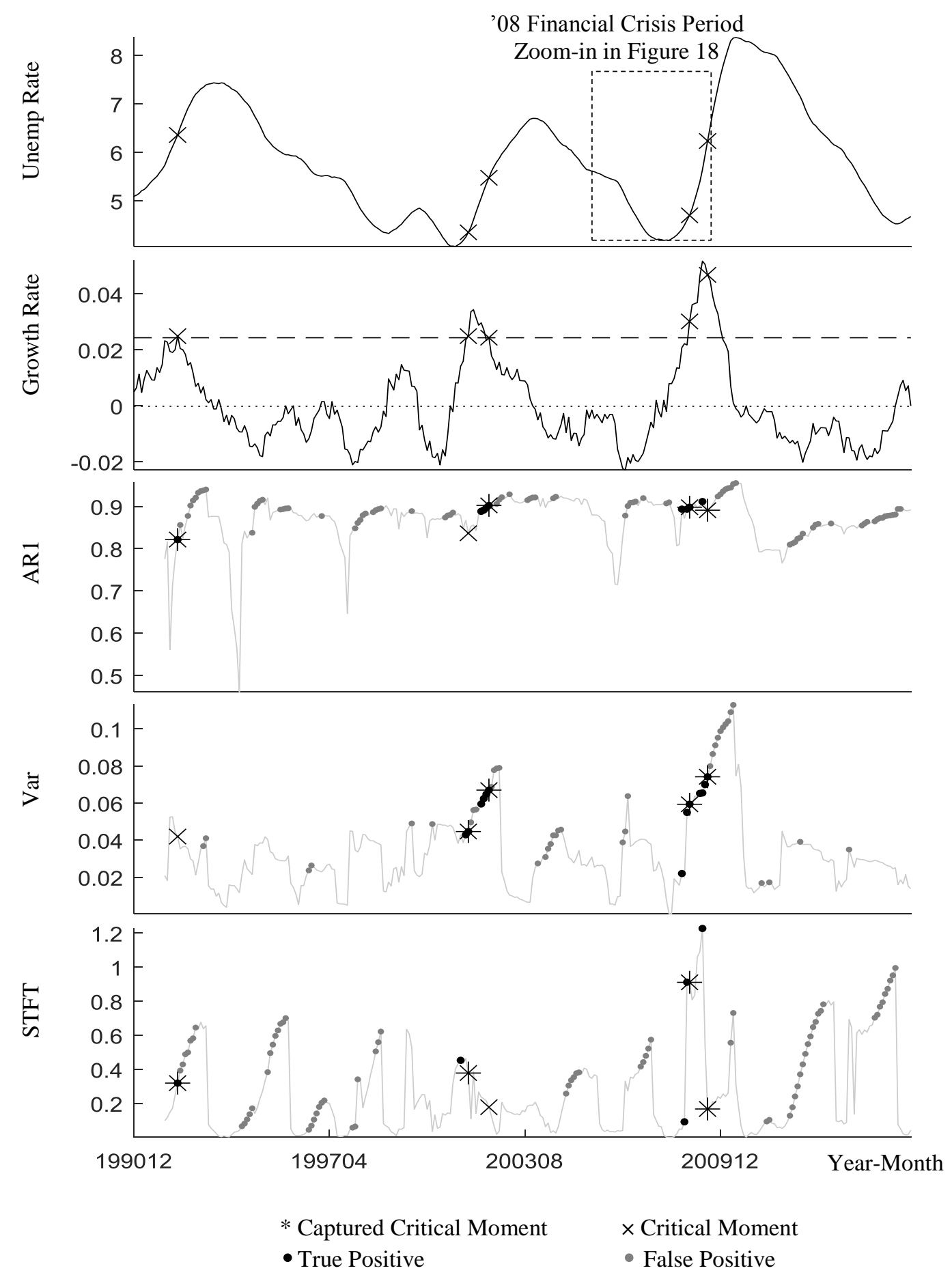

Figure 17 Unemployment Rate from 1990/12 to 2016/12 

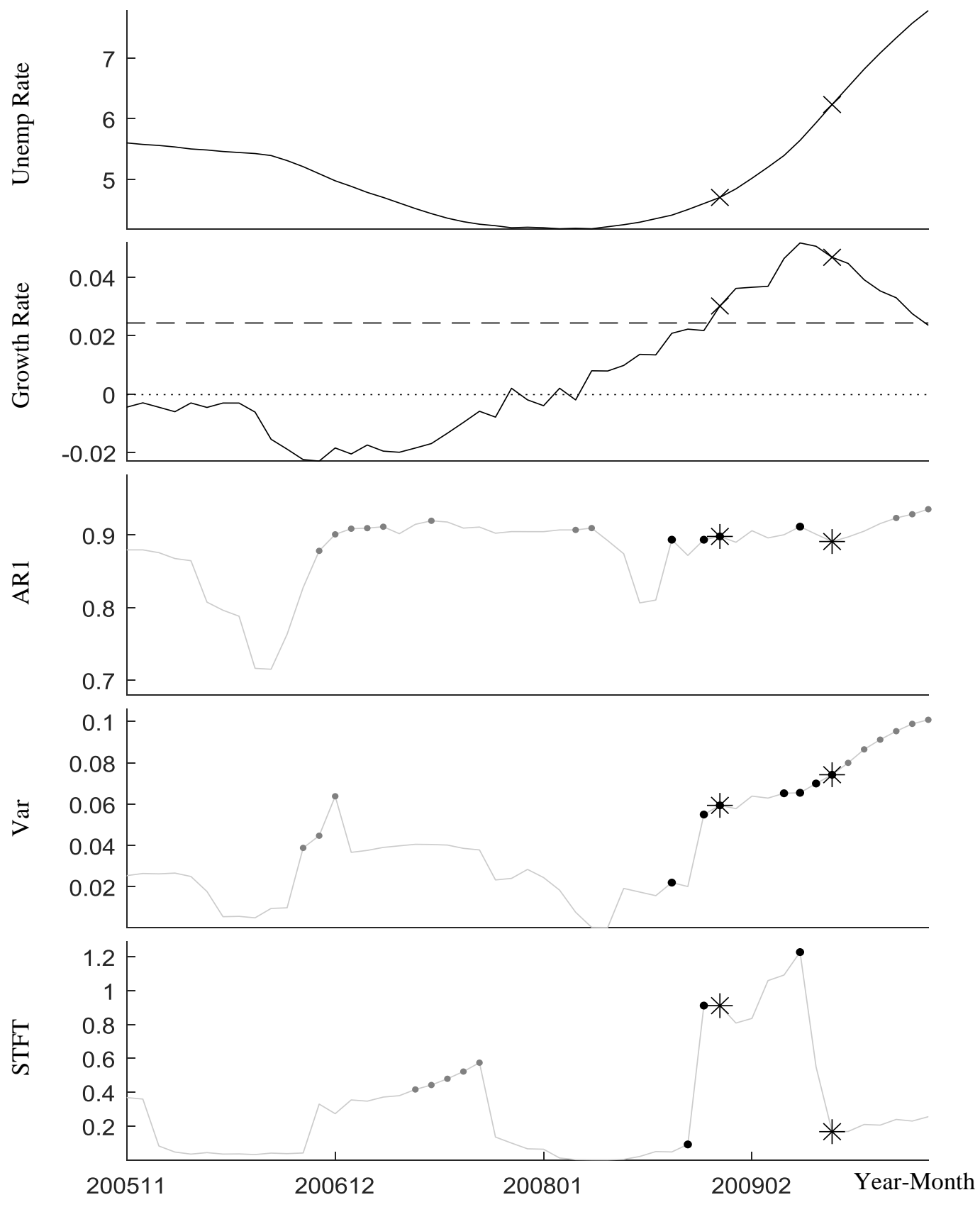

* Captured Critical Moment $\quad \times$ Critical Moment

- True Positive - False Positive

Figure 18 Unemployment Rate from 2005/11 to 2010/01 


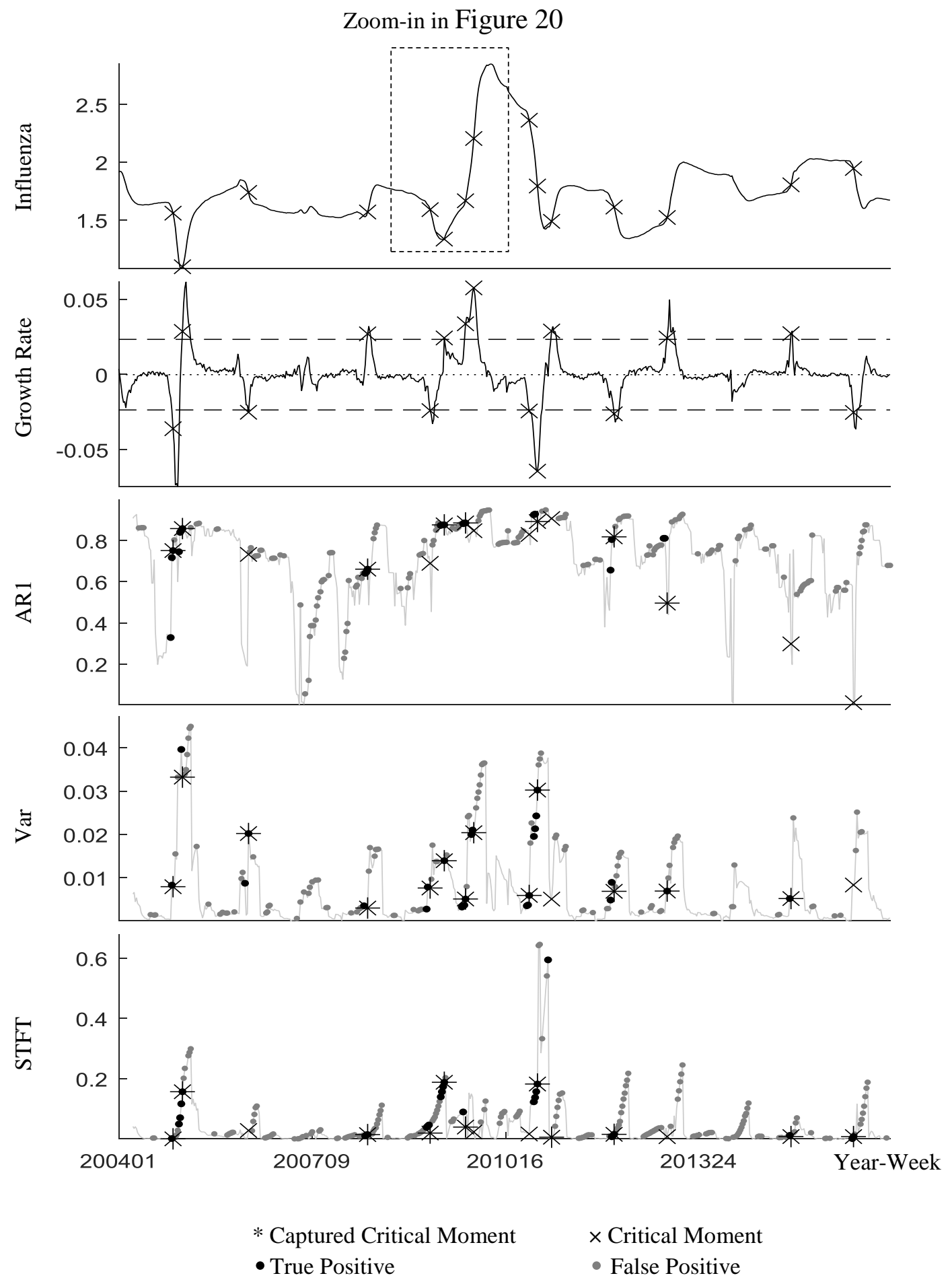

Figure 19 Influenza from 2004/01W to 2016/29W 

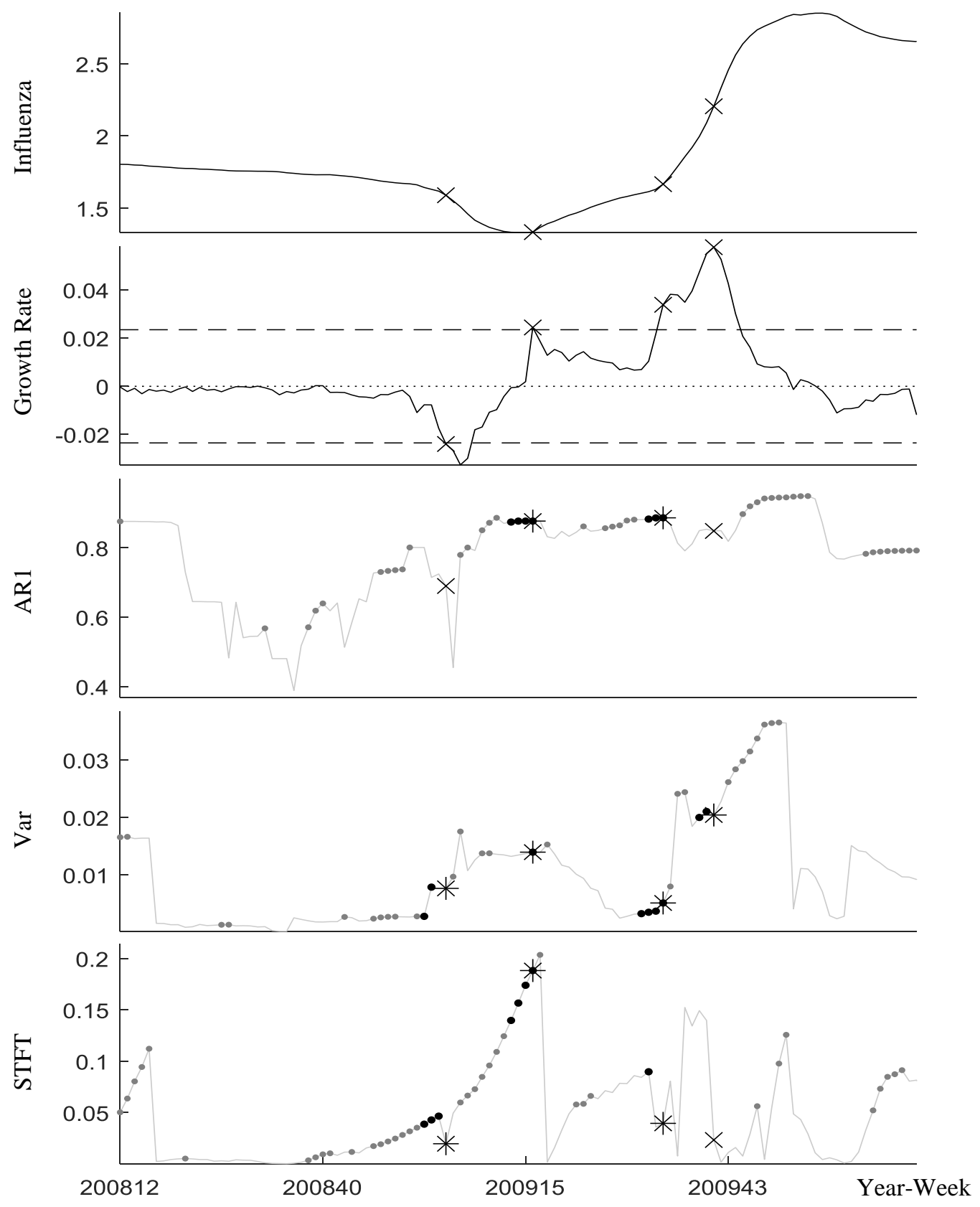

* Captured Critical Moment $\quad \times$ Critical Moment

- True Positive - False Positive

Figure 20 Influenza from 2008/12W to 2010/17W 


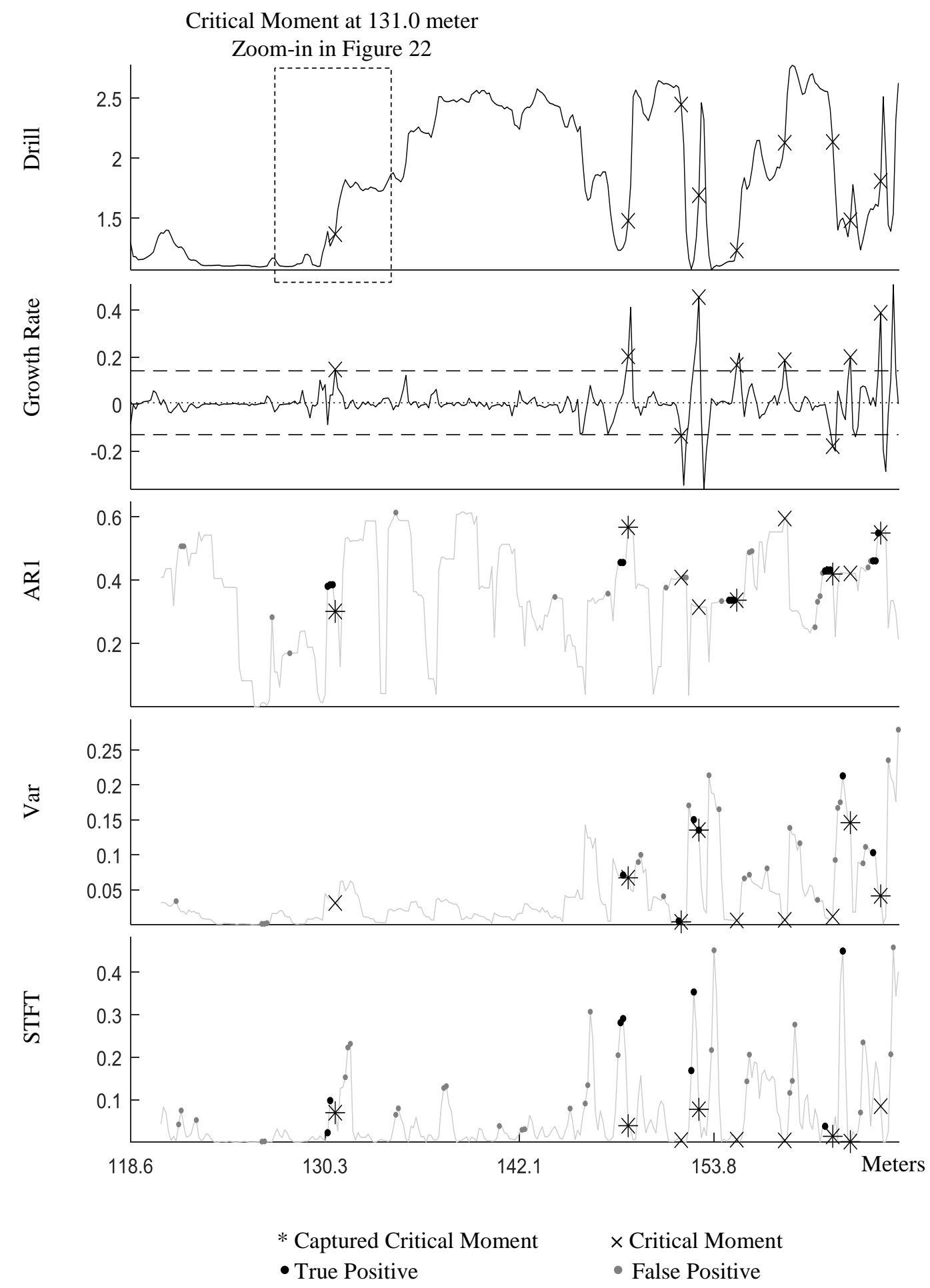

Figure 21 Drill from 118.6 meter to 164.9 meter 

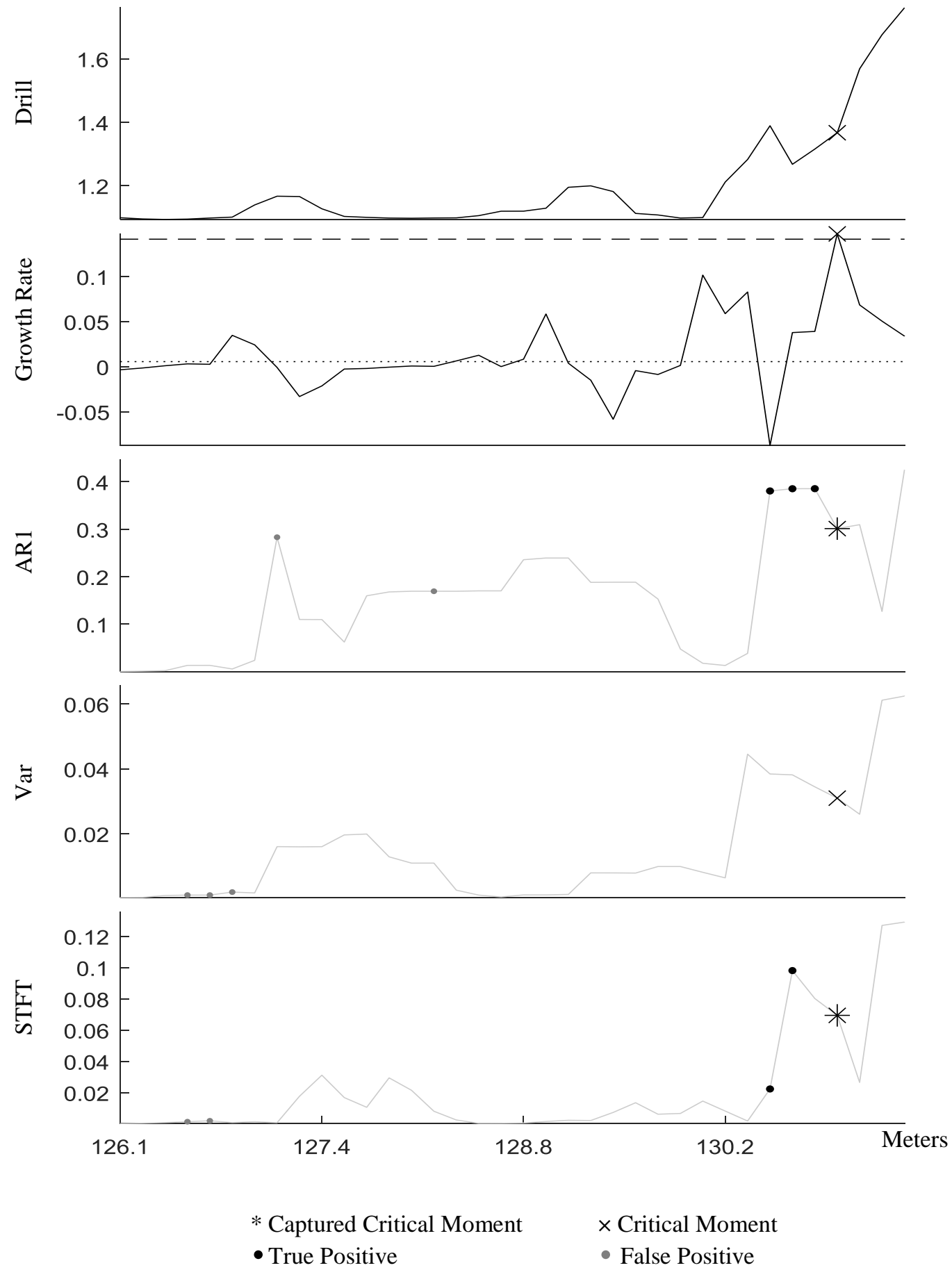

Figure 22 Drill from 126.1 meter to 131.4 meter 

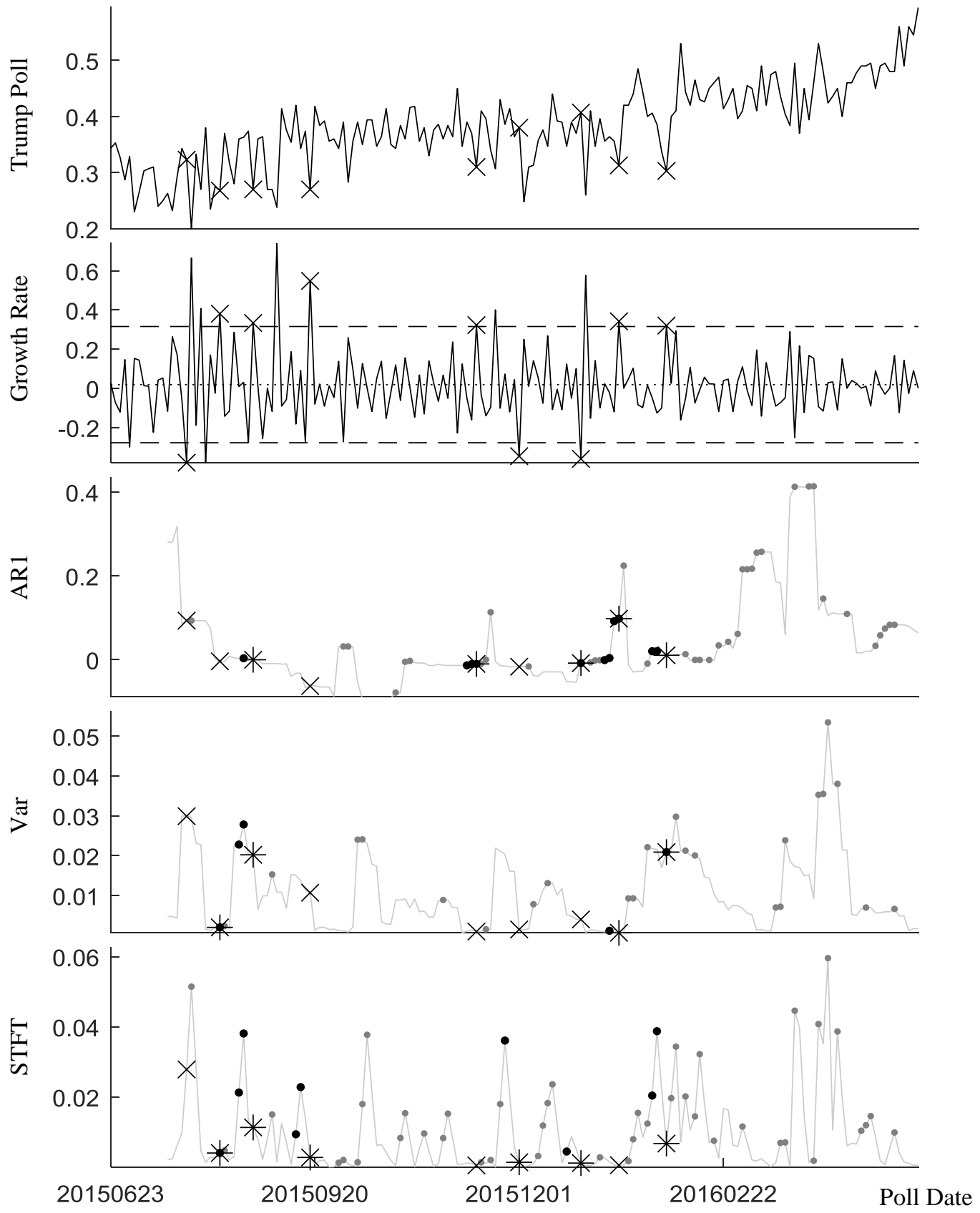

* Captured Critical Moment $\times$ Critical Moment

- True Positive

- False Positive

Figure 23 Trump Poll in GOP Campaign 


\subsection{Summary}

This dissertation confirms that the EWS theory is universally applicable. In every case, this study method shows more than 50 percent in capturing success rate and less than 5 percent in false negative rate. This accuracy justifies that this model is applicable to other variables, which need a short-term forecast. However, the reliability of this model is based on an arbitrary parameter, which is moving window length used for the exponential smoothing.

This study subjectively determines the moving window length, which is the minimum required distance for the exponential smoothening. This approach is controversial, due to the dynamic nature of each data pattern. The Fourier transform method is an alternative, because it identifies the period associated with each input's frequency. The calculated period of a low frequency can be used as a moving window to predict long-term transitions. Similarly, the period of a high frequency can be used to predict short-term transitions. In practice, however, this Fourier method cannot be applicable. Unpredictable data patterns, in real data, prevent the conversion method from providing a visible periodicity, leading to difficulty to define an optimal moving window length.

In addition, previous studies do not provide adequate background to address the issue about the window length. For example, many studies used a Gaussian smoothing method, which uses prior and future data to determine the momentary average, and assign an arbitrary window to this smoothing method. In this case, the arbitrary choice does not differentiate the smoothing result, because that method uses both past and 
future data. In contrast, the exponential model presented by this dissertation only relies on the past data and the length substantially impacts the result. Therefore, from the best knowledge at the current moment, empirically selecting a window length is still necessary. To avoid the ambiguity of the window selection, this study applies the moving window of three to all the data. If the length is systemically determined, the EWS performance can increase. Discussing this issue in the future is desirable. 


\section{RISK ASSESSMENT AND MORNITORING METHODOLOGY}

\subsection{Framework for Risk Assessment and Monitoring}

The TIF bond indenture document consists of common and specialized parts. The common part includes typical features such as general information, reimbursement security, and supplemental information, while the nature of the TIF project and the repayment sources are described in the specialized part. This specialized part describes the underlying TIF characteristics, such as the TIF zone location, with visualization of the location and the surrounding environment, the project list including the details of the projects that will be delivered using raised funds, and the asset value history or the overview of underlying asset performance, if available.

Each of these components of the bond contract has a distinctive impact on the credit risk. For example, if the expansion of local streets and highways fails to result in an increase in traffic count, this could potentially signal that the property taxes in the TIF zone may not increase to support the debt obligation. This highlights the importance of careful interpretation of the bond indenture and, more specifically, the TIF-specific sections. In addition to these endogenous factors defined within the contract, the credit risk is impacted by exogenous factors such stock market indices, macroeconomic parameters, local economy, and so on. Note that the sensitivity to these endogenous and exogenous factors will depend on adopted risk mitigation strategies. The credit rating agencies review this sensitivity, using both quantitative and qualitative methods, and provide the best estimate of the TIF asset's performance and the underlying credit risk. 
However, as previously mentioned, the credit ratings are often performed only at the time the bond is issued and, therefore, the creditability of this rating becomes questionable as the asset moves towards maturity. For addressing the issue of lack of reliability with outdated credit ratings and changed conditions, this dissertation presents a risk assessment and monitoring framework that:

a) Reconstitutes the asset credit risk profile using publicly available data collected at regular time intervals. Note that these time intervals are at much shorter periods (often monthly) than the yearly financial statements;

b) Uses the history of the credit risk profile to compare and contrast the current risk in relation to the risk reported at the time the asset was initially rated and/or last updated; and

c) Processes newly available data to detect early warning signs that a component or components of the asset's risk profile may be transitioning and, therefore, likely to result in changes to the asset credit risk in the near future.

Figure 24 summarizes the proposed risk assessment and monitoring framework. The first step in the process is to assess bond indenture and capture the key factors that affect the credit risk. As mentioned before, those can be endogenous and exogenous factors. Public data sets are then analyzed to identity time series data that can reflect these factors. Based on the identified publicly available indices, one can reconstitute the risk profile, using and monitoring the changes as updated data become available. 


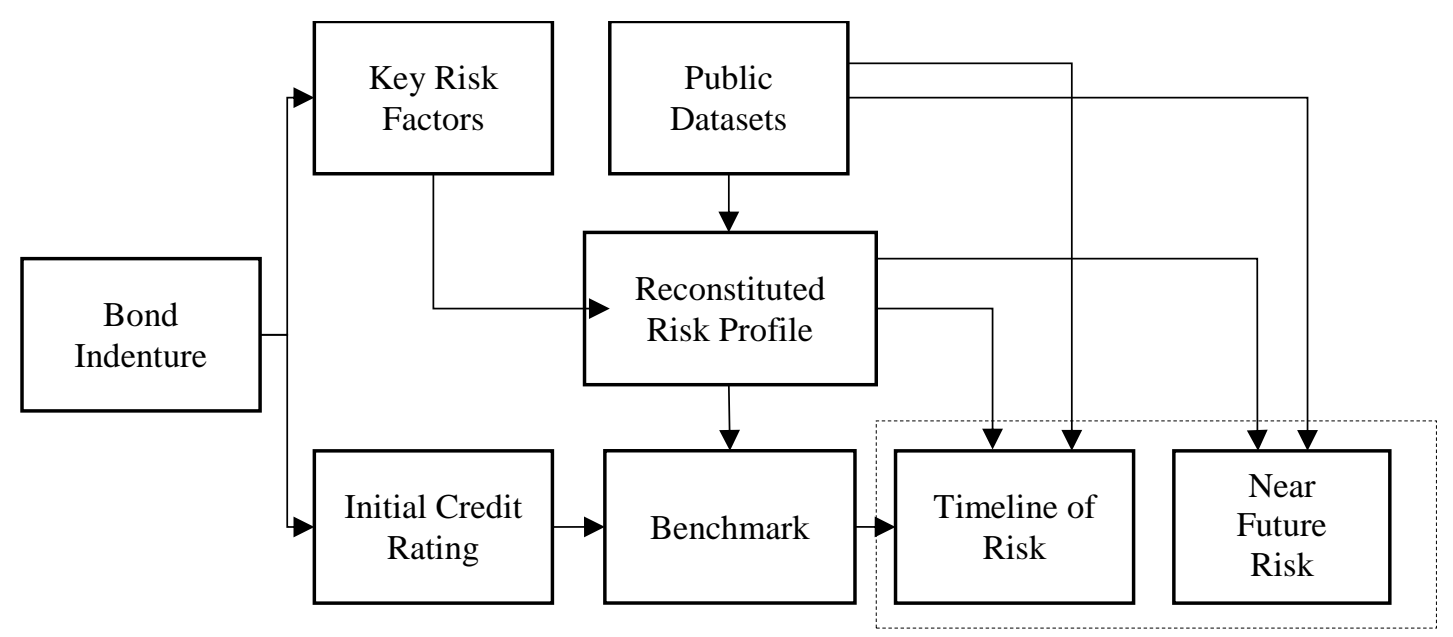

Figure 24 Risk Assessment and Monitoring Framework

To compare the evolving risk against the risk at the time of issuance, the value of indices reflecting endogenous and exogenous factors during the initial credit rating are used as benchmarks. Lastly, the proposed framework leverages early warning signal methodology to forecast the future risk by detecting whether the indices are in a 'stable' or 'unstable' condition.

\subsection{Reconstitution of Credit Risk Profile}

The risk profile of an asset can be developed from the information available in the bond indenture document. In fact, credit rating agencies often use this information to determine influencing factors and to develop the credit risk model. Note that this credit rating model is generally not available to the public. However, the report discussing the key considerations, projections, and the sensitivity of the results to the changes in the assumption, is published and is publicly available as a supplemental document to the 
rating. It is this report, along with the bond indenture, that provides the basis upon which the key endogenous and exogenous factors can be defined, the corresponding publicly available data sources identified, and the asset risk profile (re)constituted.

There are a number of publicly available data sets that are relatively frequently updated. In fact, many government agencies, non-profit, and for-profit organizations regularly publish data that reflects socio-economic conditions in the country. These and similar data sources can be used to define indicators, such as indices, of the state of the asset's exogenous factors and ultimately assess and monitor the credit risk. The proposed framework structures the data and such indices based on three different levels of representation: A) macro level indicators reflecting the overall market sentiment such as Dow Jones Industrial Average (DJIA), Real Estate Investment Trust (REIT) funds, Gross Domestic Product (GDP) data, and so on, B) regional level indicators defining the state of the regional economy and competitiveness, such as employment rate, House Price Index (HPI), foreclosure data, as well as stock performance of the biggest regional employers, and C) micro level indicators specific to the TIF zone, such as Zillow property valuation. The zip-code based monthly property values data available from Zillow provides information similar to the annual appraisal values within the TIF zone. The geographical configuration of zip codes may not fully match the TIF boundaries; however, Zillow indices still provide a basis for analyzing the trends in property valuation. This time series data can supplement the annually published financial statements and can provide the needed frequency, to reaffirm the credit rating and provide a bridge for risk assessment between the reporting periods. While this increased 
frequency in the assessment of risk may not be warranted from the perspective of the volatility in credit rating status, it is essential for detecting early warnings that the monitored exogenous factors are becoming unstable. To provide an analogy, consider a production line in a manufacturing plant where samples of assembled widgets are collected on a daily basis. This is done to detect deviations from the specifications' limits. Typically, the production line process is stable and does not require managerial intervention; however, data is nevertheless collected on a daily basis to detect a pattern that could be indicative that the process will soon become out-of-control. Similarly, monitoring indices that constitute TIF bond risk profiles provide a means to detect early signals of changing conditions and, ultimately, changing credit risks.

Once the key time series data sets are identified, one can use them independently to assess the changes with respect to what was observed at the time of rating or they can be weighted and combined in an aggregate index. Here, the objective is not to re-assign the rating determined by the agencies, rather it is to determine how the credit risk factors have changed. By doing this, one can assess the current risk relative to the risk at the issuance.

\subsection{Timeline of Credit Risk Profile}

Once the risk profile is defined by assigning weights to each of the macro, regional, and micro variables, and aggregating them, the dynamics of the asset risk profile from the period of issuance until the current time can be determined. For example, the aggregation procedure can be based on Moody's TIF rating method (Moody's 2015). Figure 25 (a) and (b) illustrate the index for each variable and the 
aggregated index, respectively. The proposed framework then checks the redemption ability, using the Debt Service Coverage Ratio (DSCR) of the TIF district agency (Moody's 2015). A ratio greater than 1 implies that the agency can fully cover the debt redemption. This index has a decisive impact on the asset quality. For example, in the case when a TIF district issues a significant amount of debt, the TIF profit may not be sufficient to fully repay the debt, although the delivered project has increased the property value. However, as previously mentioned, it is impossible to directly use DSCR because the financial statements are generally issued yearly rather than monthly. To address this issue, the proposed framework adopts the Debt Service Coverage Ratio using a Tax Increment (DSCR-TI), which represents the monthly tax increment amount divided by the monthly debt service repayment. Figure 25 (c) shows a conceptual example of the trend in the annual DSCR and the monthly DSCR-TI. Next, the survival rate of the asset can also be considered (see Figure 25 (d)). The forward survival probability is calculated by subtracting one from the forward probability of default. The forward probability of default represents the conditional failure rate calculated by the number of default assets divided by the number of currently survived assets (Trück, Laub, and Rachev 2004). For assets whose ratings are close to speculative, the probabilities of survival tend to rise markedly (Trück, Laub, and Rachev 2004).

Finally, all the indices (aggregated macro/regional/micro index, DSCR-TI index, and the asset survivability rate index) can be combined to determine the reconstituted timeline of the credit risk profile. Note that it is beyond the scope of this dissertation to 
specify the weights associated with combining these indices. The risk assessment and monitoring team can use previous data and best judgment to determine such weights. 


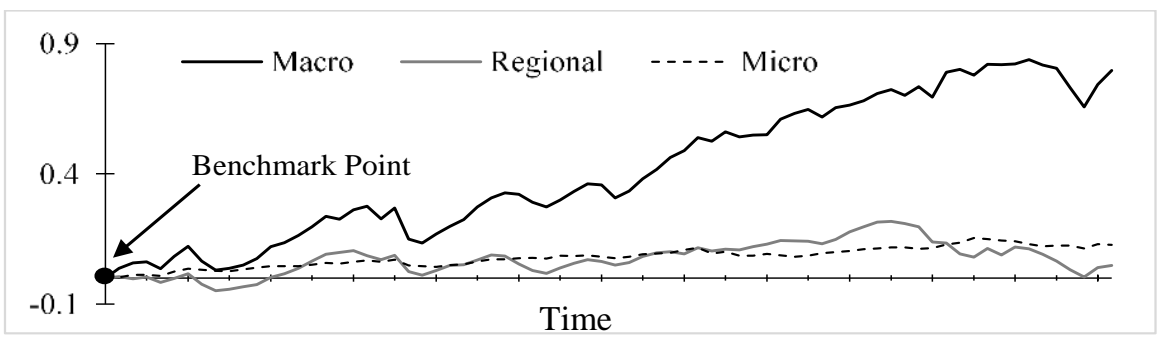

(a) Macro, Regional, and Micro Variable Indices

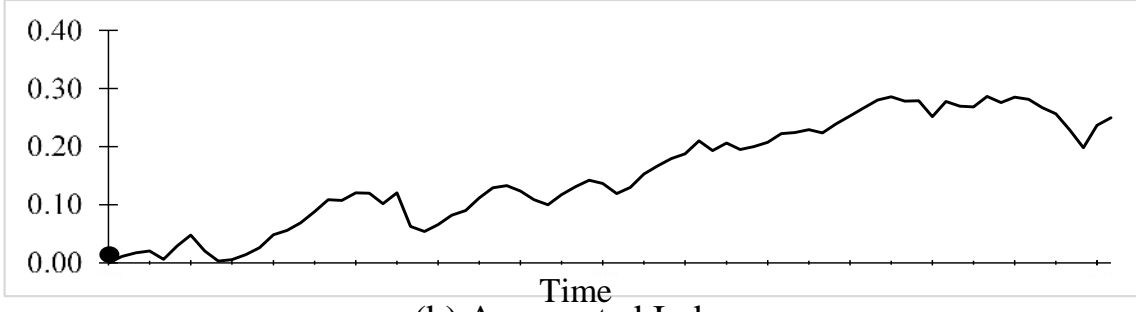

(b) Aggregated Index

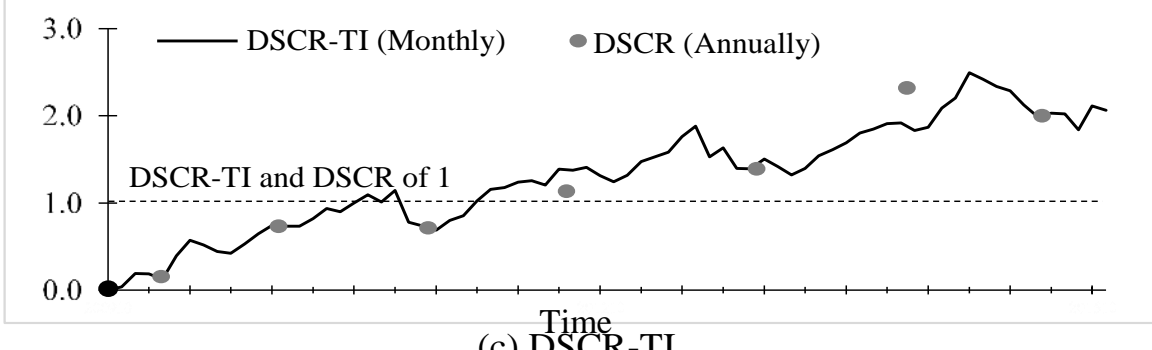

(c) DSCR-TI

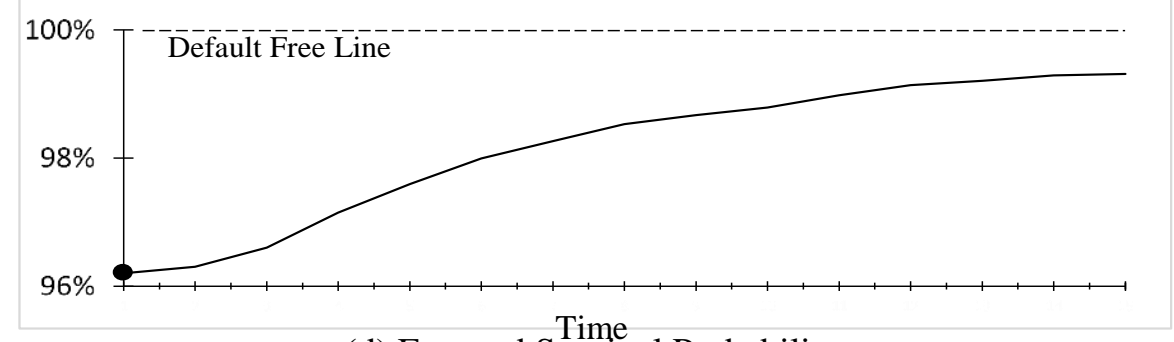

(d) Forward Survival Probability

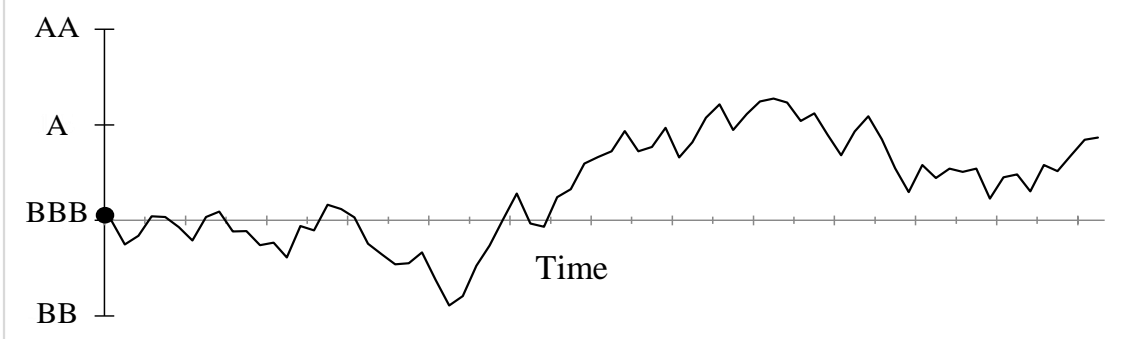

(e) Reconstituted Credit Rating at the Present Time

Figure 25 Conceptual Reconstitution of Credit Risk Profile 
For identifying the future risk of the asset at the present time, this study uses the method of Early Warning Signals, which is enabled to detect critical slowing down phenomenon and is universally applicable, regardless of the systems under investigation (Scheffer et al. 2009). The autoregressive order one (AR1) analysis and variance (Var) have been broadly used for determining EWS. This detection method can be applied to both climate change and financial markets (Scheffer et al. 2009).

More specifically, in the proposed method, each of the macro, regional, and micro variables are analyzed with the EWS model to detect signs of potential changes in trends of the variables (see Figure 26). The calculation process consists of three parts; residuals calculation, stationary intervals definition, and EWS amplitude calculation by the autoregressive order one (AR1), variance (Var), and spectral density, derived by Short Time Fourier Transformation (STFT). These are common procedures for EWS analysis; but to better capture early warning, this study optimizes the length of the moving window at each point. 
The EWS Method

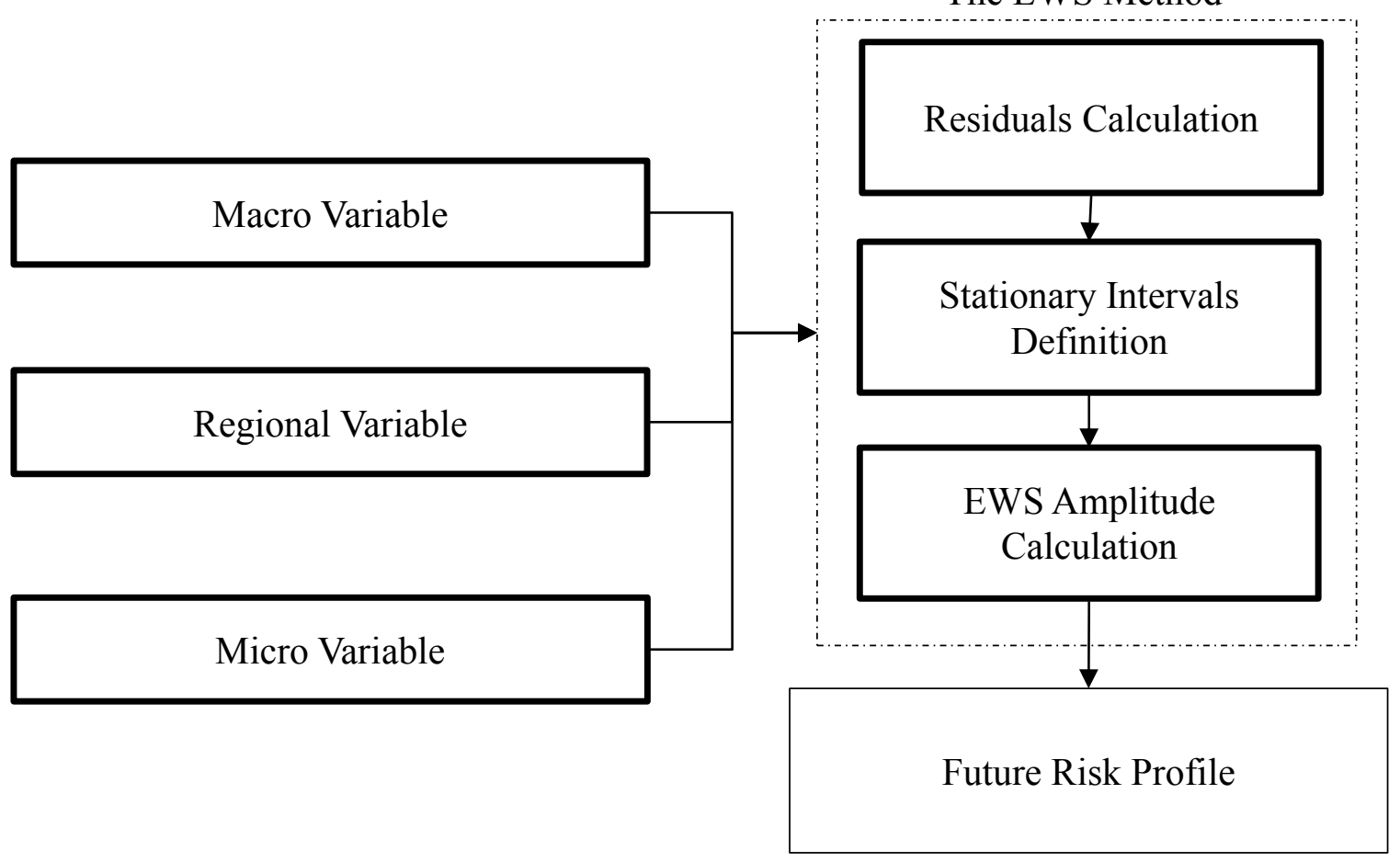

Figure 26 Future Risk Profile Process

Figure 27 illustrates the EWS analysis procedure using the macro variable data in Figure 25 (a). One risk is observed in the index and that moment is highlighted with a vertical dotted line (Figure 27 (a)). The hypothesis of the EWS method is that an EWS should be detected before the turning point. In this example, Var and STFT correctly generate an alert, but AR1 detects one true and one false alarm (Figure 27 (b),(c),(d)). These errors cannot be avoided because the actual data stream is dynamic and unpredictable and the detection characteristics of the EWS method are different. To incorporate all the detection capacities of these three methods, this method compiles the amplitude of each curve and determines the future risk profile of the input (Figure 27 
(e)). Finally, the asset's future risk profile is determined by aggregating the future risk profile of each variable according to the same procedure as the current risk profile's aggregation process. 


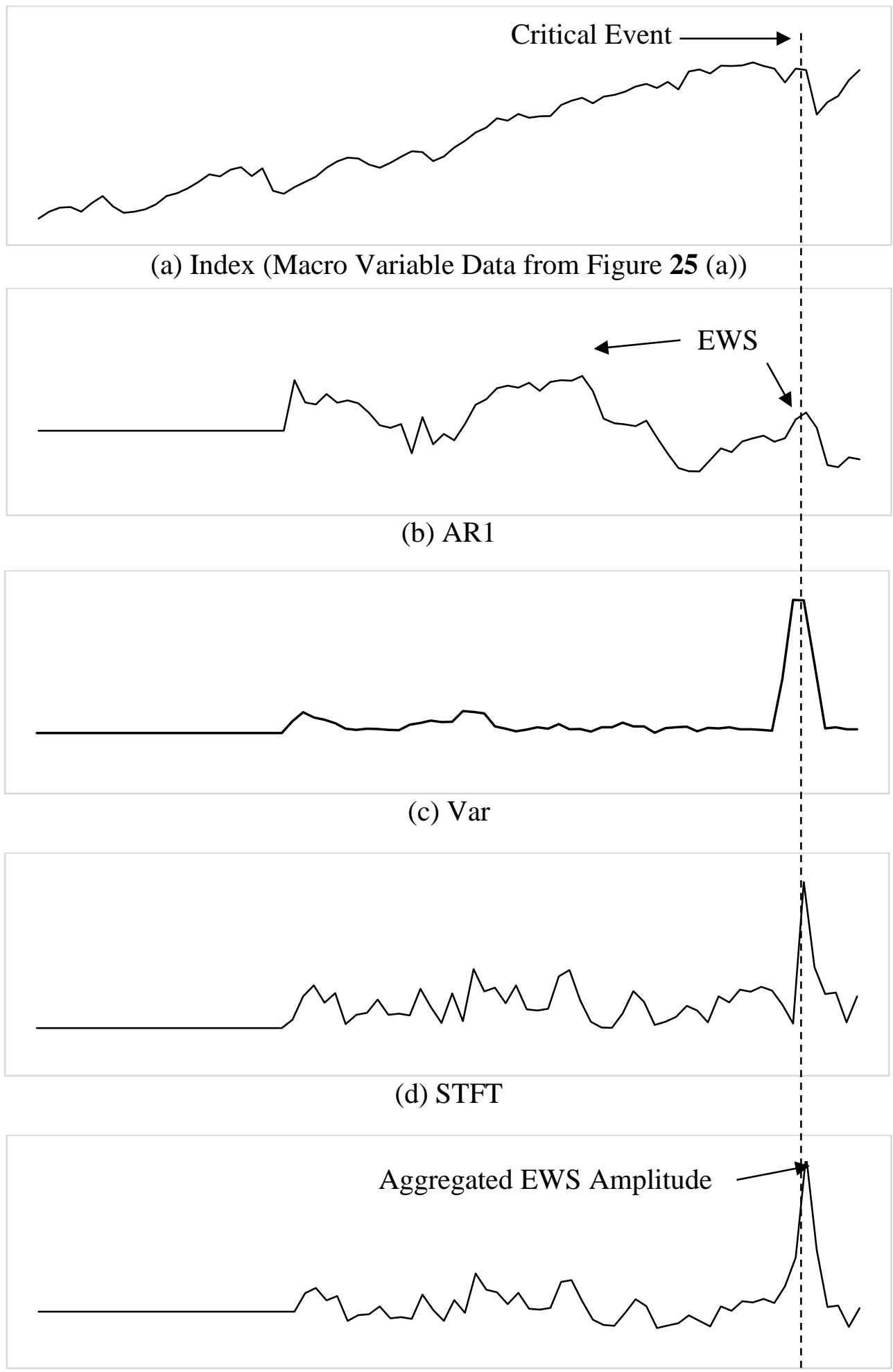

(e) Future Risk Profile

Figure 27 Future Credit Risk Profile Conceptual Diagrams 


\subsection{Summary}

The developed profile does not fully reflect the risk picture. In fact, market indicators are known to be imperfect in synthesizing information (Collin-Dufresn, Goldstein, and Martin 2001). To determine changes in market indicators, one needs to analyze the data for its dynamic potential and stability. For identifying this stability and the near-future risk trends, this framework uses the Early Warning Signals (EWS) method. The EWS method is an approach to detect critical slowing down phenomenon and is universally applicable, regardless of the systems under investigation (Scheffer et al. 2009). The autoregressive order one (AR1) analysis and variance (Var) have been broadly used for determining EWS. This detection method can be applied to a broad application area, including both climate change and financial markets (Scheffer et al. 2009).

More specifically, in the proposed method, each of the macro, regional, and micro variables are independently analyzed with the EWS model to detect signs of potential changes in the trends. The calculation process consists of three parts; residuals calculation, stationary intervals definition, and EWS amplitude calculation by the autoregressive order one (AR1), variance (Var), and spectral density derived by Short Time Fourier Transformation (STFT). These are common procedures for the EWS analysis; but to better capture an early warning, this study optimizes the length of the moving window at each point. 


\section{CASE STUDY}

\subsection{Houston's Tax Increment Reinvestment Zone (TIRZ)}

In 1991, the city of Houston approved the first Tax-increment Reinvestment Zone (TRIZ) ordinance. Similar to TIF, the TIRZ allows the districts to fund new projects using tax increments. Currently, the city operates 20 active TIRZs. Among those 20 active TIRZs, 8 TIRZs have issued debt.

This dissertation presents the TIRZ case study for the TIF bond (CUSIP: \#916856GD3) issued by the "Uptown Development Authority." This TIRZ was established in 1999 by the ordinance \#1999-709. The TIF reinvestment zone was defined to include locations west of Houston's central business district along IH-610. The reinvestment zone district primarily consisted of residential and commercial areas, including 'The Galleria' shopping mall. Except for the area around the shopping mall, the district's land use patterns of rundown buildings and the poor condition of lifeline infrastructure were determined to be a threat to the public health. As such impairment is the subject of the TIRZ requirements (for more details in the Section 311.005 of the Texas Tax Code), the city was able to pass the ordinance establishing the TIRZ.

This TIF revenue bond was issued by the "Uptown Development Authority" TIRZ in October 2009, for the amount of $\$ 42.2$ million, with a maximum maturity of 20 years. The bond did not include an insurance feature and was initially rated as BBB + . Note that this rating was downgraded in 2011 to BBB. Since then, no new rating updates have been issued (S\&P Global Ratings 2017). 
As this TIF bond is a revenue-based bond without insurance, the repayment source solely depends on property tax revenue increments. Therefore, the main risk factor in credit analysis is the future real estate values. The bond contract also stipulated that continuing disclosure of the information would be provided through the Municipal Securities Rule Making Board (MSRB), and included the 2008 financial statements of the issuer, visualization of the configuration of TIRZ \# 16, and historical trends in tax increment revenue. However, the document did not include the list of specific projects, suggesting that the raised funds would be used as needed.

Real estate market valuation is highly influenced by four key factors: local demographics, benchmark interest rates, the general state of the economy, and governmental policies and subsidies (Nguyen 2017). These factors can be assessed at three different levels of spatial representation such as: A) the national level reflected in macroeconomic and market factors, the regional level reflected by the state of the regional economy, and the micro level, reflected in local demographics and the state of the real estate market. This study assumes that the Dow Jones Industrial Average (DJIA) and Real Estate Index (REIT) will reflect the state of the macro factors as they reflect economic activities. Employment, the House Price Index (HPI), the Regional foreclosure rate, and the oil price index (XOI) are considered regional variables. Regional employment rates indirectly indicate economic stability. Regional HPI represents the real estate market outlook. In addition, the number of news articles about foreclosures in the Houston area can be considered a real estate market outlook because their increase could imply a negative signal in the mortgage market and could negatively impact the 
real estate market. Finally, XOI is included because Houston is a petroleum industry hub. The property value trends in postal codes \#77007 and \#77056 are considered micro factors, as they reflect local information. These zip codes were selected because they overlap with properties in the TIRZ zone.

Data about DJIA, REIT, and XOI was pulled from the Yahoo Finance portal, the HPI index data came from the Federal Housing Finance Agency, the employment rate was accessed from the Bureau of Labor Statistics, the number of foreclosures mentioned in the Houston area was obtained from Google Trends, and the postal code based property values were downloaded from Zillow. All data sets were updated monthly. The final data set covered the period between January 2008 and November 2015 (95 months).

\subsection{Data Analysis}

The previously described macro, regional, and micro indices of the TRIZ are shown in Figure 28 (a). Note that the full history for individual input variables is shown in Figure 29. The $\mathrm{Y}$ axis represents the monthly cumulative growth rate in relation to the benchmark value at the time of the issuance. The interval of analysis and data ranges from January 2008 to September 2015. 


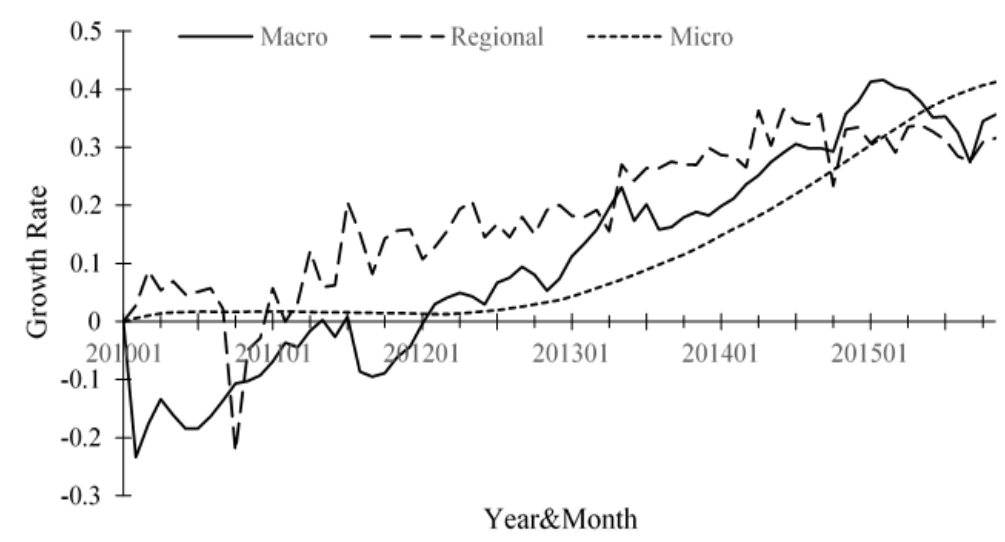

(a) Macro, Regional, and Micro Indices

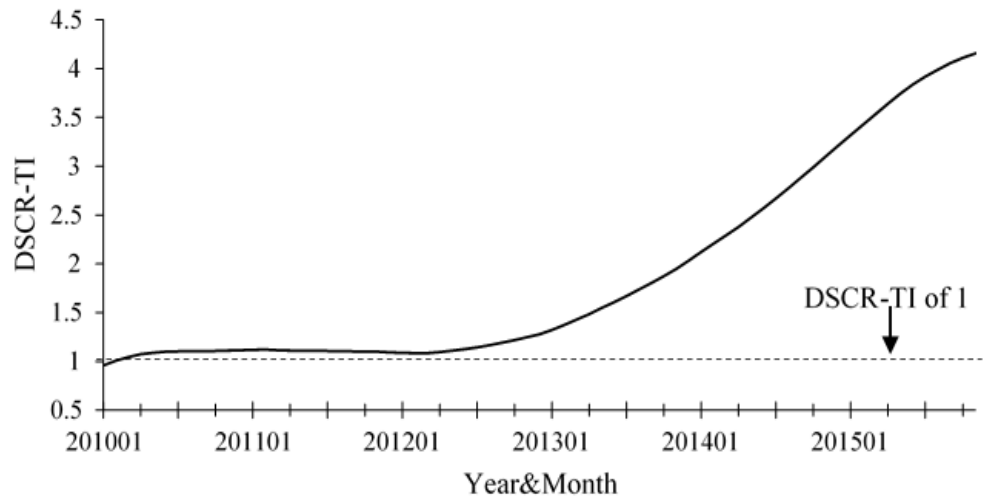

(b) DSCR-TI

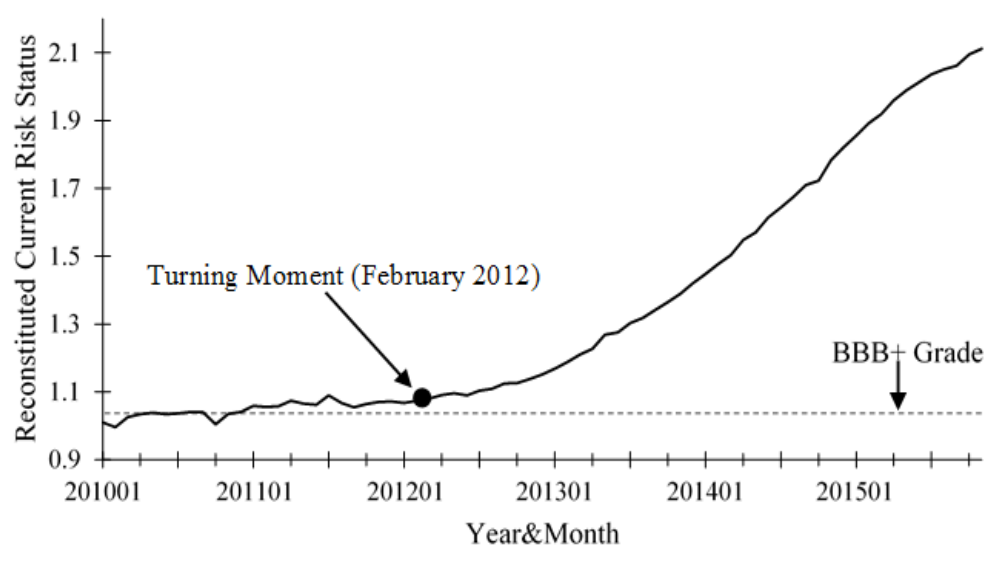

(c) Reconstituted Current Risk Profile

Figure 28 Current Risk Profile 


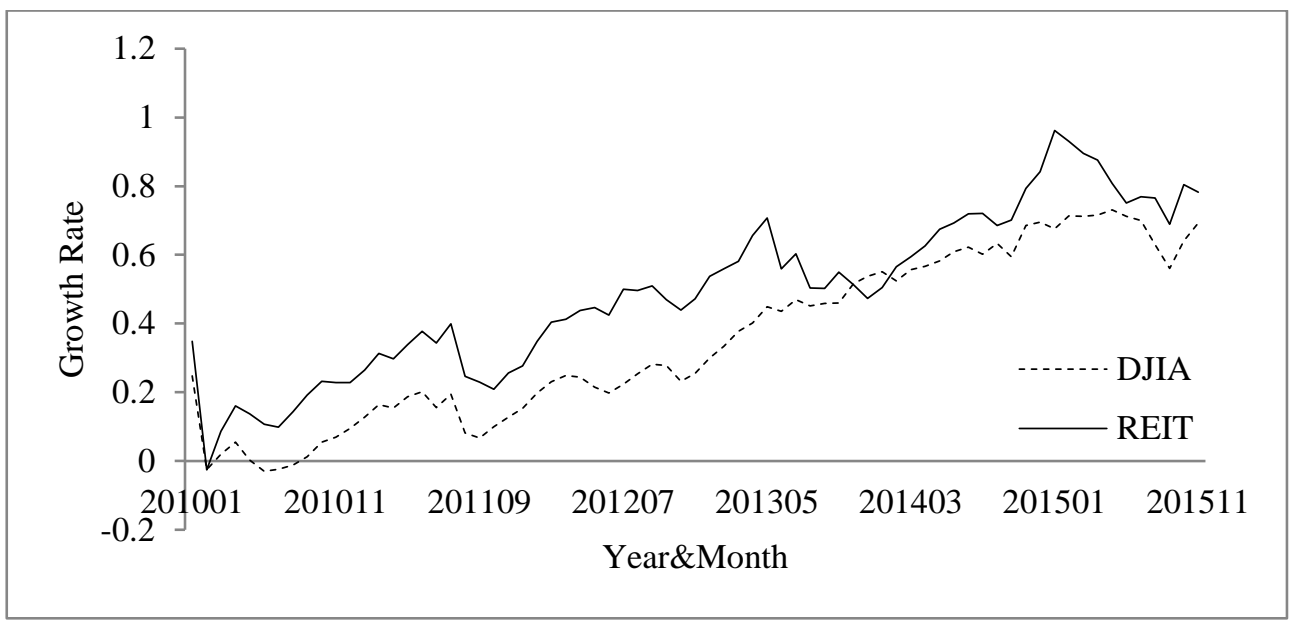

(a) Macro Variable Growth Rate

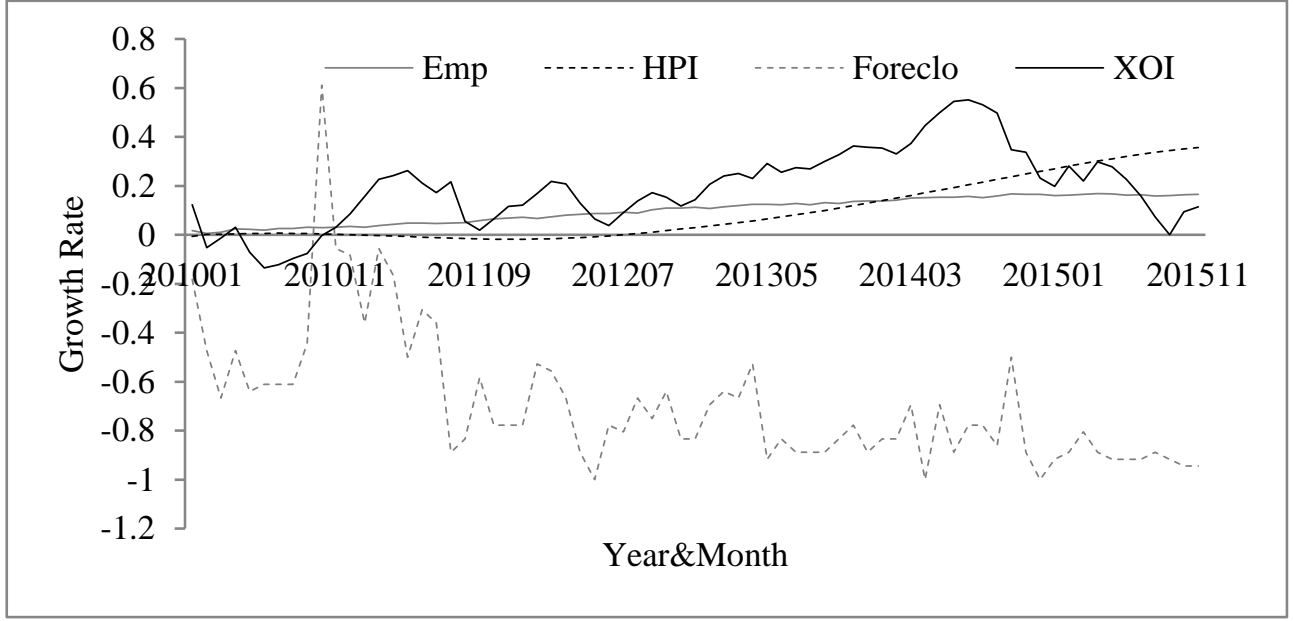

(B) Regional Variable Growth Rate

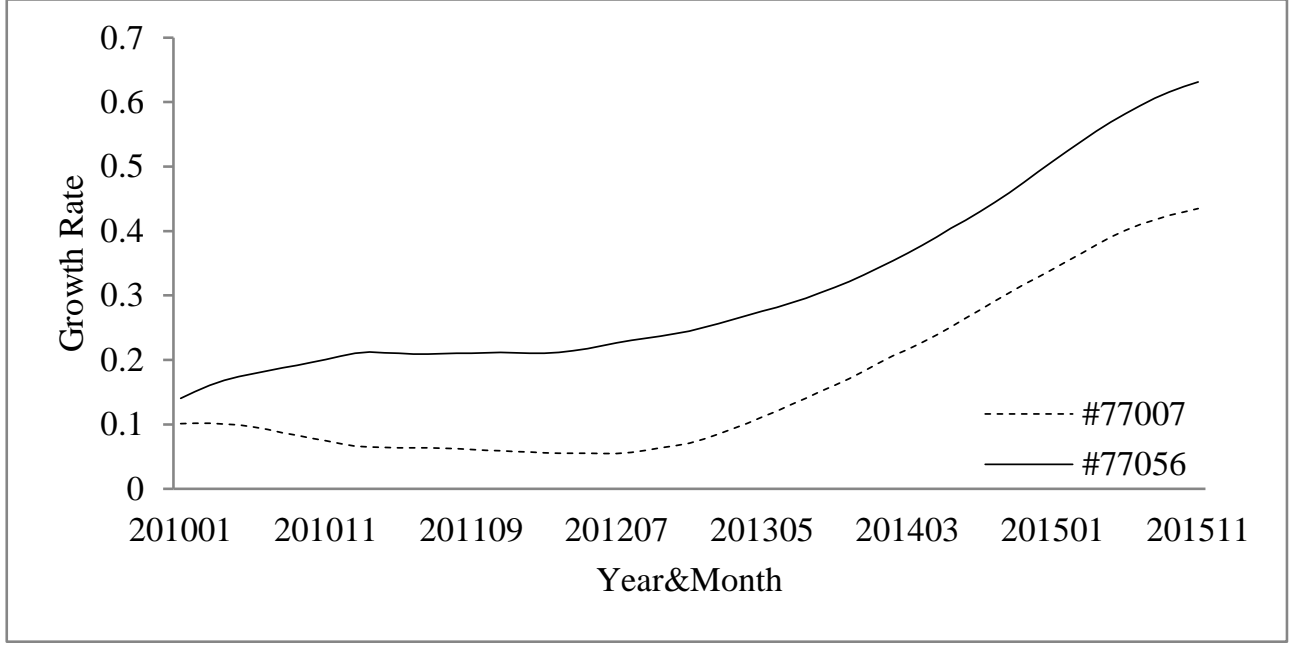

(c) Micro Variable Growth Rate

Figure 29 Current Status 
The time series data shows an upward (risk reducing) trend, but the variability is clearly visible. More specifically, the variance over time in macro and regional indices is greater than that of the micro-level index. This relative lack of elasticity among them is due to the nature of the market and relative stability in real estate prices over short-term periods. Short of real estate bubbles, it takes longer periods of decline at the macro and regional levels to be reflected at the micro index (real estate prices).

Figure 28 (b) illustrates DSCR-TI behavior. It is very similar to the behavior of the micro variables in Figure 29 (c) as they both reflect changes in local real estate prices. More specifically, this case study conservatively assumes that the TIRZ agency can use 10 percent of the tax increment above the baseline. The loan amount repaid monthly from the total issued amount is calculated as $\$ 0.288 \mathrm{M}$ by assigning interest rate of 5.5 percent (CUSIP: \# 916856GD3). The results of these two calculations are used to create a monthly DSCR-TI index. If the index value is less than one, it implies that the incremental amount cannot repay the monthly debt. Otherwise, the increment is sufficient for repayment.

Finally, Figure 28 (c) describes the reconstituted timeline of the risk profile that accounts for all indices such as, macro, regional, and micro. One can notice that this index shows a distinct change in the trend from a relatively stable position with minimal growth to a distinct upward trend. This change starts from February 2012. This point is referred as a turning moment or a tipping point. However, this risk reducing trend has not triggered an update in credit rating. In fact, during the initial period of the bond's tenure, the credit rating was downgraded to BBB. This update was justified as the key 
macro, regional, and micro indices stagnated, and in some instances in 2011, even showed a negative outlook. However, as previously mentioned, the conditions started improving in the second half of the year. In general, the reconstructed timeline indicates an increased confidence and diminishing risk in long-term debt. This suggests that the credit rating needed to be upgraded to reflect the changed condition.

However, the current upward trend does not guarantee that the asset will not default. As with the 2008 financial crisis, asset valuation can suddenly decrease. To assess this potentially significant near-future risk, the proposed framework implements the EWS method to Houston TIRZ data. The results are shown in Exhibit 4. The bar graph represents the amplitude which is the strength of the EWS for individual macro, regional, and micro indices, whereas the solid lines represent the monthly marginal growth of each variable. Note that the growth rate is derived by subtracting the current cumulative growth rate from the previous growth rate. With growth rate time series defined, one can formulate the following hypotheses: A) the EWS of the micro-level index generates a warning signal prior to a long-term transition and B) the EWS of the macro and regional indices provides a warning before a short-term transition. In the case that a significant change in trend was actually observed, the EWS bar is shown in black.

For macro level EWS (Figure 30 (a)), both the first and second strongest EWS successfully capture the tipping point moment. At points ' 1, ' '2,' ' 3 ,' ‘4, ' 6 ,' '7,' ' 8 ,' and '9,' the EWS generates an alert before the downward trend begins, and the EWS at ' 5 ' generates an alert before the upward trend begins. The warnings come in a range up to 3 months before transition occurs. In fact, if the EWS is observed, on average, it 
implies a four times increased likelihood of near-future transitioning, with false negative at near zero levels.

The micro level EWS (Figure 30 (c)) show an even greater level of reliability. The EWS at point ' 1 ' captures the critical event where the trend transitions from a stable, near zero, growth, while at point ' 2 ' it captures the change in the acceleration rate. Therefore, if one observes a high amplitude EWS for the micro-level index, it is fair to say that the index will transition in the near future. This is very important as the micro variable is the key factor in determining the shape of the reconstituted risk profile and can have a tremendous impact on the asset's credit risk.

Unlike the previous models, the regional EWS model does not provide an accurate prediction of tipping points (Figure 30 (b)). Although the EWS at the point of ' 1 ' and ' 2 ' captures events, this model misses many critical transitions. To capture these missing transition points, one can lower the threshold EWS amplitude, but it will risk having an increase in the number of false positives. In summary, two out of three EWS models share the same warning signals for a February 2012 tipping point and, as such, have a potential to provide a warning signal prior to critical events.

So, how can one use this information? From the reconstituted profile, one can see that a TIRZ credit risk profile has changed since the time it was initially rated. In particular, one can note a rather large increase in performance of macro, regional, and micro indictors, which is also reflected in DSCR-TI ratios. While it would still be hard to say what should the new rating of this asset should be, it is fair to say that it is much higher than $\mathrm{BBB}+$. By the end of 2015, there are no significant early warning indicators 
at the macro level; however, there were some indications that marginal growth would transition at the regional and micro levels. Since the previous marginal growth rate at the micro level was declining, the near future transition would most likely result in an increasing growth rate. In summary, it is possible to infer from this analysis that a long position of this asset is relatively safe. 


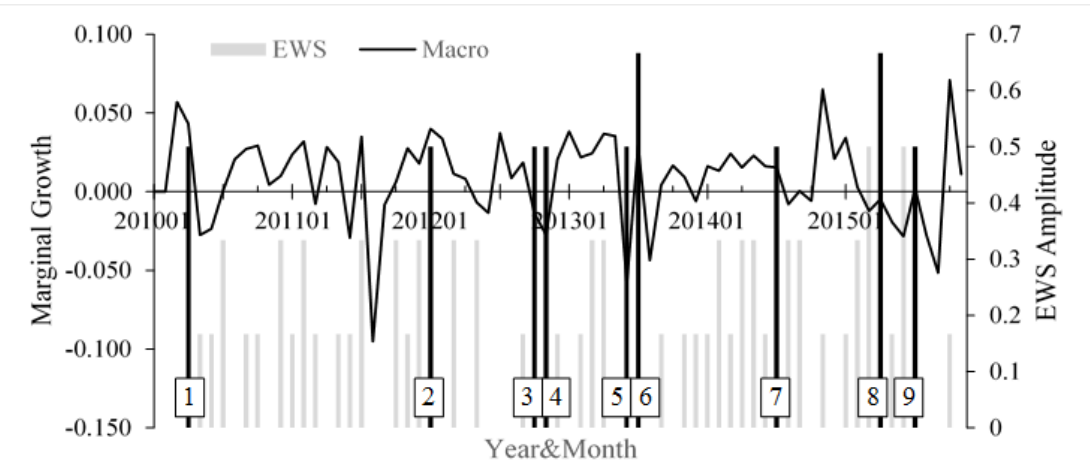

(a) Macro EWS

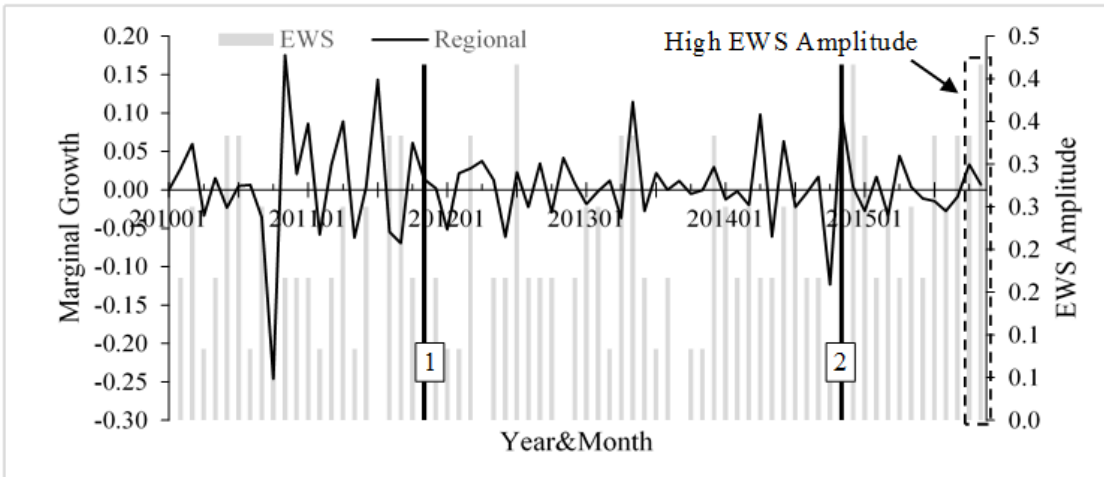

(b) Regional EWS

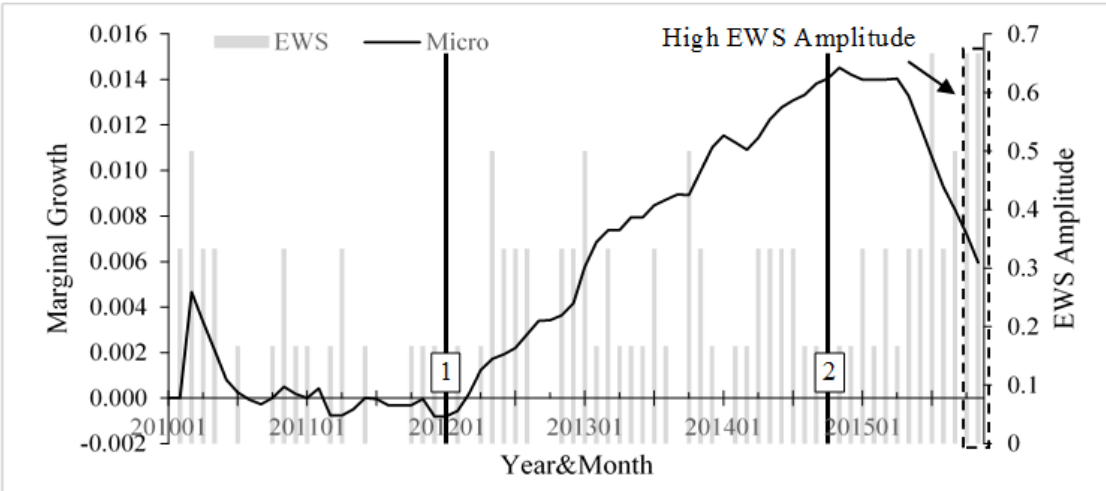

(c) Micro EWS

Figure 30 Future Risk Profile derived by EWS Method 


\section{SUMMARY AND CONCLUSIONS}

\subsection{Conclusions}

Infrastructure deterioration issues have become common across the nation. The American Society of Civil Engineers confirmed those issues by stating that the grade of overall infrastructure qualities is D+ in the 2017 infrastructure report card. This issue, however, is not new. Many administrations planned providing state-of-the-art infrastructure system in order to meet the demand. However, the main problem to such purpose is finding funding sources. In most cases, conventional sources are fully budgeted for ongoing or pre-scheduled projects, so public entities need to find alternative ways.

Tax Increment Financing (TIF) has a potential to provide a number of benefits in delivering new public infrastructure. However, this financing method comes with its own challenges. From the investors' point of view, the biggest challenge is how to assess and monitor the risks, given the limited data. Unlike stocks where huge amounts of transactions are made due to the consistency of financial instruments, bonds are not traded frequently due to the complexity of the contract between the issuer and the investor. This environment means that potential buyers in the bond market have more difficulties in collecting relevant information in the market due to lack of transaction data than potential buyers in the stock market. Among the bond markets, TIF bonds are traded on a fairly small scale because the amount of repayment is attributable to project revenue without the guarantees of the issuer's taxing power. This project-oriented 
redemption exacerbates information asymmetry problems for potential buyers. In addition, the credit rating of TIF bonds is rarely announced. Due to the timing difference between rating and investment, the latest rating information may become obsolete. This implies that at the time of investment, potential buyers may be exposed to investment risks associated with a lack of information availability. The information unavailability can negatively impact on investment decisions and ultimately raise the risk premium of TIF bonds.

This dissertation provides a framework for reconstituting the credit risk profile of TIF bonds and assessing the future risk trends. The proposed framework uses publicly available data sets which can be representative of endogenous and exogenous influencing factors and then analyzes signals for early warnings. This provides a number of important advantages. First, the proposed methodology helps reduce the information asymmetry problem by linking and monitoring the TIF project's impact on factors defining real estate valuation. Second, the approach, based on accessing publicly available information, allows for the continuous monitoring of credit risk status. Finally, the proposed EWS methodology provides a means to detect near-future stability in factors and to provide warnings of upcoming instabilities.

Combined with other assessment tools, the proposed EWS framework will contribute to decreasing risk premiums in TIF bond investments and further facilitate trades of TIF products. 


\subsection{Limitations}

The proposed EWS model is based on the theory of critical slowing down, which captures a moment where recovery rate slows down. For the capturing process, previous research, as well as the proposed model, generally use autoregressive order one (AR1), variance (Var), and short time Fourier transformation (STFT), as principal methods. All the EWS studies confirm that those methods have the potential to predict an upcoming critical event before its occurrence in universal areas. In practice, applying EWS to realworld situations may be difficult due to the subjective nature of parameter decisions, the ambiguity of the standard settings to filter the results, and the inconsistency between data collection and application of results.

First, subjectively defining the length of a moving window for mean structure calculation is a major issue. As one of the major parameters to the EWS model, a moving window defines an input size to calculate the mean at a moment. A change in window length leads to a change in mean structure and, eventually, to a change in EWS outcome configuration. In spite of the importance of securing accuracy in the window length, previous studies did not clearly describe the length determination process. Also, this research uses a fixed length of eleven data points, which is a minimal amount for calculating stationarity, regardless of the input stream.

Second, the difficulty of applying a common threshold for early warning makes the EWS method less practical. For example, in terms of AR1 ranging from - 1 to 1 , in some instances, when relatively small variations are observed in the input, a small threshold is large enough to predict an upcoming critical event. However, that small 
threshold cannot be applicable when an input heavily fluctuates, because it can point to signals too far away from a critical moment to be an early warning. Most real input data has combinations of small and large dynamicity; therefore, a threshold needs to be set, depending on situations.

Lastly, due to the infrequency of the data input, investors may not secure the most updated information from the model. The data interval used here is monthly, but transactions occur in a second. If a transaction is made in the middle between the data intervals, the asset risk exposure at this moment may be different from the risk level at the last updated moment in time. In general, bond asset conditions fluctuate less than other financial products, so the most recently updated risk assessment information provided by this model can be used as an indicator at the transaction moment; however, investors should be aware of the infrequency of updating.

\subsection{Further Research Direction}

The EWS methodology contributes to increasing the accuracy of predicted critical moments by producing early warnings. However, to apply this method universally, it is necessary to overcome the limitations discussed in the section above. More specifically, further research is needed to address the subjectivity of determining the length of a moving window and the obscurity of setting an EWS threshold. In addition, it is necessary to study how to interpret the derived EWS results, considering other quantitative and qualitative analyses. Therefore, academia should discuss this approach further to ensure its usefulness. These active discussions have the potential of refining this research. 


\section{REFERENCES}

Aldrete, Rafael M, Sharada Vadali, Carl James Kruse, David Salgado, Abhisek Mudgal, Juan Carlos Villa, Lorenzo Cornejo, and Deog Sang Bae. 2017. Tools for Port Authority Transportation Reinvestment Zones (TRZ) and TRZs for Multimodal Applications. Texas A\&M Transportation Institute.

Aven, Terje. 2013a. "A Conceptual Framework for Linking Risk and the Elements of the Data-Information-Knowledge-Wisdom (Dikw) Hierarchy." Reliability Engineering \& System Safety 111:30-36.

Aven, Terje. 2013b. "Practical Implications of the New Risk Perspectives." Reliability Engineering \& System Safety 115:136-145.

Aven, Terje. 2014. Risk, Surprises and Black Swans: Fundamental Ideas and Concepts in Risk Assessment and Risk Management: Routledge.

Beard, Alan N. 2004. "Risk Assessment Assumptions." Civil Engineering and Environmental Systems 21 (1):19-31.

Blaschke, Winfrid, Maria Soledad Martinez Peria, Giovanni Majnoni, and Matthew T Jones. 2001. Stress Testing of Financial Systems: an Overview of Issues, Methodologies, and FSAP Experiences. Vol. 1: International Monetary Fund.

Bozarth, Cecil. 2011. "Double Exponential Smoothing: Approaches to Forecasting : A Tutorial." accessed Jul 16, 2016. https://scm.ncsu.edu/scm-articles/article/doubleexponential-smoothing-approaches-to-forecasting-a-tutorial. 
Braswell, Ronald C, E Joe Nosari, and DeWitt L Sumners. 1983. "A Comparison of the Rule Interest Costs of Competitive and Negotiated Underwritings in the Municipal Bond Market: Note." Journal of Money, Credit and Banking 15 (1):102-106.

Briffault, Richard. 2010. "The Most Popular Tool: Tax Increment Financing and The Political Economy of Local Government." The University of Chicago Law Review:65-95.

Byrne, Paul F. 2006. "Determinants of Property Value Growth for Tax Increment Financing Districts." Economic Development Quarterly 20 (4):317-329. Capeci, John. 1991. "Credit Risk, Credit Ratings, and Municipal Bond Yields: A Panel Study." National Tax Journal:41-56.

Carpenter, SR, and WA Brock. 2006. "Rising Variance: A Leading Indicator of Ecological Transition." Ecology letters 9 (3):311-318.

Cervero, Robert. 1988. "Paying for Off-Site Road Improvements through Fees, Assessments, And Negotiations: Lessons from California." Public Administration Review:534-541.

Challis, R. E., and R. I. Kitney. 1990. "Biomedical Signal Processing (in four parts): Part 1 Time-Domain Methods." Medical and Biological Engineering and Computing $28(6): 509-524$.

Chipman, Hugh, Edward I George, Robert E McCulloch, Merlise Clyde, Dean P Foster, and Robert A Stine. 2001. "The Practical Implementation of Bayesian Model Selection." Lecture Notes-Monograph Series:65-134. 
Collin-Dufresn, Pierre, Robert S Goldstein, and J Spencer Martin. 2001. "The Determinants of Credit Spread Changes." The Journal of Finance 56 (6):21772207.

Council on Development Finance Agencies. 2006. "National Roundup: Tax Increment Financing." accessed Nov 1, 2017.

https://www.cdfa.net/cdfa/cdfaweb.nsf/ordredirect.html?open\&id=tifnationalrou ndup.html.

Covello, Vincent T, and Jeryl Mumpower. 1985. "Risk Analysis and Risk Management: An Historical Perspective." Risk Analysis 5 (2):103-120.

Crowell, Victor L. 1937. "The Scientific Method." School Science and Mathematics 37 (5):525-531.

Dakos, Vasilis, Stephen R Carpenter, William A Brock, Aaron M Ellison, Vishwesha Guttal, Anthony R Ives, Sonia Kefi, Valerie Livina, David A Seekell, and Egbert H van Nes. 2012. "Methods for Detecting Early Warnings of Critical Transitions In Time Series Illustrated using Simulated Ecological Data." PloS ONE 7 (7):e41010.

Dakos, Vasilis, Marten Scheffer, Egbert H van Nes, Victor Brovkin, Vladimir Petoukhov, and Hermann Held. 2008. "Slowing Down as an Early Warning Signal for Abrupt Climate Change." Proceedings of the National Academy of Sciences 105 (38):14308-14312. 
Daniels, Kenneth, Demissew Diro Ejara, and Jayaraman Vijayakumar. 2010. "Debt Maturity, Credit Risk, and Information Asymmetry: the Case of Municipal Bonds." Financial Review 45 (3):603-626.

Davis, Don. 1989. "Tax Increment Financing." Public Budgeting \& Finance 9 (1):6373.

Dunetz, Mark L, and James M Mahoney. 1988. "Using Duration and Convexity in the Analysis of Callable Bonds." Financial Analysts Journal 44 (3):53-72.

Eisenmann, Robert C. 1998. Machinery Malfunction Diagnosis and Correction: Vibration Analysis And Troubleshooting for the Process Industries: Prentice Hall PTR.

Ellestad, Myrvin H. 1986. "Stress Testing: Principles and Practice." Journal of Occupational Medicine 28 (11):1142-1144.

Flage, Roger, and Terje Aven. 2009. "Expressing and Communicating Uncertainty in Relation to Quantitative Risk Analysis." Reliability \& Risk Analysis: Theory \& Application 2 (13):9-18.

Fleming, Michael J. 2000. "The Benchmark US Treasury Market: Recent Performance and Possible Alternatives." Federal Reserve Bank of New York Economic Policy Review 6 (1):129-145.

Fletcher, Neville H. 1993. "Autonomous Vibration of Simple Pressure- Controlled Valves in Gas Flows." The Journal of the Acoustical Society of America 93 (4):2172-2180. 
Greenbaum, Robert T, and Jim Landers. 2014. "The TIFF Over TIF: A Review of the Literature Examining the Effectiveness of the Tax Increment Financing." National Tax Journal 67 (3):655.

Greifer, Nicholas. 2005. An Elected Official's Guide to Tax Increment Financing: Gfoa. Guckenheimer, John, Philip Holmes, and M Slemrod. 1984. "Nonlinear Oscillations Dynamical Systems, and Bifurcations of Vector Fields." Journal of Applied Mechanics 51:947.

Hamilton, Chris. 2017. "What Happens When Revenue Bonds Default? ." accessed Feb 23, 2017. http://thefinancebase.com/happens-revenue-bonds-default-5084.html. Harris, Lawrence, and Michael S Piwowar. 2004. "Municipal Bond Liquidity." AFA 2005 Philadelphia Meetings.

Harris, Richard ID. 1992. "Testing for Unit Roots using the Augmented Dickey-Fuller Test: Some Issues Relating to the Size, Power and the Lag Structure of the Test." Economics letters 38 (4):381-386.

Iacono, Mike, David Matthew Levinson, and Zhirong Zhao. 2010. Value Capture for Transportation Finance.

Investopedia. "Fixed-Rate Bond." accessed Oct 27, 2016. http://www.investopedia.com/terms/f/fixedrate-bond.asp.

Ives, Anthony R. 1995. "Measuring Resilience in Stochastic Systems." Ecological Monographs 65 (2):217-233.

James, Raymond. "A Guide to Understanding Floating-Rate Securities." accessed Oct 27, 2016. http://www.raymondjames.com/fixed_income_floating_rate.htm. 
Jobst, Andreas. 2008. "What is Securitization?", accessed Jan 21, 2017. http://www.imf.org/external/pubs/ft/fandd/2008/09/pdf/basics.pdf.

Joehnk, Michael D, and David S Kidwell. 1979. "Comparative Costs of Competitive and Negotiated Underwritings in the State And Local Bond Market." The Journal of Finance 34 (3):725-731.

Katok, Anatole, and Boris Hasselblatt. 1997. Introduction to the Modern Theory of Dynamical Systems. Vol. 54: Cambridge university press.

Kidwell, David S, Eric H Sorensen, and John M Wachowicz. 1987. "Estimating the Signaling Benefits of Debt Insurance: The Case of Municipal Bonds." Journal of Financial and Quantitative Analysis 22 (3):299-313.

Kleinen, Thomas, Hermann Held, and Gerhard Petschel-Held. 2003. "The Potential Role of Spectral Properties in Detecting Thresholds in The Earth System: Application to the Thermohaline Circulation." Ocean Dynamics 53 (2):53-63.

Lenton, T. M., V. N. Livina, V. Dakos, E. H. van Nes, and M. Scheffer. 2012. "Early Warning of Climate Tipping Points from Critical Slowing Down: Comparing Methods to Improve Robustness." Philosophical Transactions of The Royal Society A 370 (1962):1185-1204.

Lenton, Timothy M. 2011. "Early Warning of Climate Tipping Points." Nature Climate Change 1 (4):201.

Leonard, Paul A. 1983. "Some Factors Determining Municipal Revenue Bond Interest Costs." Journal of Economics and Business 35 (1):71-82. 
Linkov, Igor, FK Satterstrom, Gc Kiker, Cd Batchelor, Td Bridges, and Ed Ferguson. 2006. "From Comparative Risk Assessment to Multi-Criteria Decision Analysis and Adaptive Management: Recent Developments and Applications."

Environment International 32 (8):1072-1093.

Liu, Pu, and Fazel J Seyyed. 1991. "The Impact of Socioeconomic Variables and Credit Ratings on Municipal Bond Risk Premia." Journal of Business Finance \& Accounting 18 (5):735-746.

Longstaff, Francis A. 1992. "Are Negative Option Prices Possible? The Callable US Treasury-Bond Puzzle." Journal of Business:571-592.

Longstaff, Francis A, and Eduardo S Schwartz. 1995. "A Simple Approach to Valuing Risky Fixed and Floating Rate Debt." The Journal of Finance 50 (3):789-819.

Marcus, Norman. 1983. "Air Rights in New York City: TDR, Zoning Lot Merger and the Well-Considered Plan." Brook. L. Rev. 50:867.

Moody's. 2015. "Tax Increment Debt." accessed Jul 23, 2017. https://www.moodys.com/researchdocumentcontentpage.aspx?docid=PBM_PB $\underline{\mathrm{M} 181116 .}$

Nguyen, Joseph. 2017. "4 Key Factors that Drive the Real Estate Market." Investopedia, accessed Jul 30, 2017. http://www.investopedia.com/articles/mortages-realestate/11/factors-affecting-real-estate-market.asp.

Nicholas, James C, and Arthur C Nelson. 1988. "Determining the Appropriate Development Impact Fee using the Rational Nexus Test." Journal of the American Planning Association 54 (1):56-66. 
Pacewicz, Josh. 2012. "Tax Increment Financing, Economic Development Professionals and the Financialization of Urban Politics." Socio-Economic Review 11 (3):413440.

Packard, Norman H, James P Crutchfield, J Doyne Farmer, and Robert S Shaw. 1980.

"Geometry From a Time Series." Physical review letters 45 (9):712.

Peirce, Charles Sanders, Charles Hartshorne, and Paul Weiss. 1935. "Collected Papers of Charles Sanders Peirce: Vol. III, Exact Logic." Philosophical Review 44 (1):85.

Peng, Jun, and Peter F Brucato. 2004. "An Empirical Analysis of Market and Institutional Mechanisms for Alleviating Information Asymmetry in the Municipal Bond Market." Journal of Economics and Finance 28 (2):226-238.

Public-Private Infrastructure Advisory Facility (PPIAF). 2013. "Steps to Issuing a Municipal Bond an Interactive Module." accessed Nov 1, 2017. https://www.slideshare.net/AmsaleBumbaugh/einteractivestepstoamunicipalbond.

Rolon, Abigail. 2008. "Evalulation of Value Capture Mechanisms from Linkage Capture to Special Assessment Districts." Transportation Research Record: Journal of the Transportation Research Board 2079:127-135.

Rybeck, Rick. 2004. "Using Value Capture to Finance Infrastructure and Encourage Compact Development." Public Works Management \& Policy 8 (4):249-260.

S\&P Global Ratings. 2017. "Summary: Uptown Development Authority, Texas; Tax Increment." accessed Nov 1, 2017. http://www.alacrastore.com/s-and-p-credit- 
research/Summary-Uptown-Development-Authority-Texas-Tax-Increment$\underline{1801357 .}$.

Salon, Deborah. 2014. "Location Value Capture Opportunities for Urban Public Transport Finance." accessed Oct 26, 2016. http://library.rpa.org/pdf/TLS-2014Research-Paper-Value-Capture.pdf.

Scheffer, Marten, Jordi Bascompte, William A Brock, Victor Brovkin, Stephen R Carpenter, Vasilis Dakos, Hermann Held, Egbert H Van Nes, Max Rietkerk, and George Sugihara. 2009. "Early-Warning Signals for Critical Transitions." Nature $461(7260): 53$.

Scheffer, Marten, Stephen R Carpenter, Timothy M Lenton, Jordi Bascompte, William Brock, Vasilis Dakos, Johan Van de Koppel, Ingrid A Van de Leemput, Simon A Levin, and Egbert H Van Nes. 2012. "Anticipating Critical Transitions." Science 338 (6105):344-348.

Simonsen, William, and Mark D Robbins. 1996. "Does it Make Any Difference Anymore? Competitive Versus Negotiated Municipal Bond Issuance." Public Administration Review 56 (1):57-64.

Sornette, D, AB Davis, K Ide, KR Vixie, V Pisarenko, and JR Kamm. 2007. "Algorithm for Model Validation: Theory And Applications." Proceedings of the National Academy of Sciences 104 (16):6562-6567.

Stopher, Peter R. 1993. "Financing Urban Rail Projects: The Case of Los Angeles." Transportation 20 (3):229-250. 
Texas Legislature. 1987. "Tax Increment Financing Act Section 311.005." accessed Aug 30, 2017. http://www.statutes.legis.state.tx.us/Docs/TX/htm/TX.311.htm\#311.005.

Trück, Stefan, Matthias Laub, and Svetlozar Rachev. 2004. "The Term Structure of Credit Spreads and Credit Default Swaps-an Empirical Investigation." Investment Management and Financial Innovations 3.

Vadali, S. R. 2014. Using the Economic Value Created by Transportation to Fund Transportation: National Cooperative Highway Research Program

Vadali, S. R., R. M. Aldrete, and A. Bujanda. 2009. "Financial Model to Assess Value Capture Potential of a Roadway Project." In Transportation Research Record: Journal of the Transportation Research Board 1853:1-11.

Voulgaris, Carole Turley. 2016. "A TUF Sell: Transportation Utility Fees as User Fees for Local Roads and Streets." Public Works Management \& Policy 21 (4):305323.

Weick, Karl E, Kathleen M Sutcliffe, and David Obstfeld. 2008. "Organizing for High Reliability: Processes of Collective Mindfulness." Crisis Management 3 (1):81123.

Wissel, C. 1984. "A Universal Law of the Characteristic Return Time near Thresholds." Oecologia 65 (1):101-107.

Zhao, Zhirong Jerry, Kirti Vardhan Das, and Kerstin Larson. 2012. "Joint Development as a Value Capture Strategy in Transportation Finance." Journal of Transport and Land Use 5 (1):5-17. 
Zhao, Zhirong Jerry, and Kerstin Larson. 2011. "Special Assessments as a Value

Capture Strategy for Public Transit Finance." Public Works Management \& Policy 16 (4):320-340. 